\title{
Tumor-Activated Benzothiazole Inhibitors of Stearoyl-CoA
} Desaturase

Noelle S. Williams, ${ }^{a *}$ Stephen Gonzales, ${ }^{a}$ Jacinth Naidoo, ${ }^{a}$ Giomar Rivera-Cancel,,${ }^{a, b}$ Sukesh Voruganti, ${ }^{a}$ Prema Mallipeddi, ${ }^{a}$ Panayotis C. Theodoropoulos, ${ }^{a, b}$ Sophie Geboers, ${ }^{a}$ Hong Chen, ${ }^{a}$ Francisco Ortiz, ${ }^{a}$ Bruce Posner, ${ }^{a}$ Deepak Nijhawan, ${ }^{a, b, *}$ and Joseph M. Ready ${ }^{a, b, *}$

${ }^{a}$ Department of Biochemistry, ${ }^{b}$ Department of Internal Medicine, Division of Hematology and Oncology, UT Southwestern Medical Center, 5323 Harry Hines Blvd. Dallas, TX 75390-9038.

\section{Contents}

\begin{tabular}{|l|l|}
\hline Supplementary Figures & S2 \\
\hline Representative HPLC Chromatograms & S6 \\
\hline NMR Spectra & S10 \\
\hline
\end{tabular}


Figure S1. Conversion of $(R)-\mathbf{2 7}$ to $(R)-\mathbf{5 3}$ by H2122 cells in the presence or absence of CYP4F inhibitor HET0016. $100 \mathrm{nM}(\mathrm{R})-27$ was incubated with H2122 in the presence or absence of $1 \mu$ M HET0016 for the indicated amount of time and cells and media were collected for analysis of (R)-27 and (R)-53 levels by LC-MS/MS.

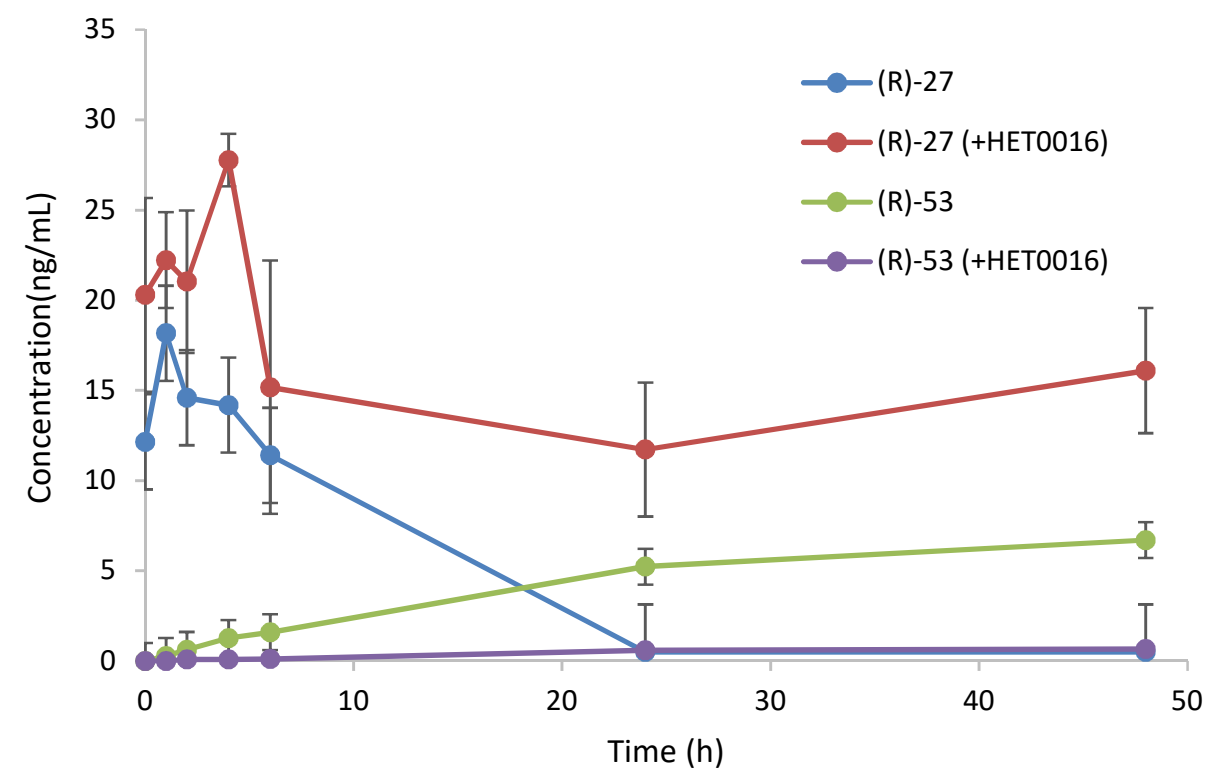

Figure S2. Plasma PK of SW208110 in CD1 mice following a $10 \mathrm{mg} / \mathrm{kg}$ IP dose, $0.2 \mathrm{ml} / \mathrm{mouse}$ formulated with $10 \%$ DMSO, 10\% Kolliphor EL (Sigma), 80 \% 50mM Lactic acid pH 5.5.

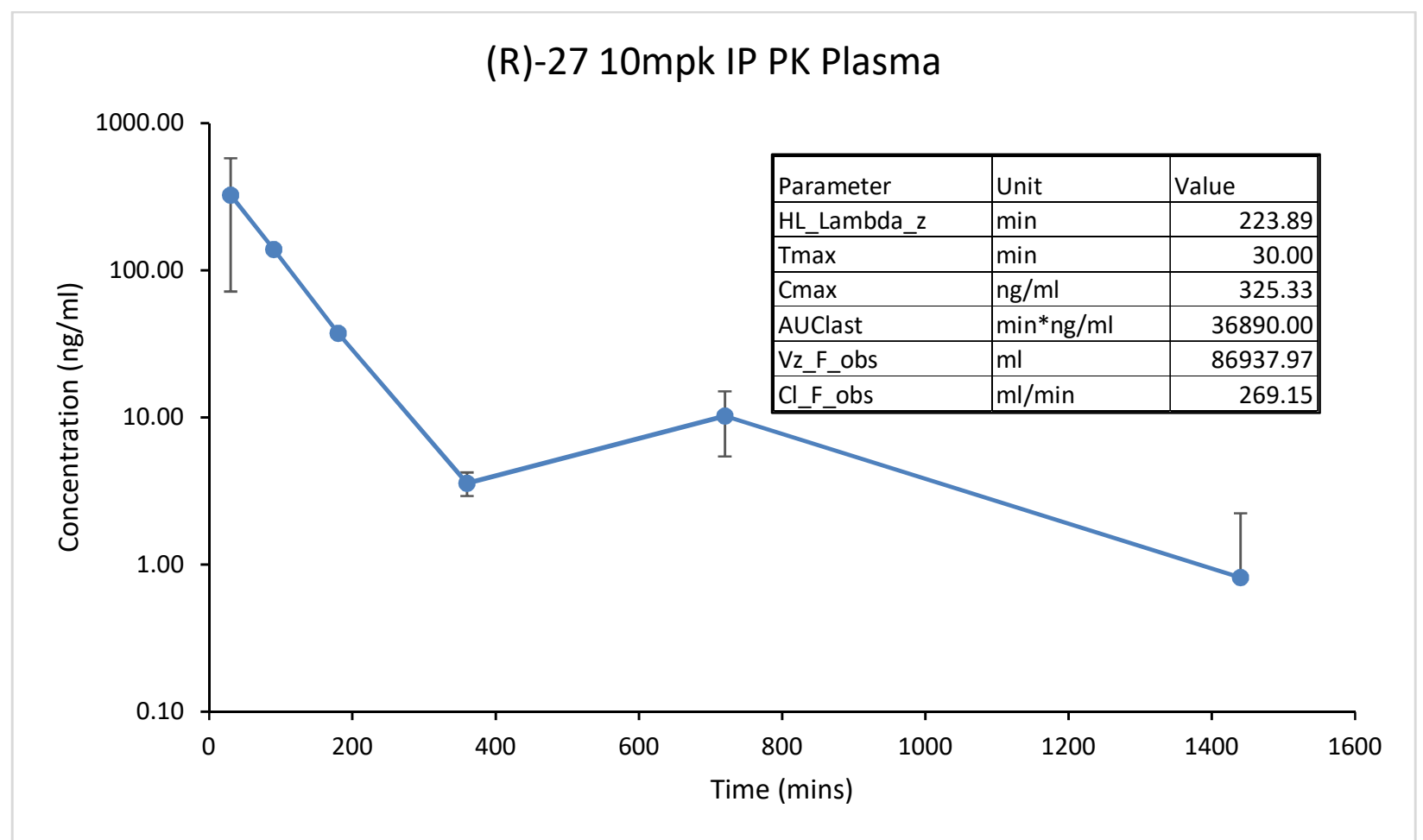


Figure S3. CYP4F Inhibitor HET0016 Does NOT block conversion of $(R)-54$ to $(R)-53.100 \mathrm{nM}(\mathrm{R})-54$ was incubated with $\mathrm{H} 2122$ in the presence or absence of $1 \mu \mathrm{M}$ HET0016 for the indicated amount of time and cells and media were collected for analysis of (R)-54 and (R)-53 levels by LC-MS/MS.

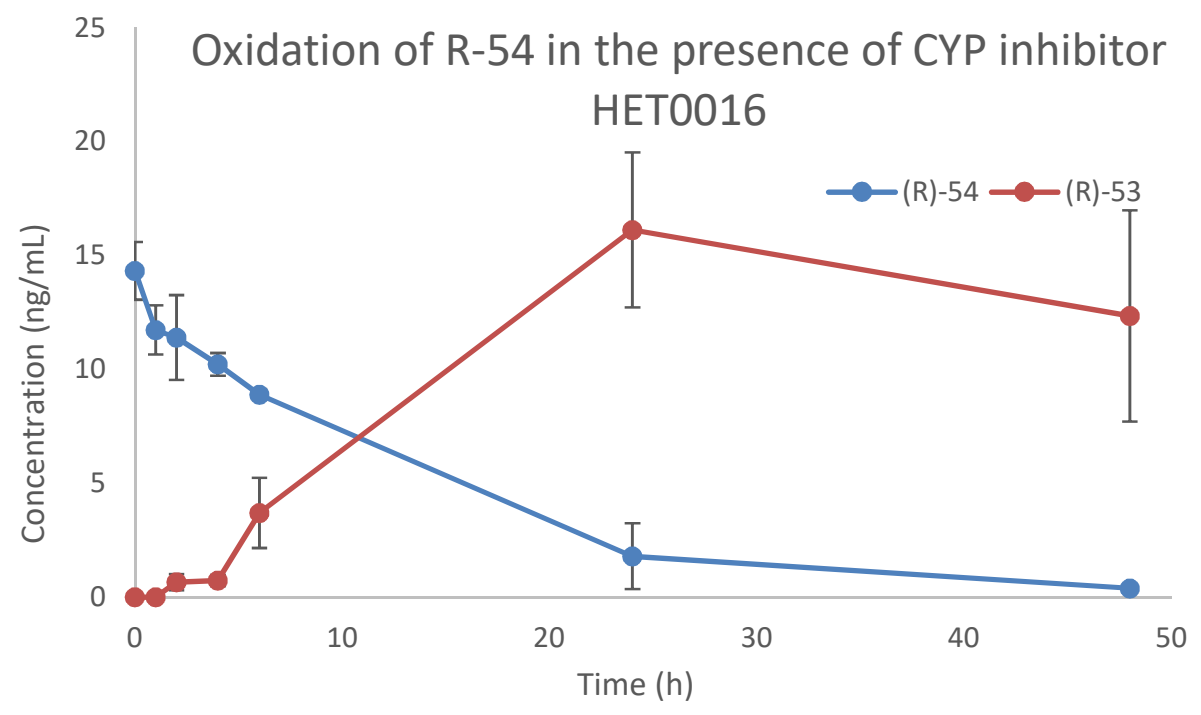


Figure S4. Compound levels from xenograft experiments. Nod-Scid female mice were fed either conventional chow (control diet) or specialized chow to control fat content (fat free diet) and implanted with 5 million $\mathrm{H} 2122$ cells in a subcutaneous site. When tumors reached $100-150 \mathrm{~mm}^{3}$, mice were dosed either QD $(20 \mathrm{mg} / \mathrm{kg})$ or BID $(10 \mathrm{mg} / \mathrm{kg})$ IP with $(R)-27$ in $0.2 \mathrm{ml} / \mathrm{mouse}$ formulated with $10 \%$ DMSO, 10\% Kolliphor EL (Sigma), $80 \% 50 \mathrm{mM}$ Lactic acid pH 5.5. After 21 days of dosing, mice were euthanized in groups of three, $3 \mathrm{~h}$ after the final dose and plasma and tumor evaluated for drug and metabolite $((R)-53)$ levels. Note difference in scales.
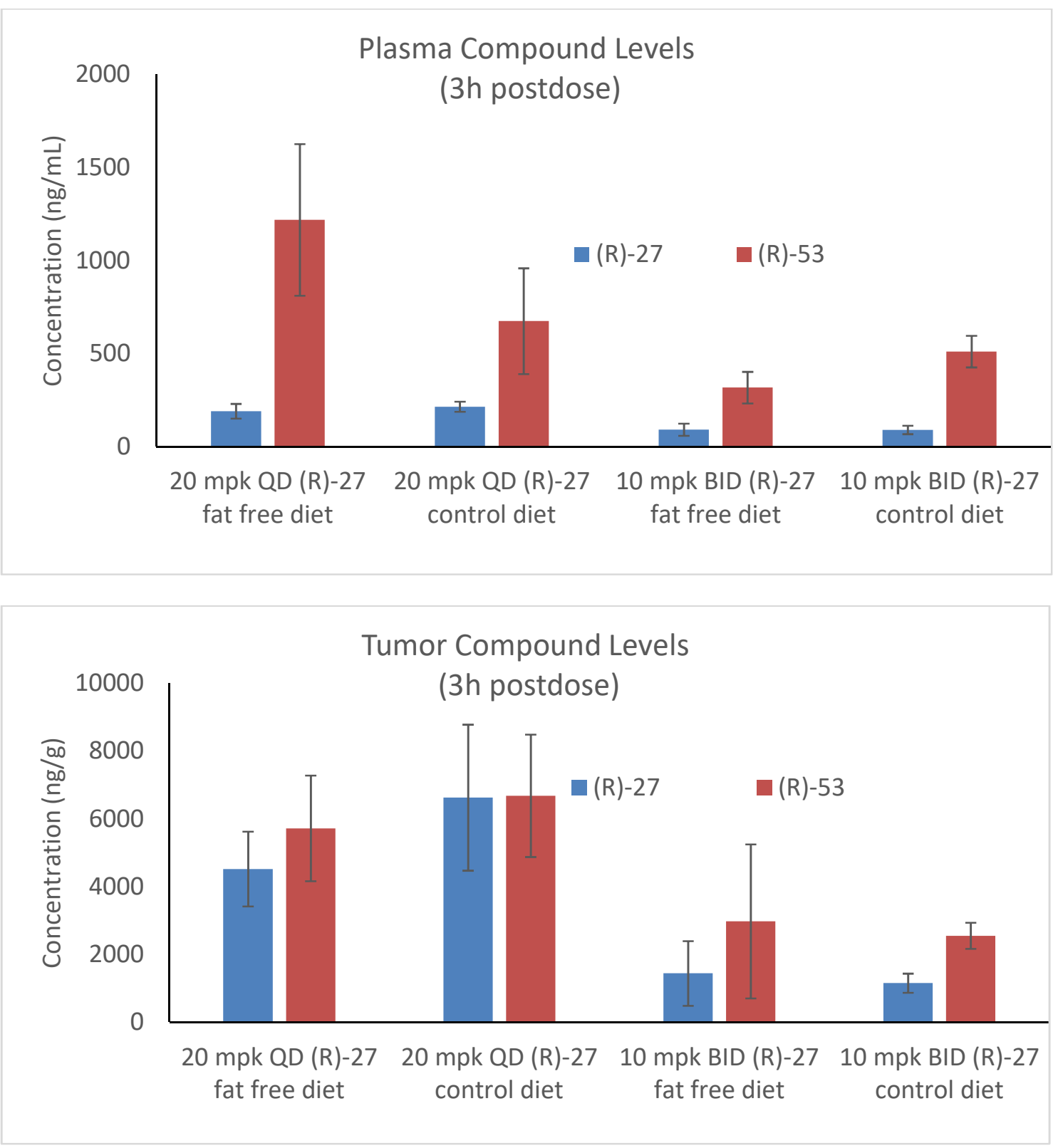
Figure S5. Mouse tumor xenograft study. Tumors were formed from $\mathrm{H} 2122$ cells, and treatment with (R)-27 (10 mg/kg BID or $20 \mathrm{mg} / \mathrm{kg}$ QD) was initiated after they reached $100 \mathrm{~mm}^{3}$ size.

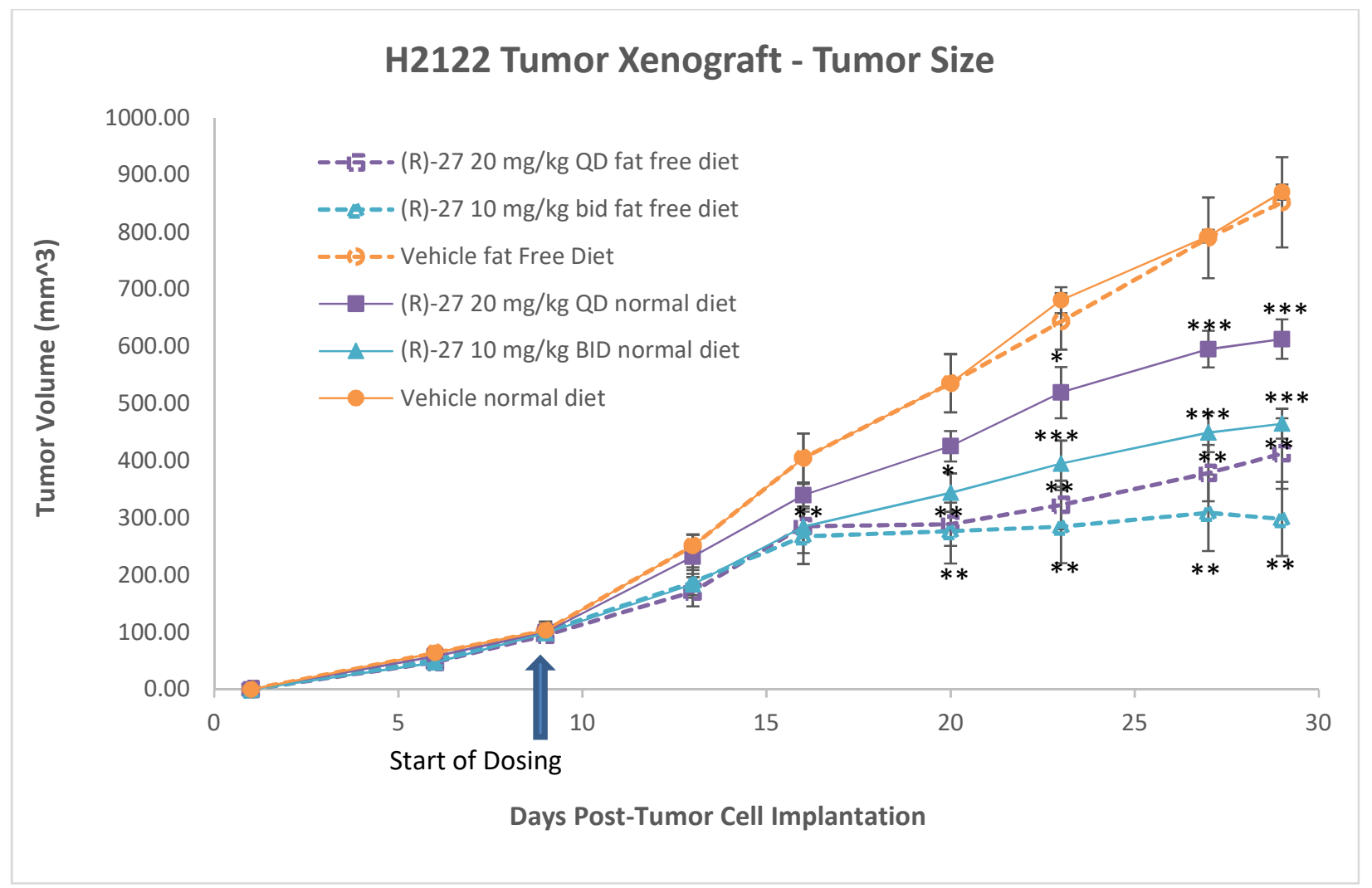

Figure S6. Mouse tumor xenograft study. Body weight changes associated with tumor sizes shown in Figure S6.

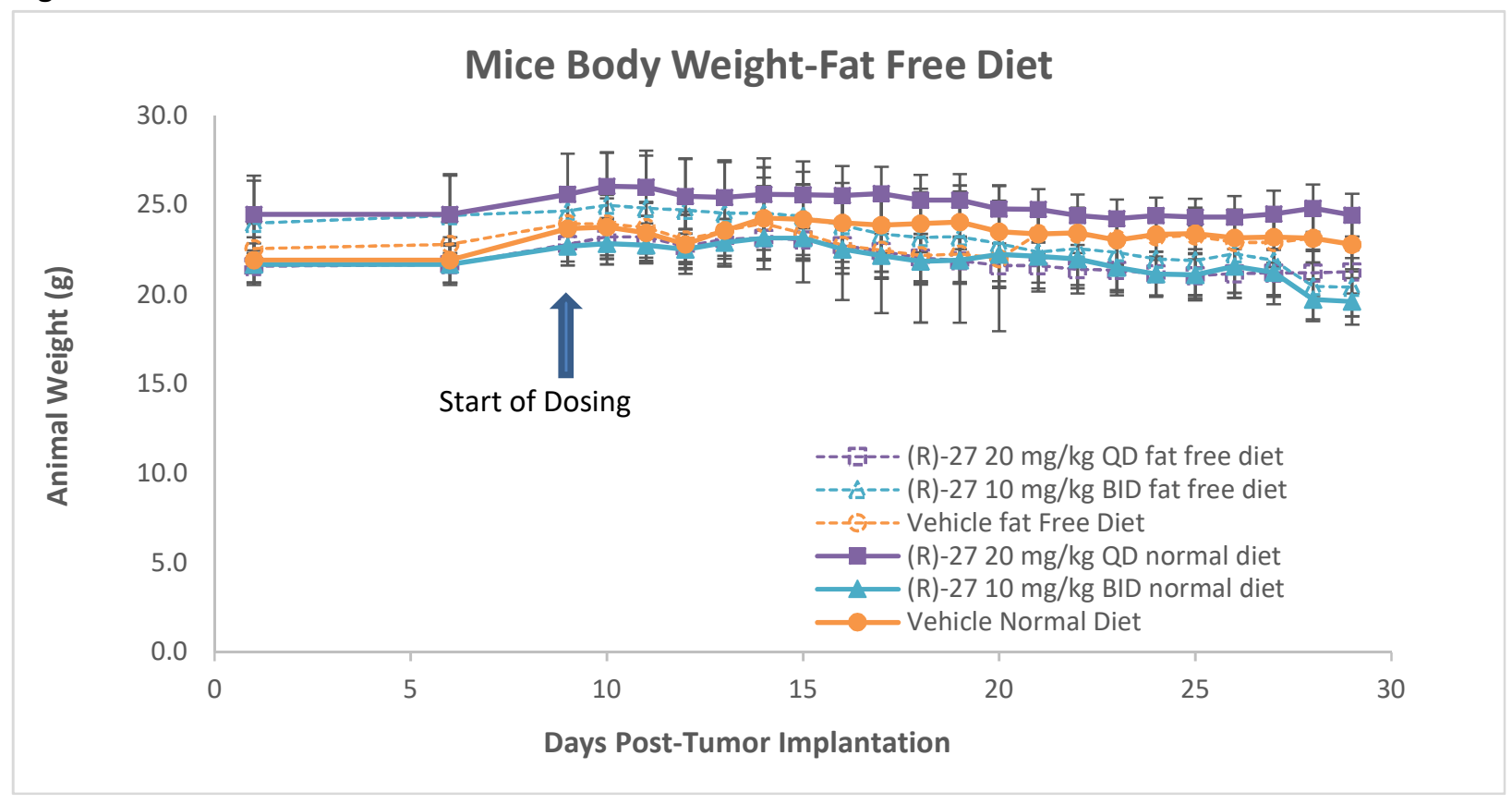


Representative HPLC Chromatograms (254 nM)
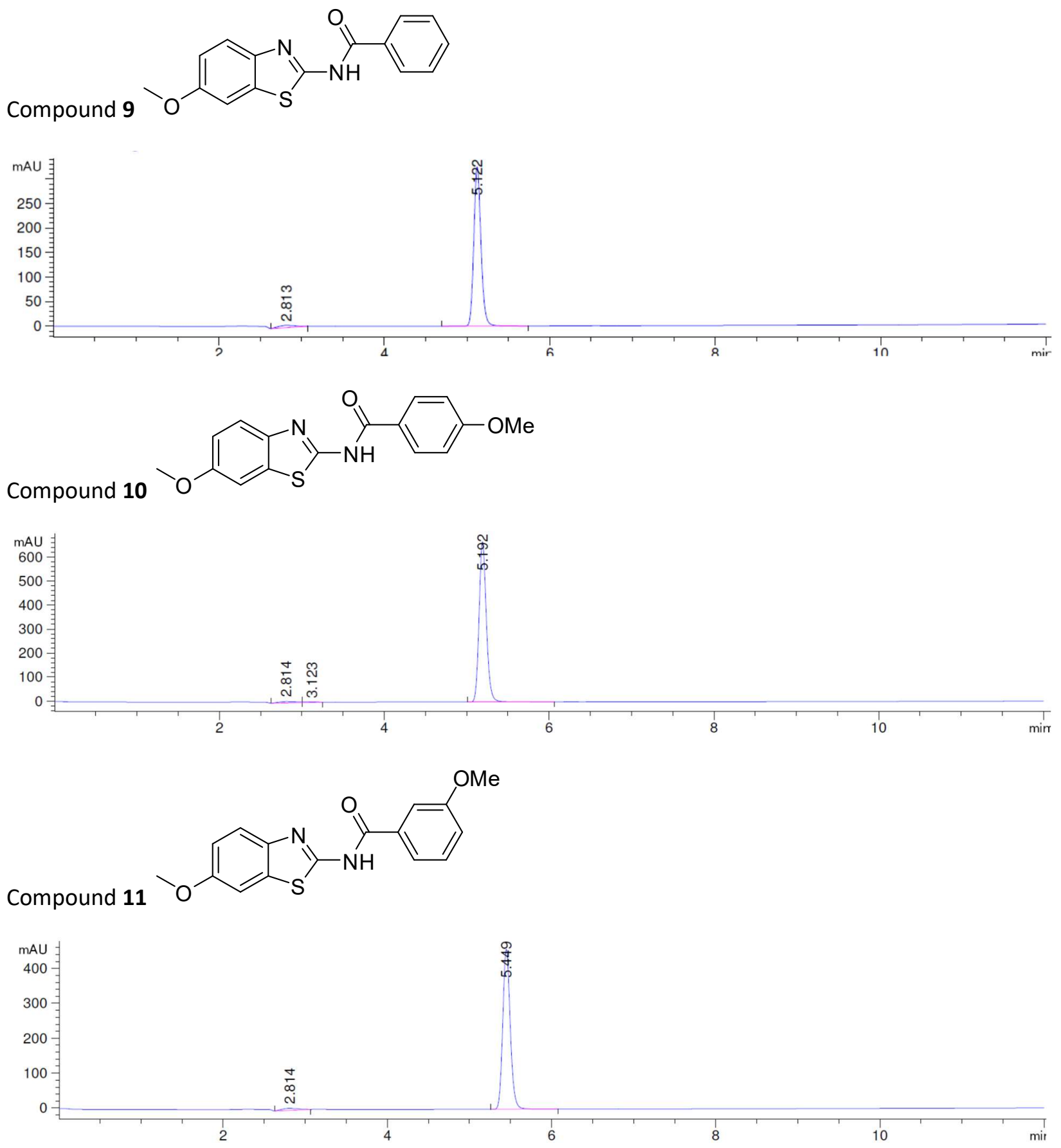

SG 
Compound 12
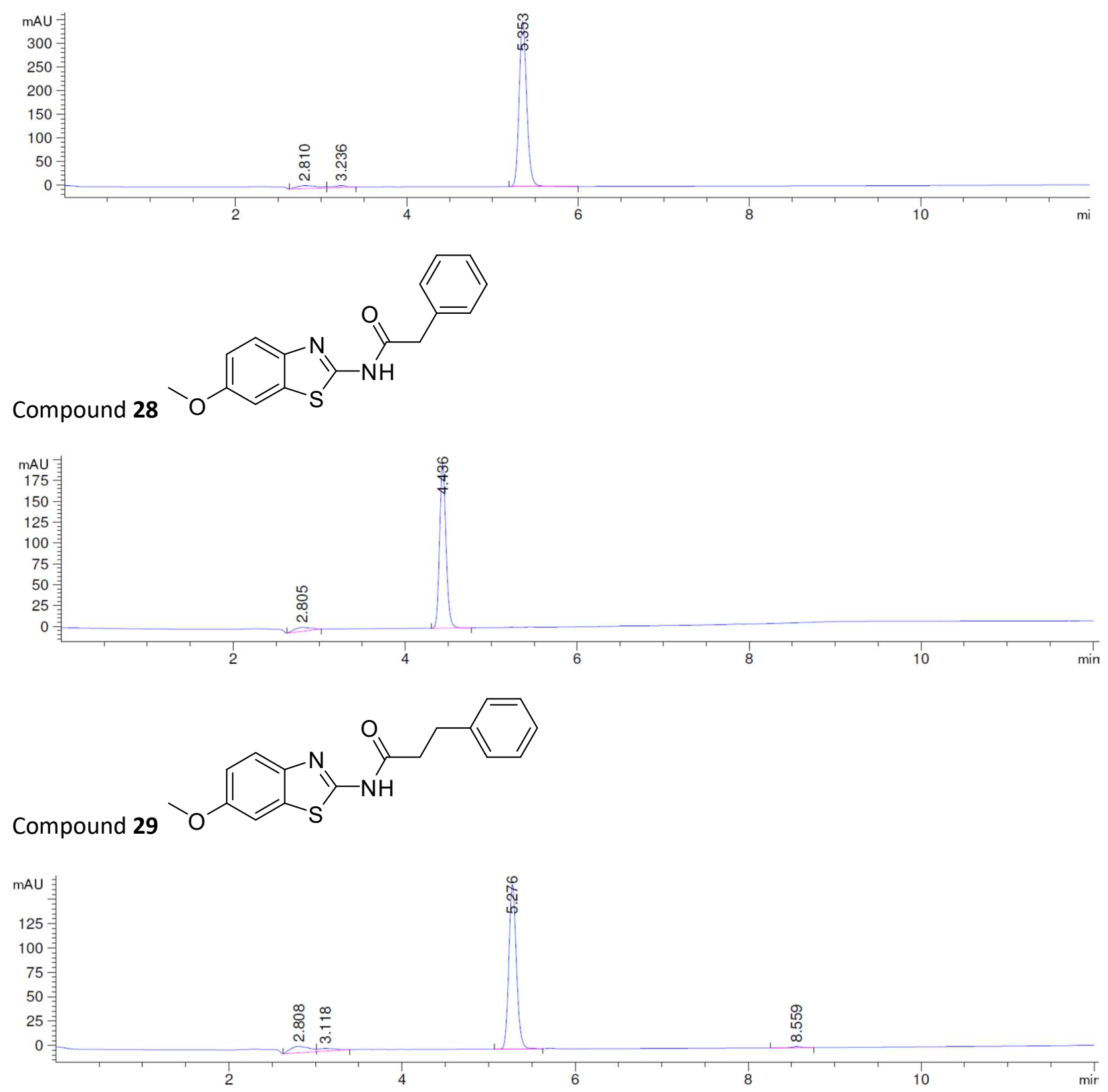
Compound $30>0$

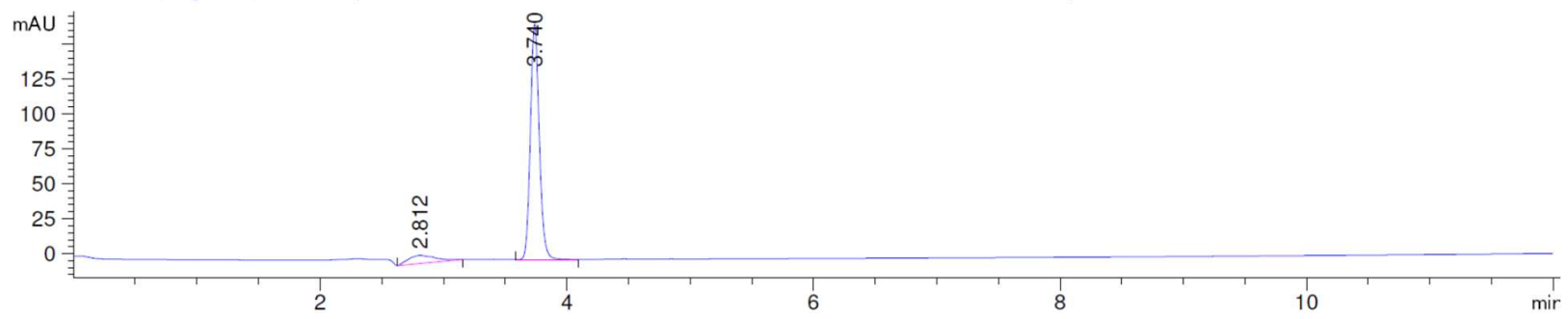<smiles>CCCCCCCOC(C)=O</smiles>

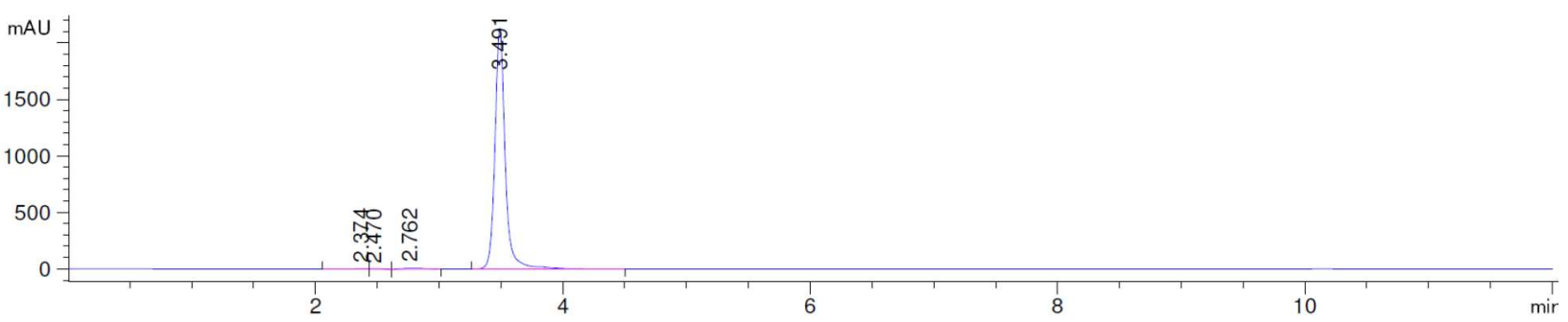

Compound $39{ }_{S}$

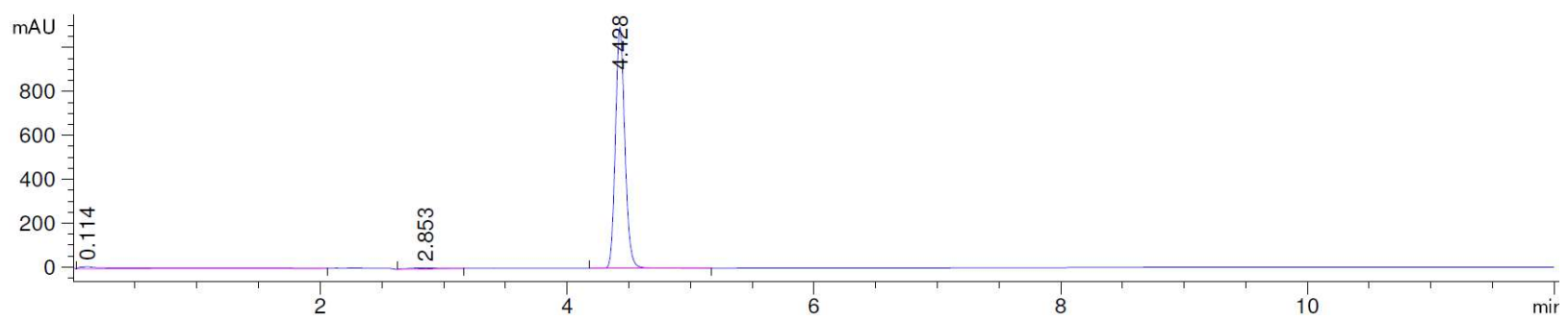


Compound 40
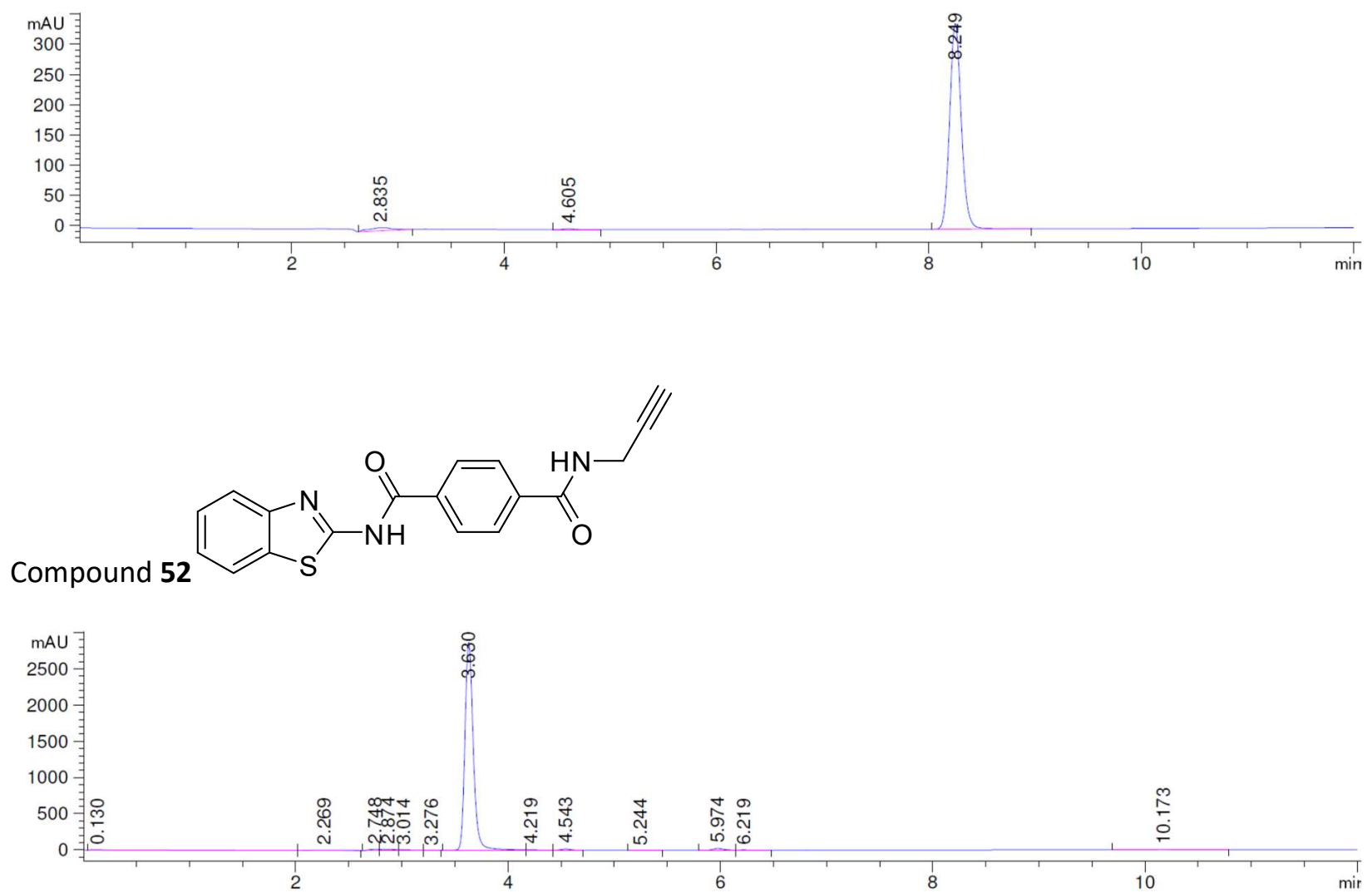


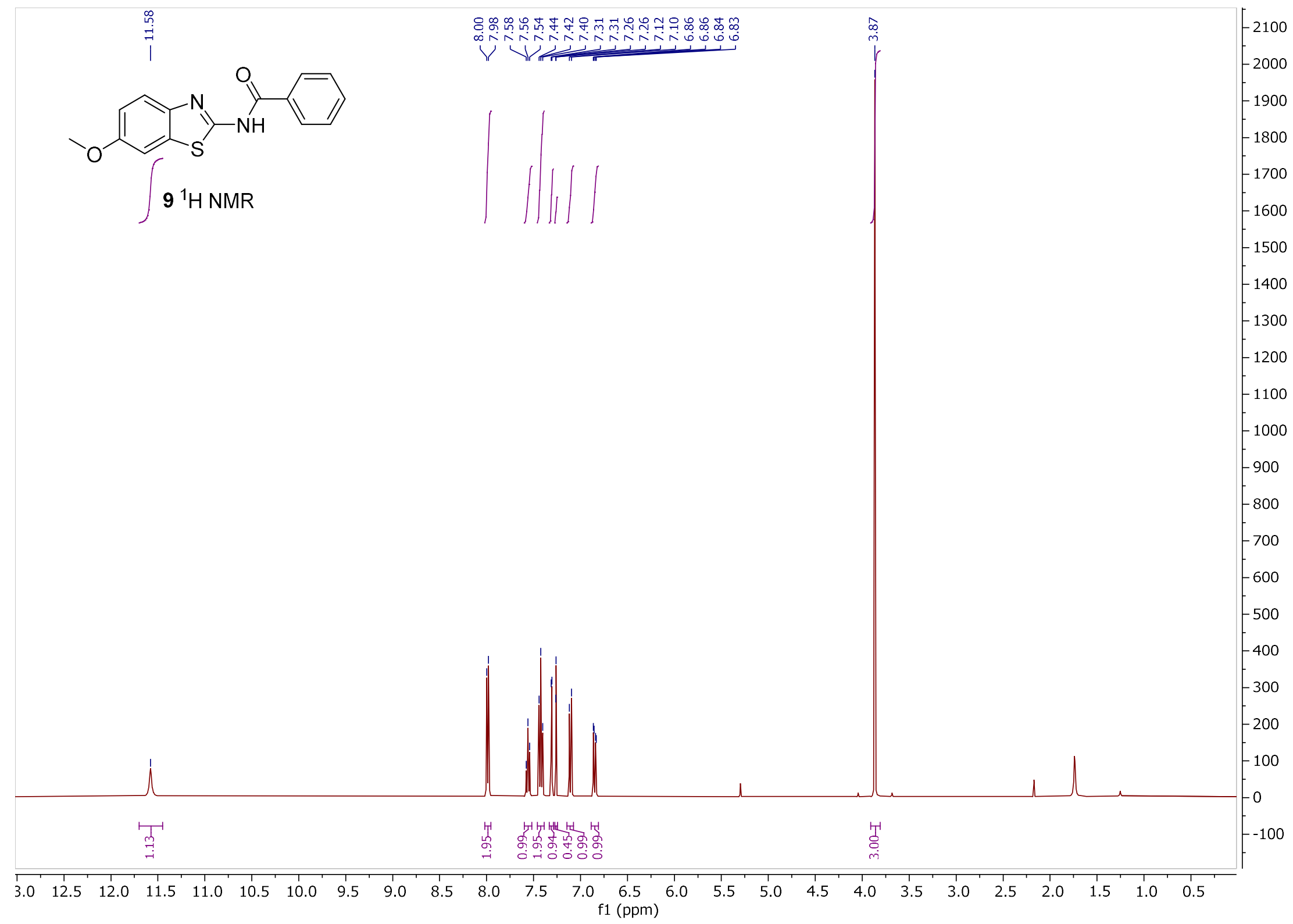




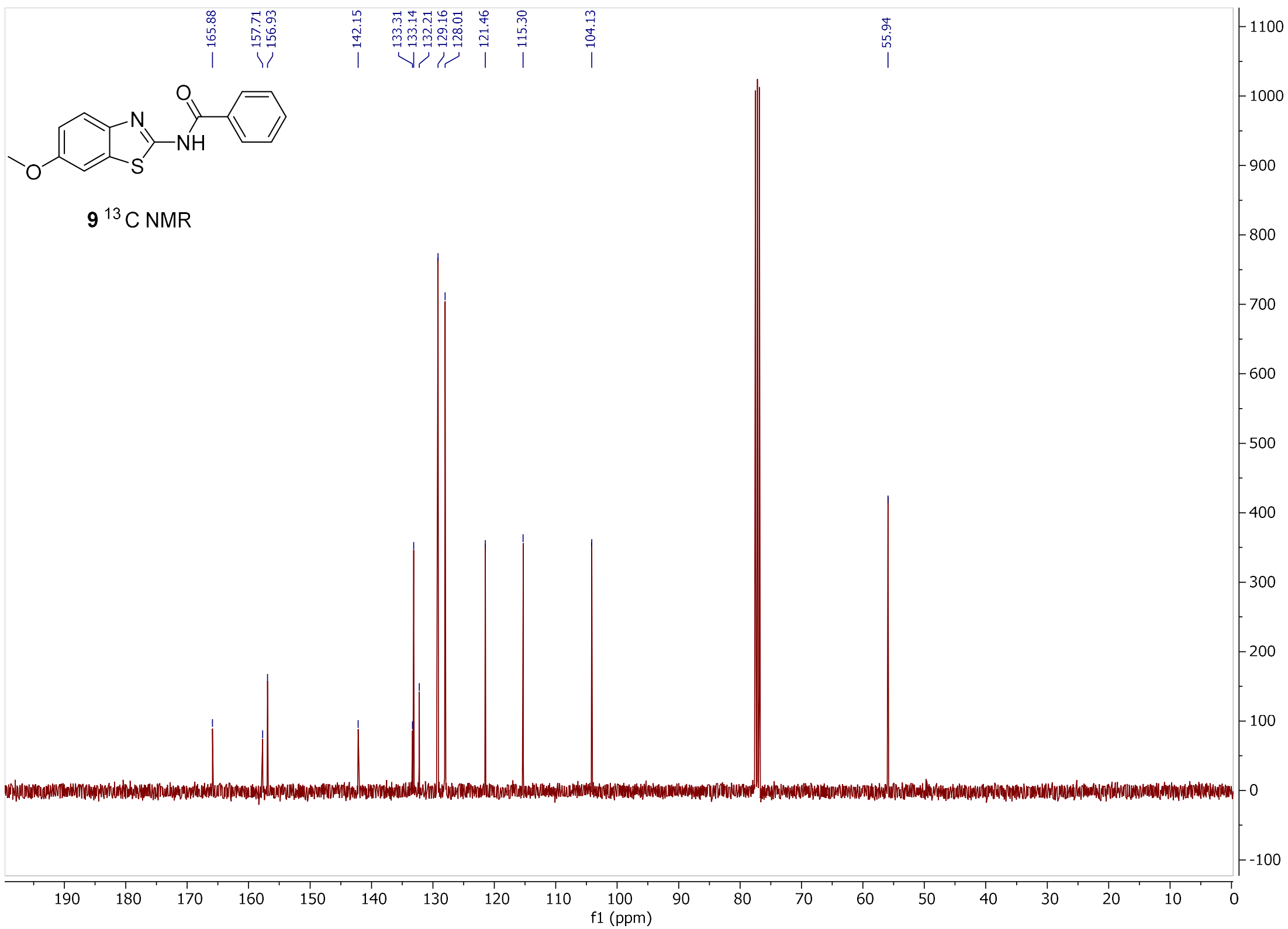




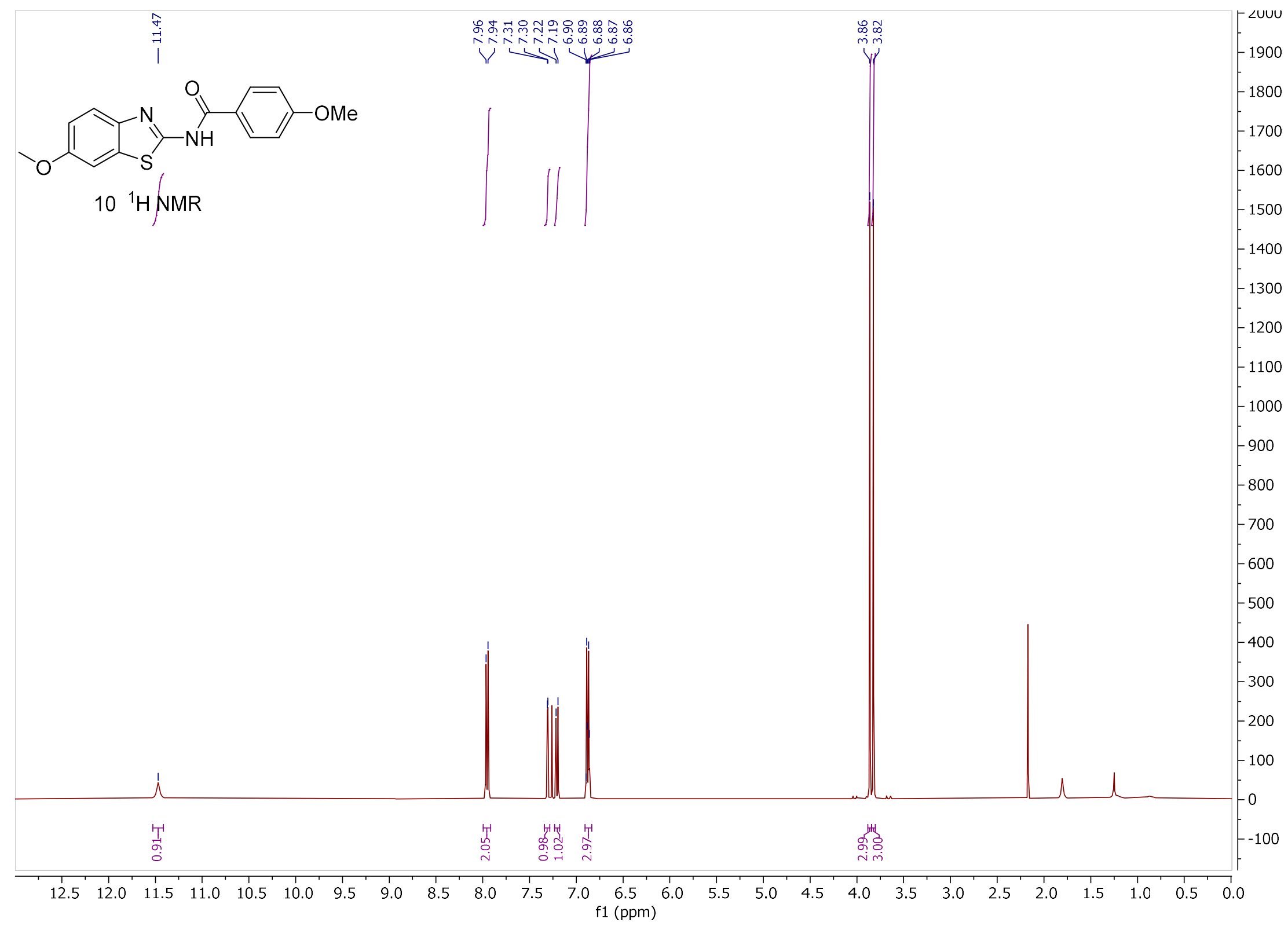




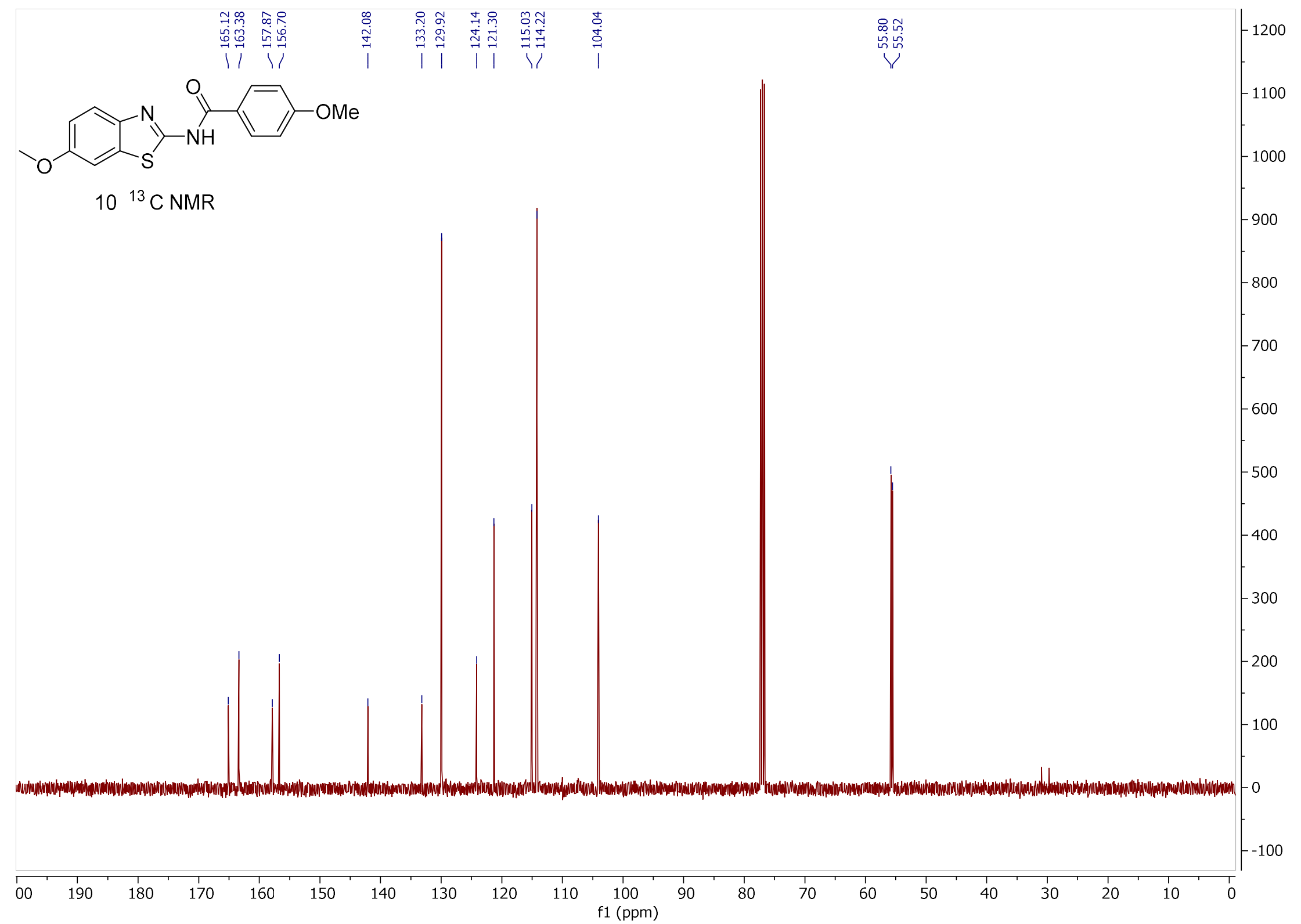




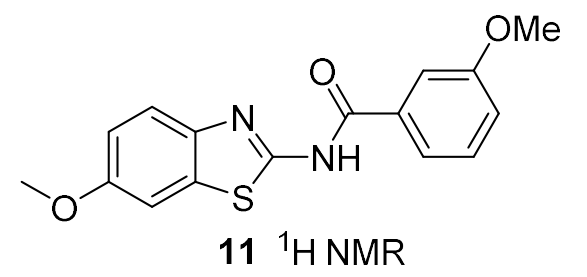




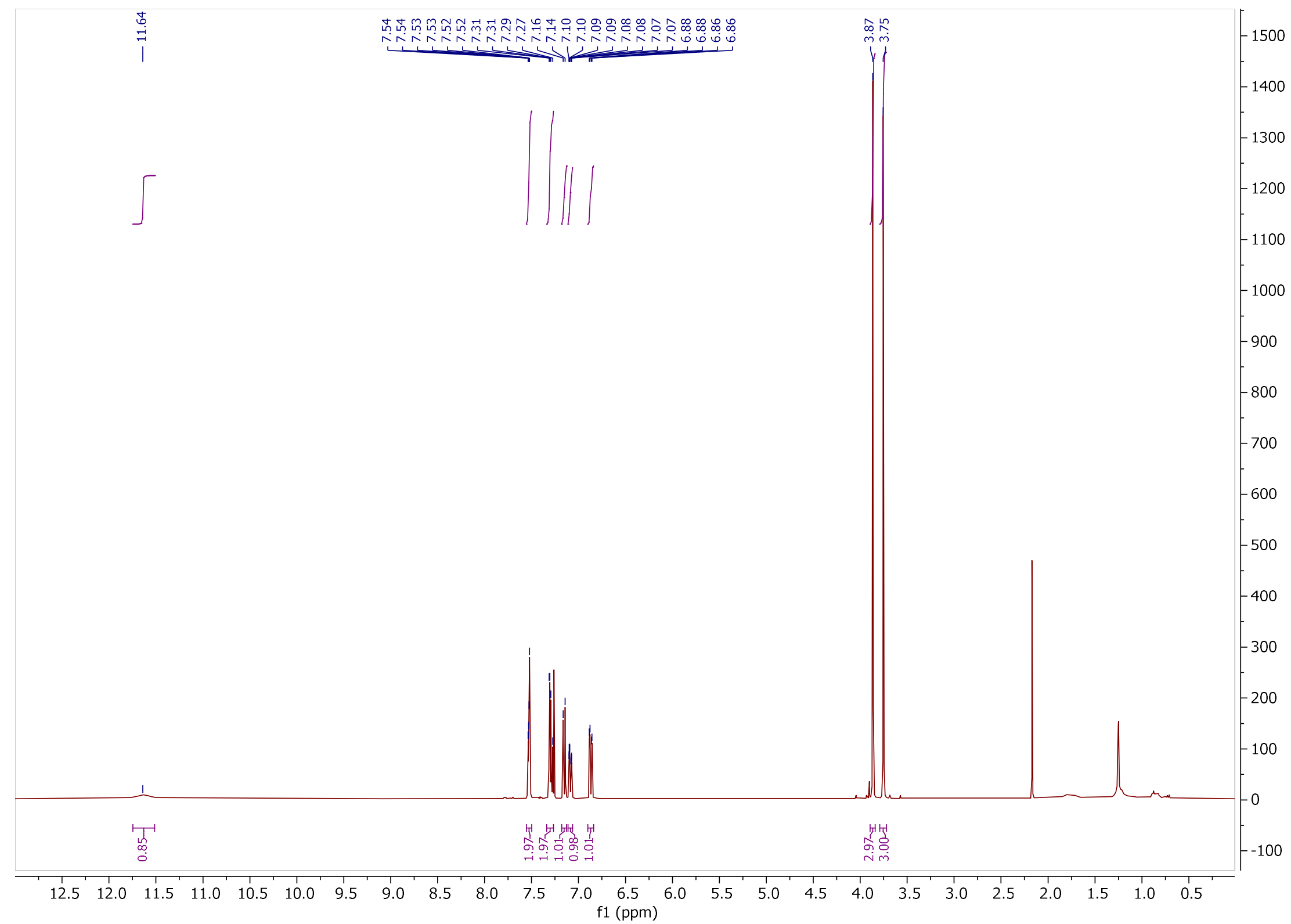




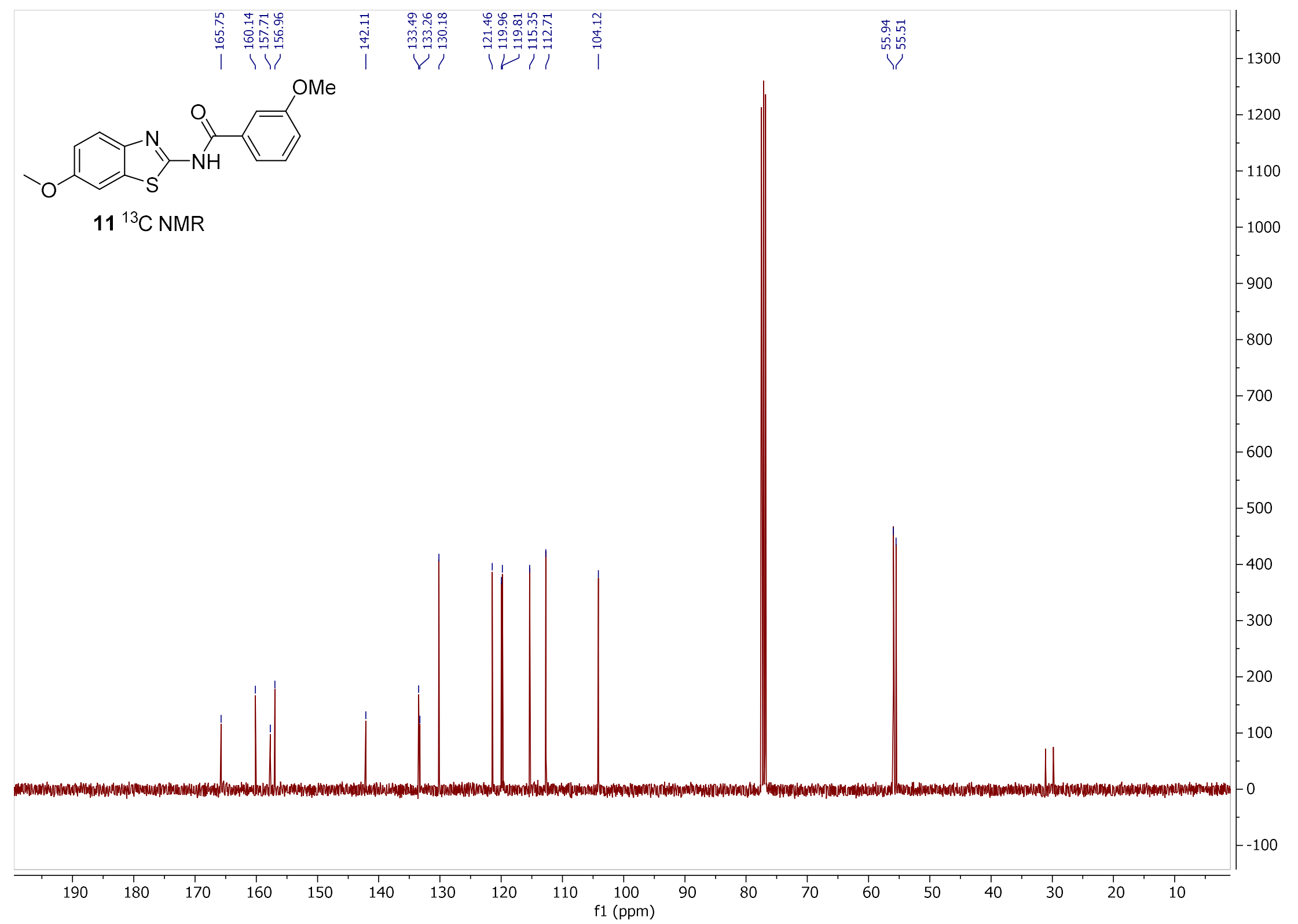




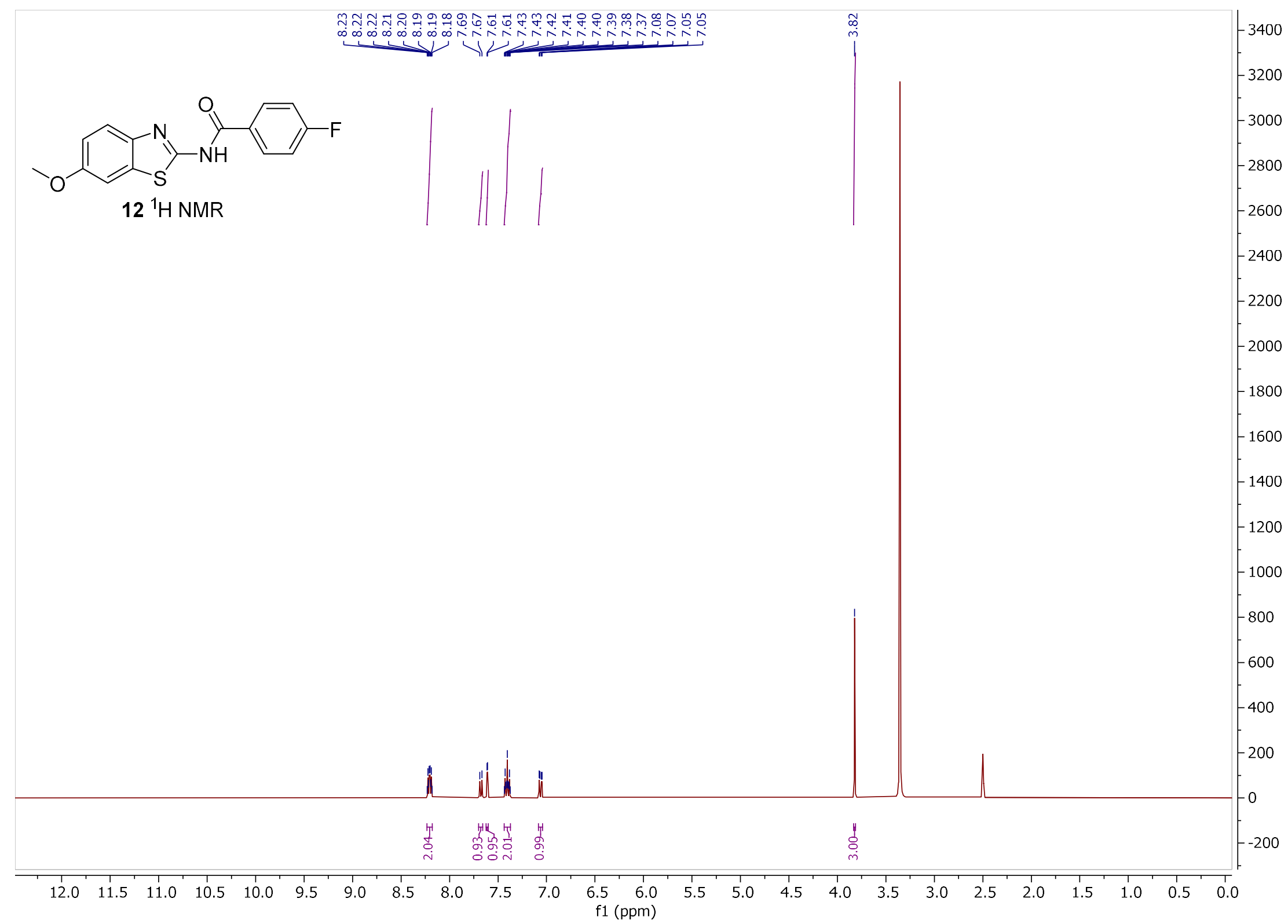




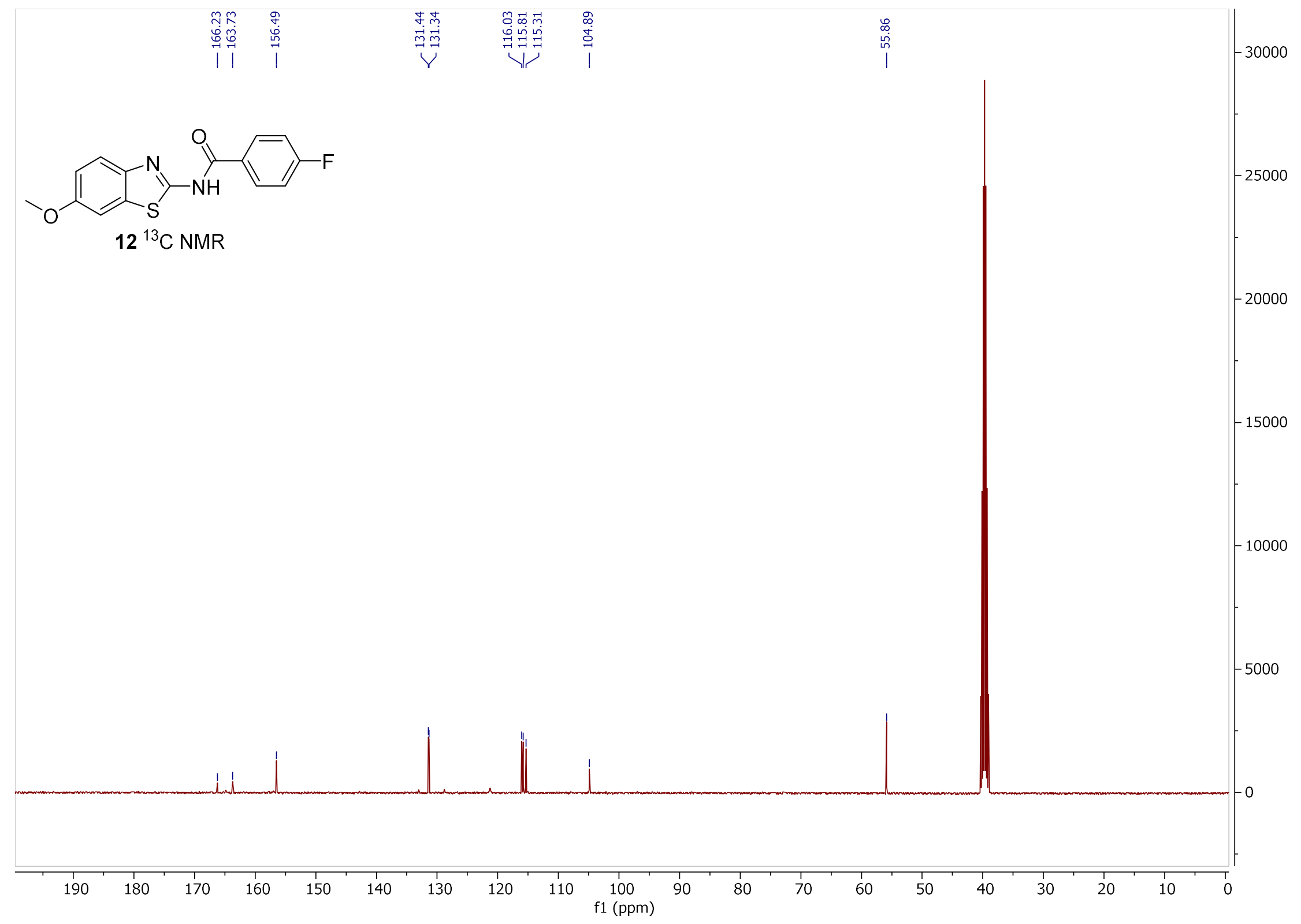




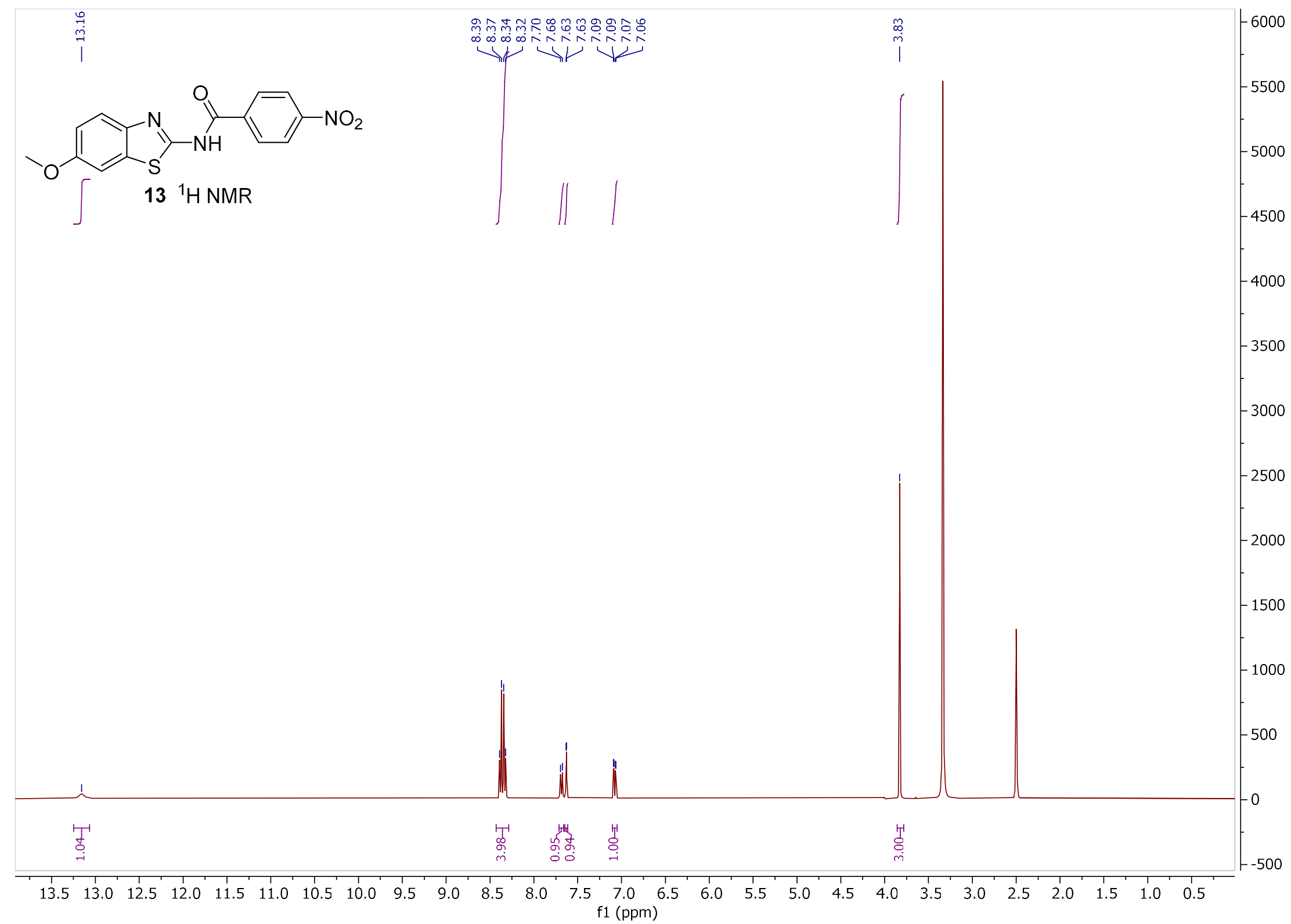




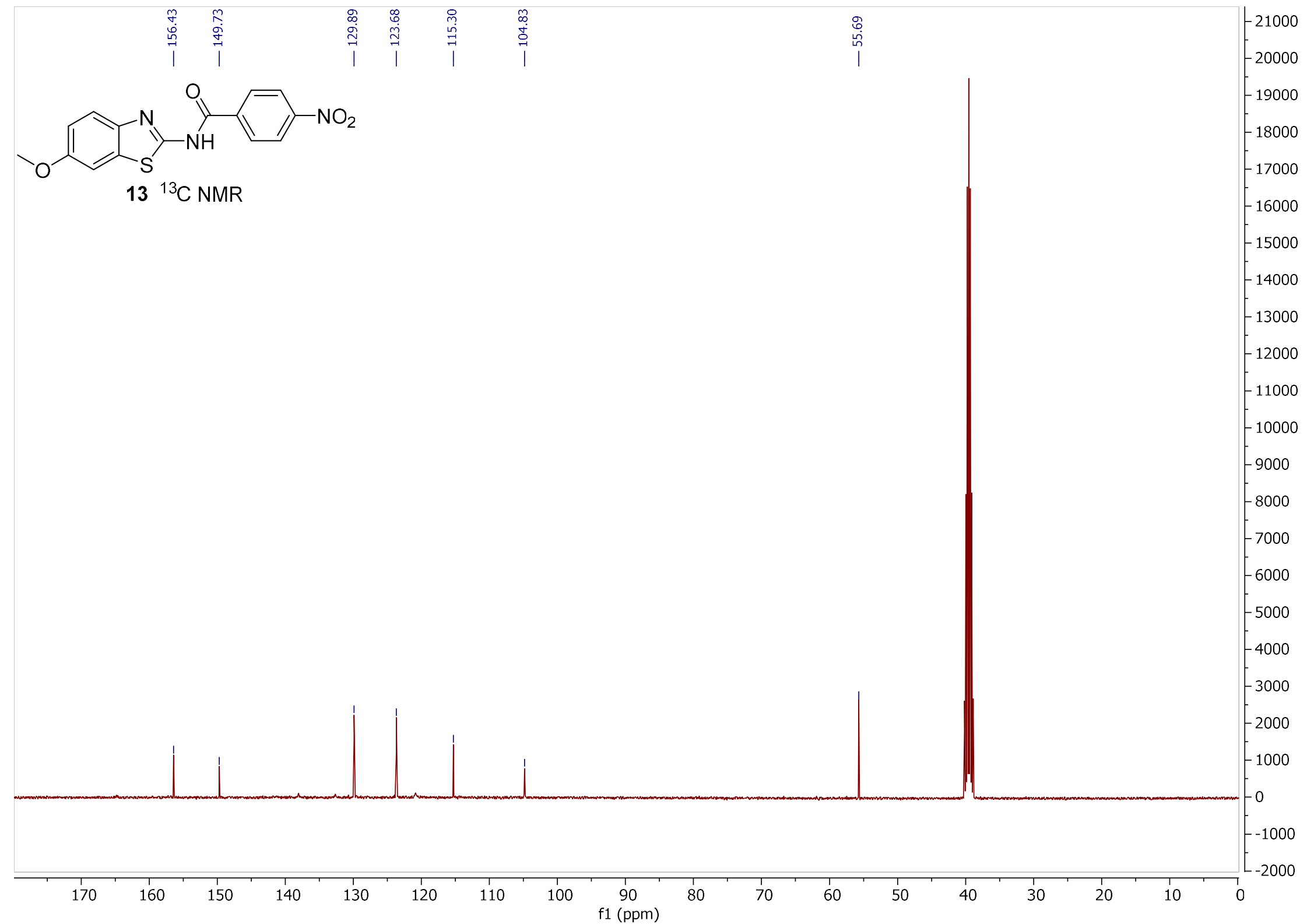




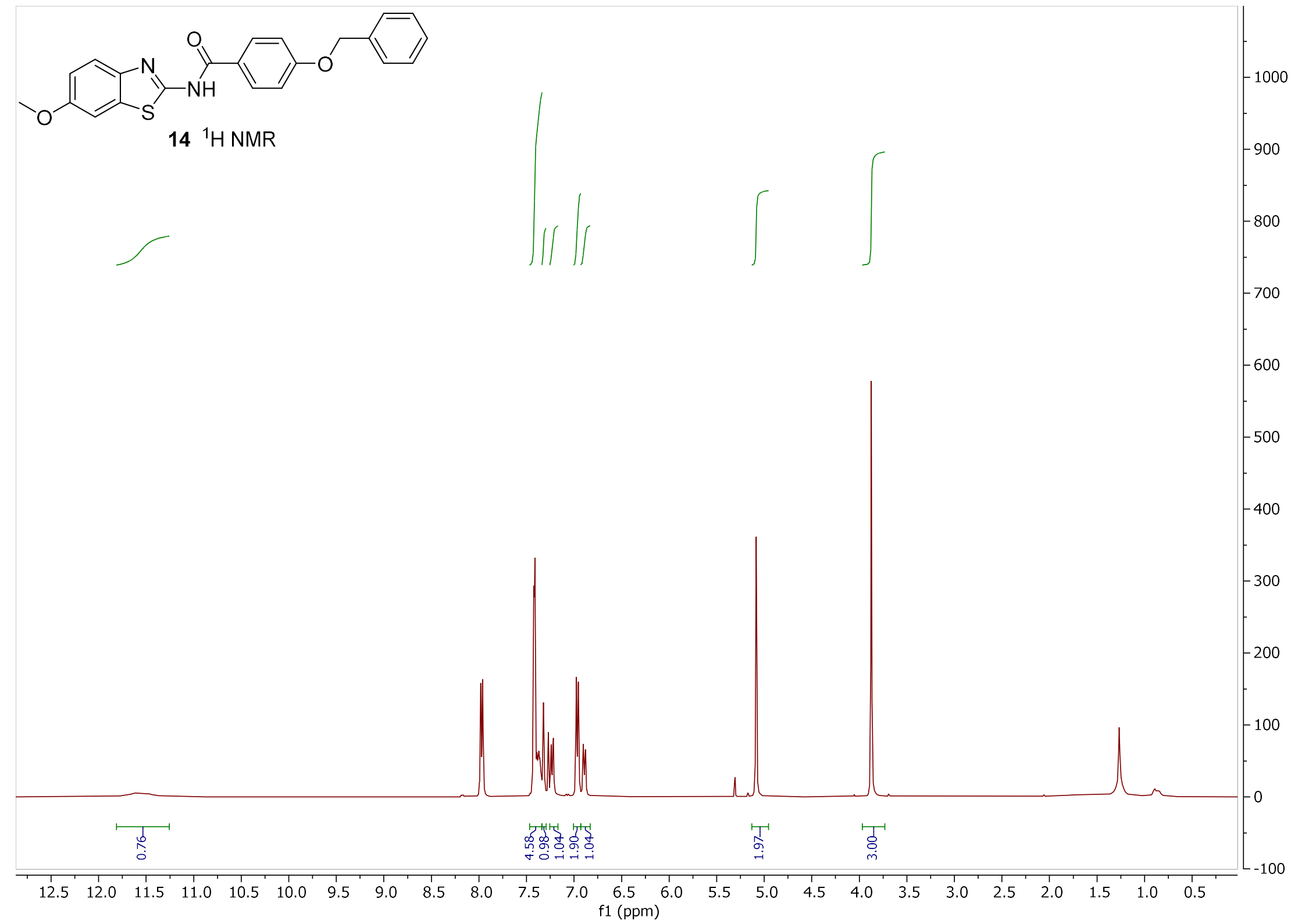




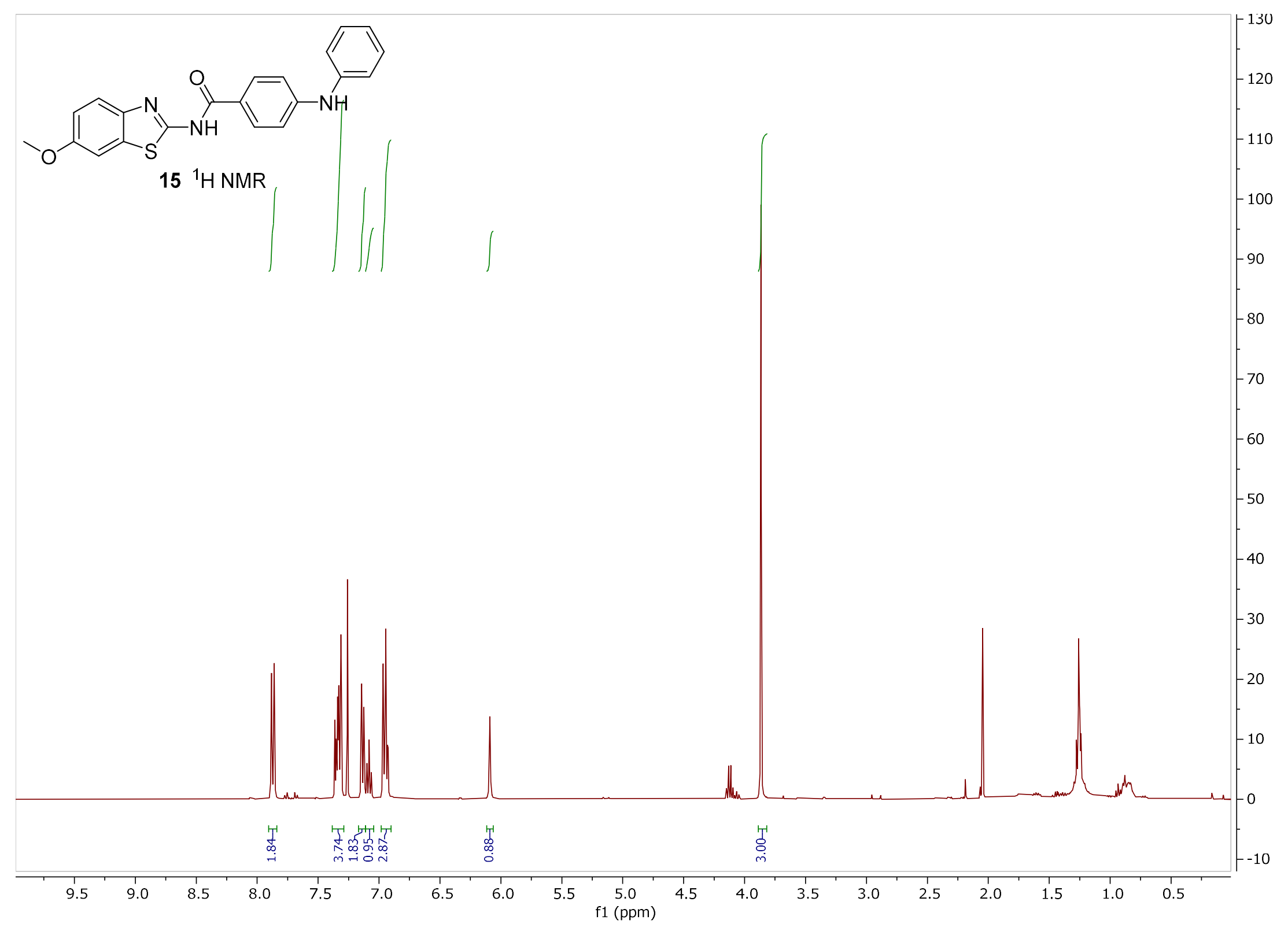




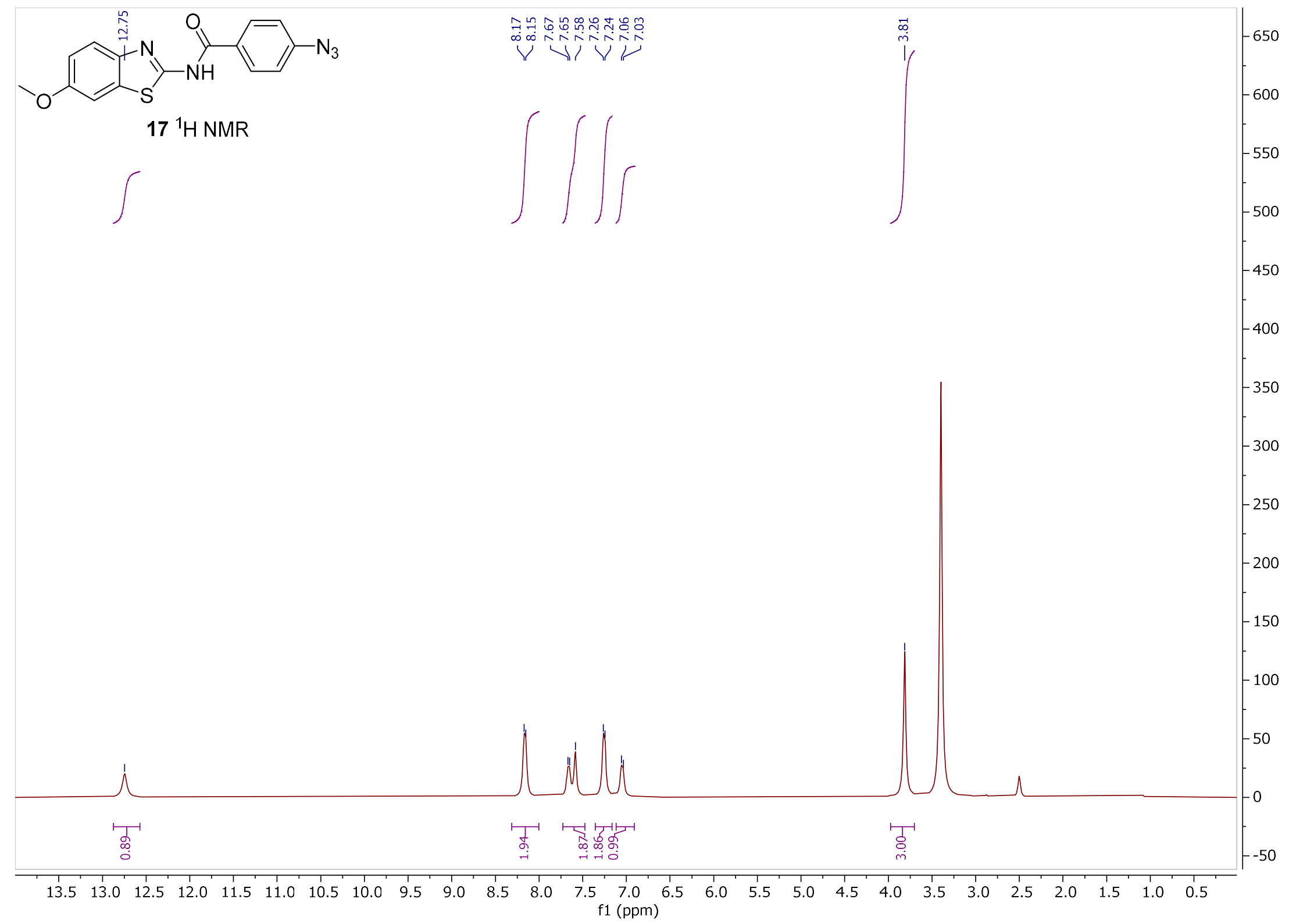




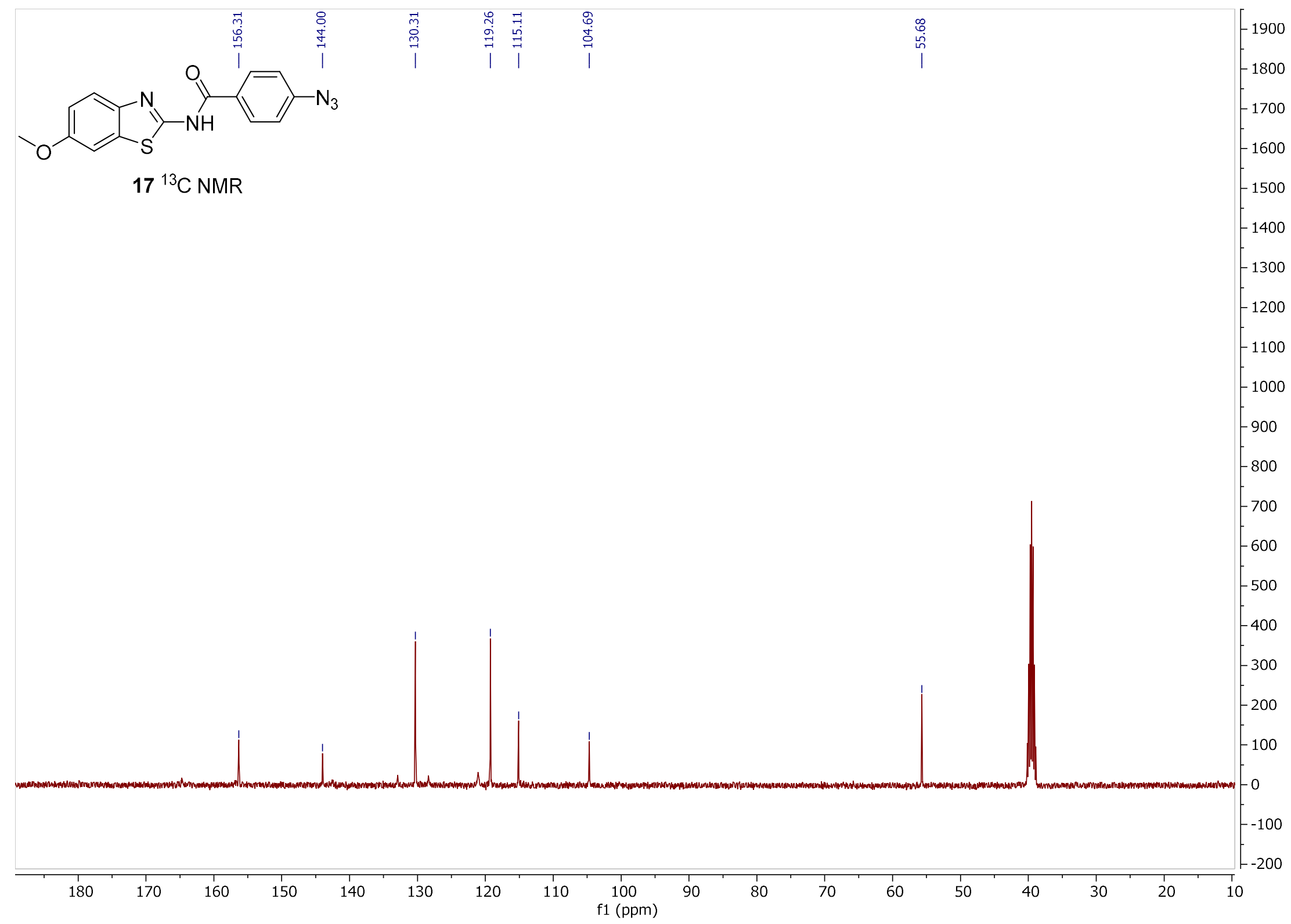




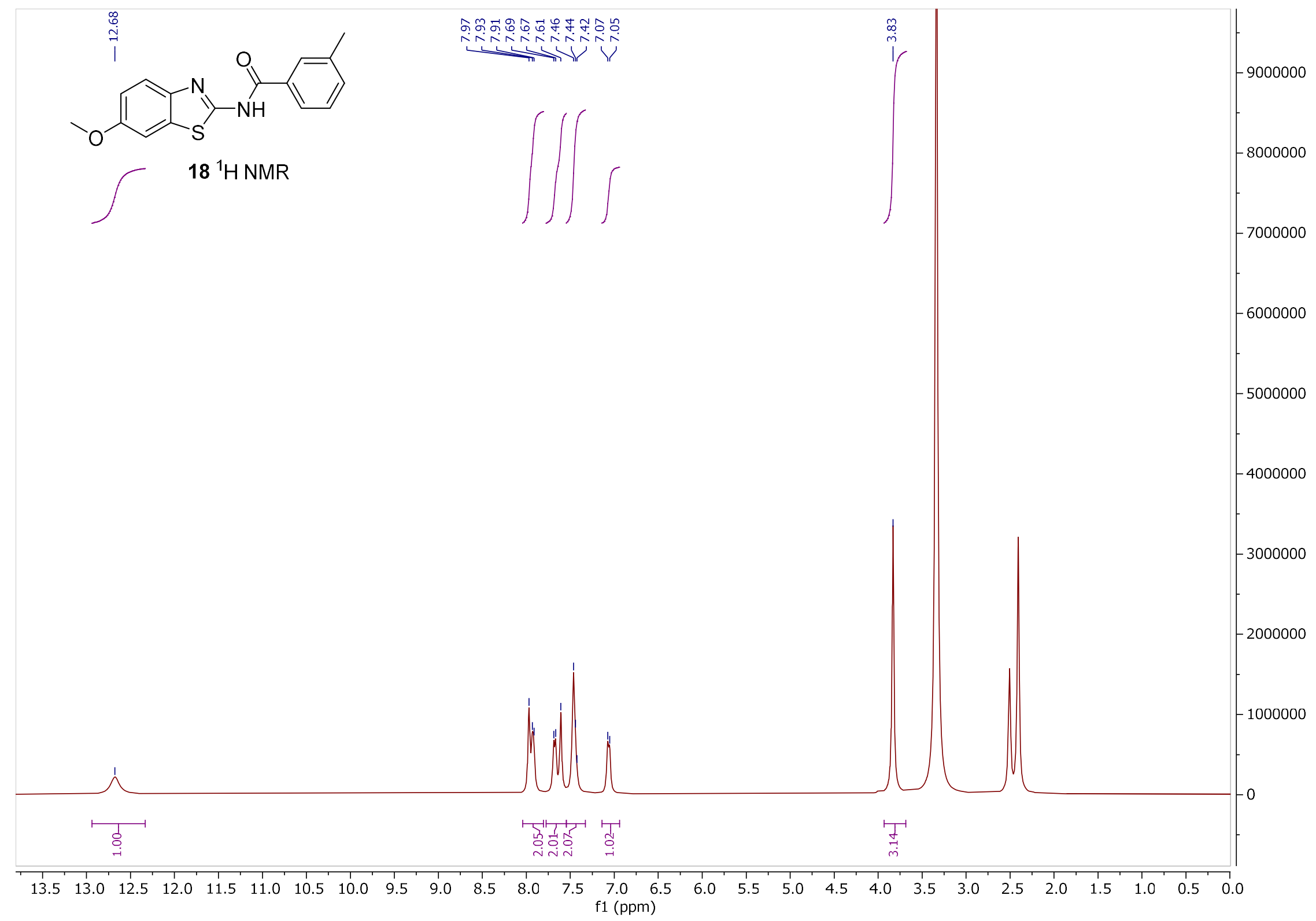




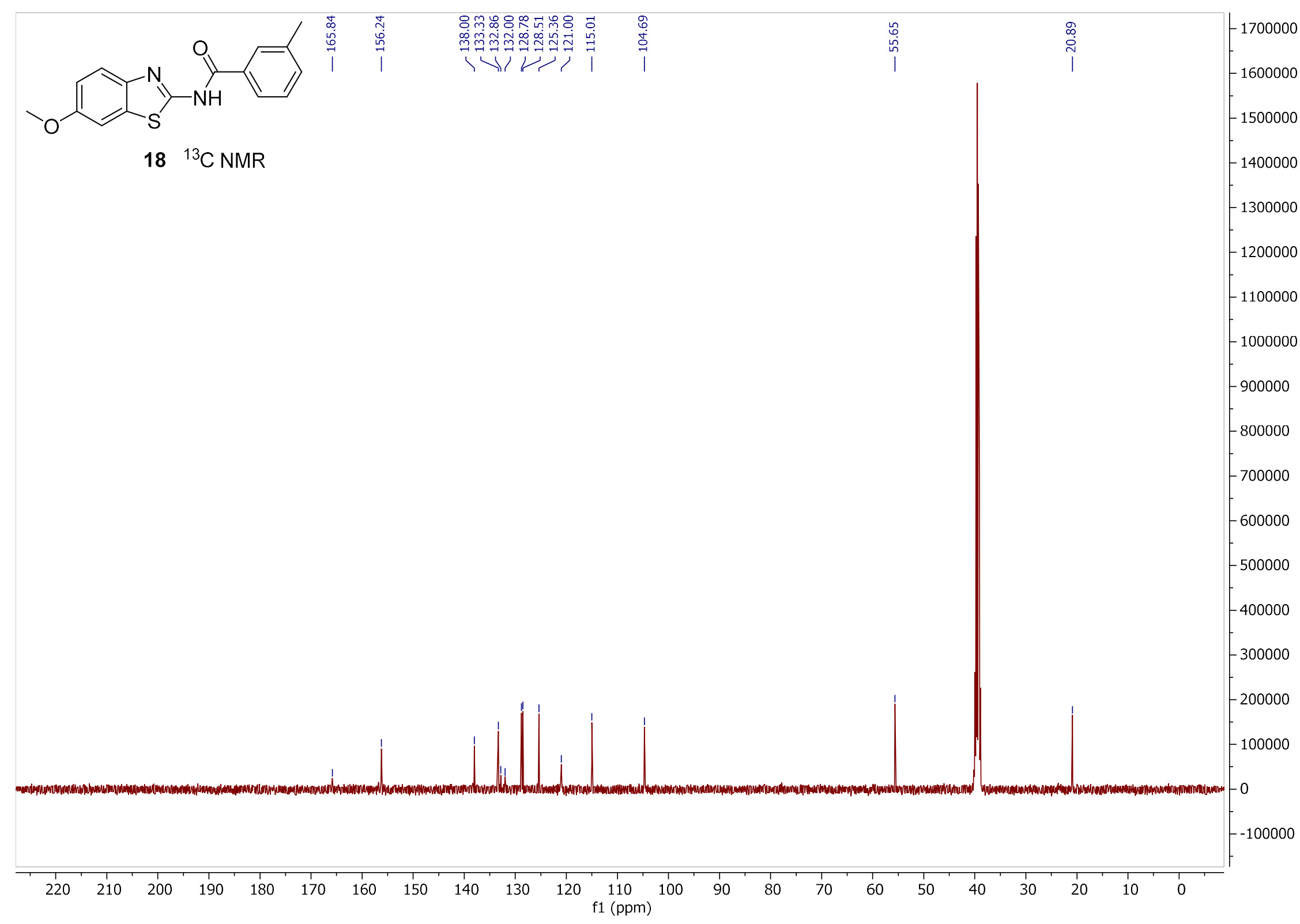




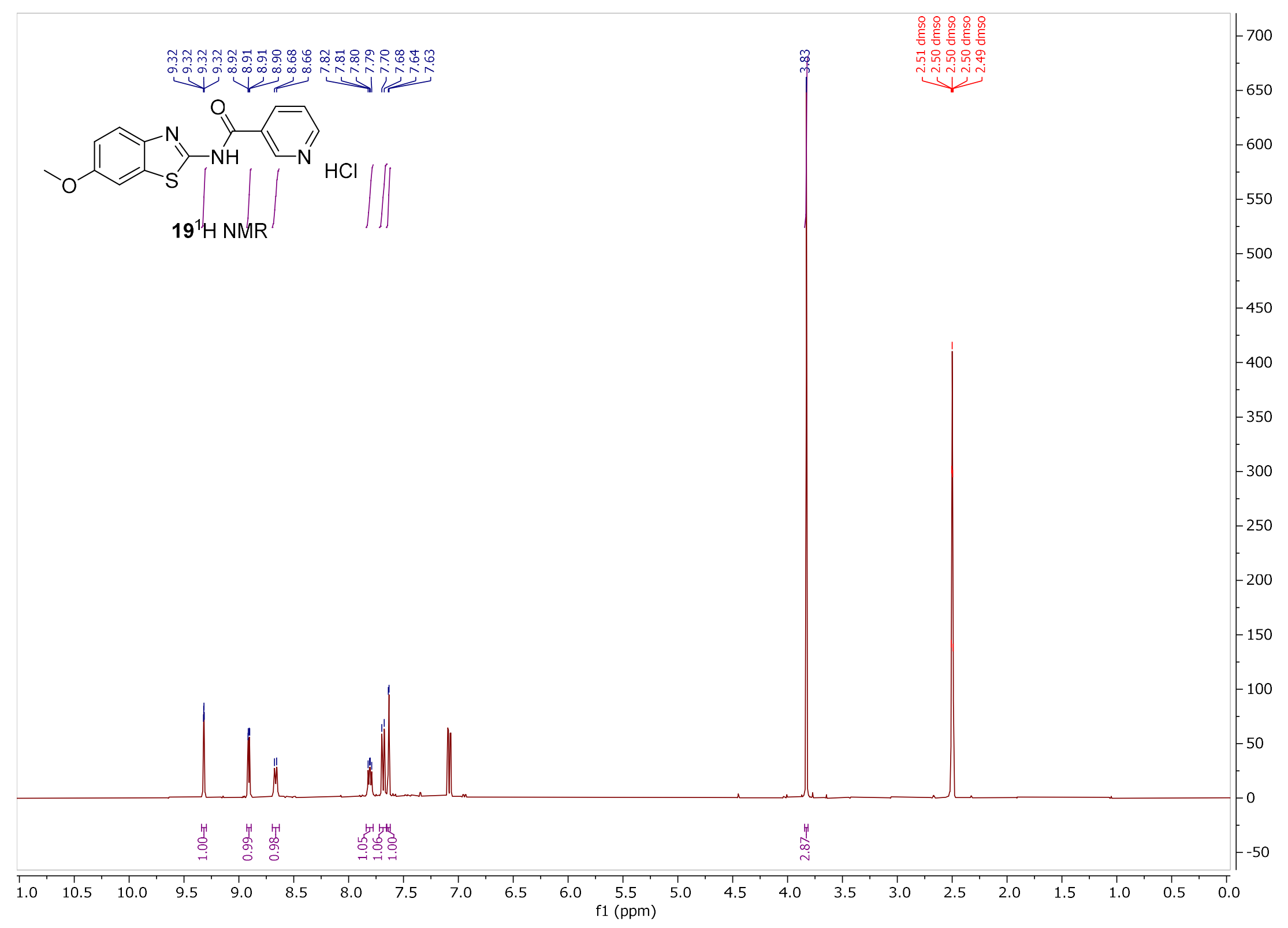




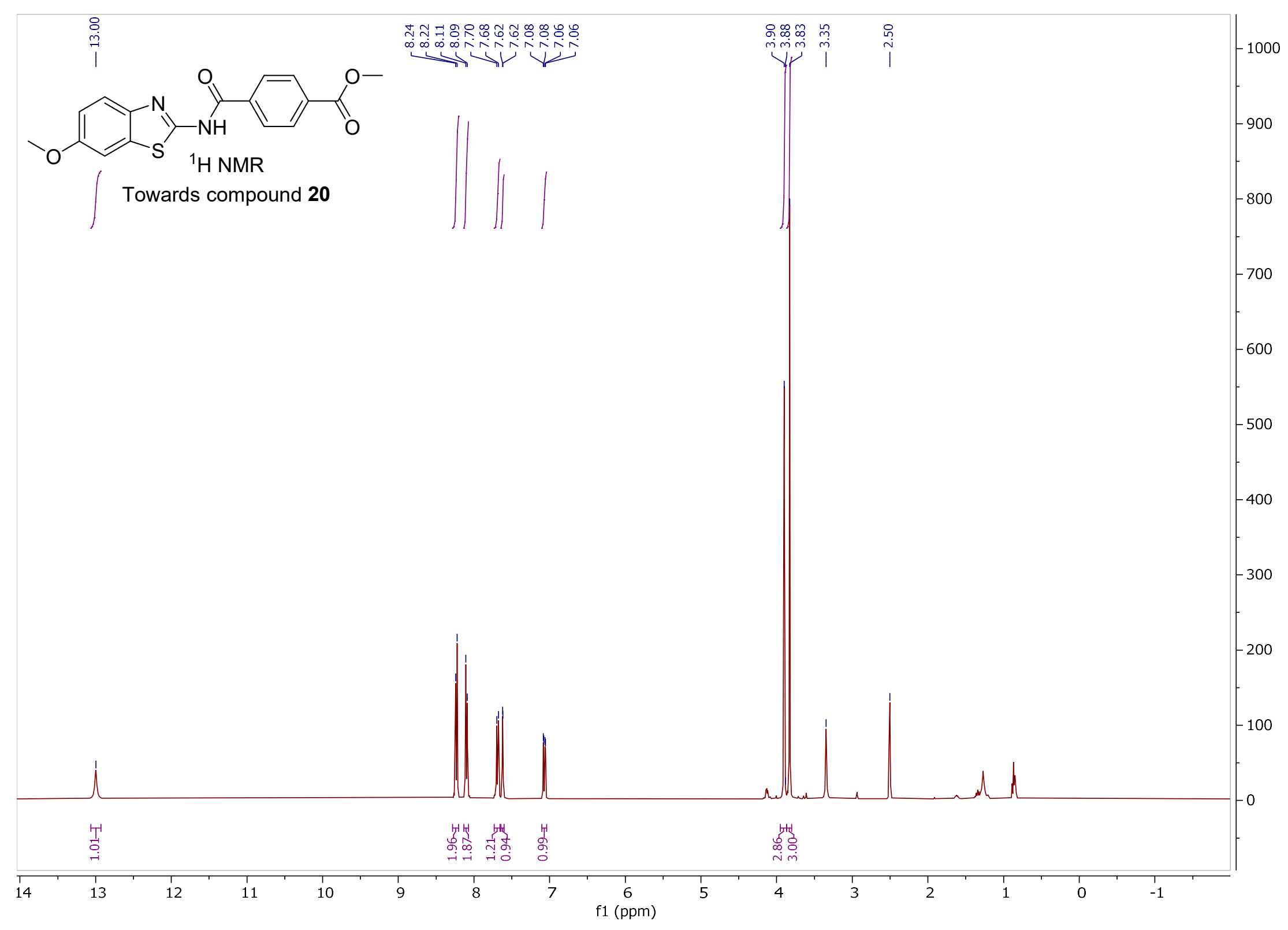




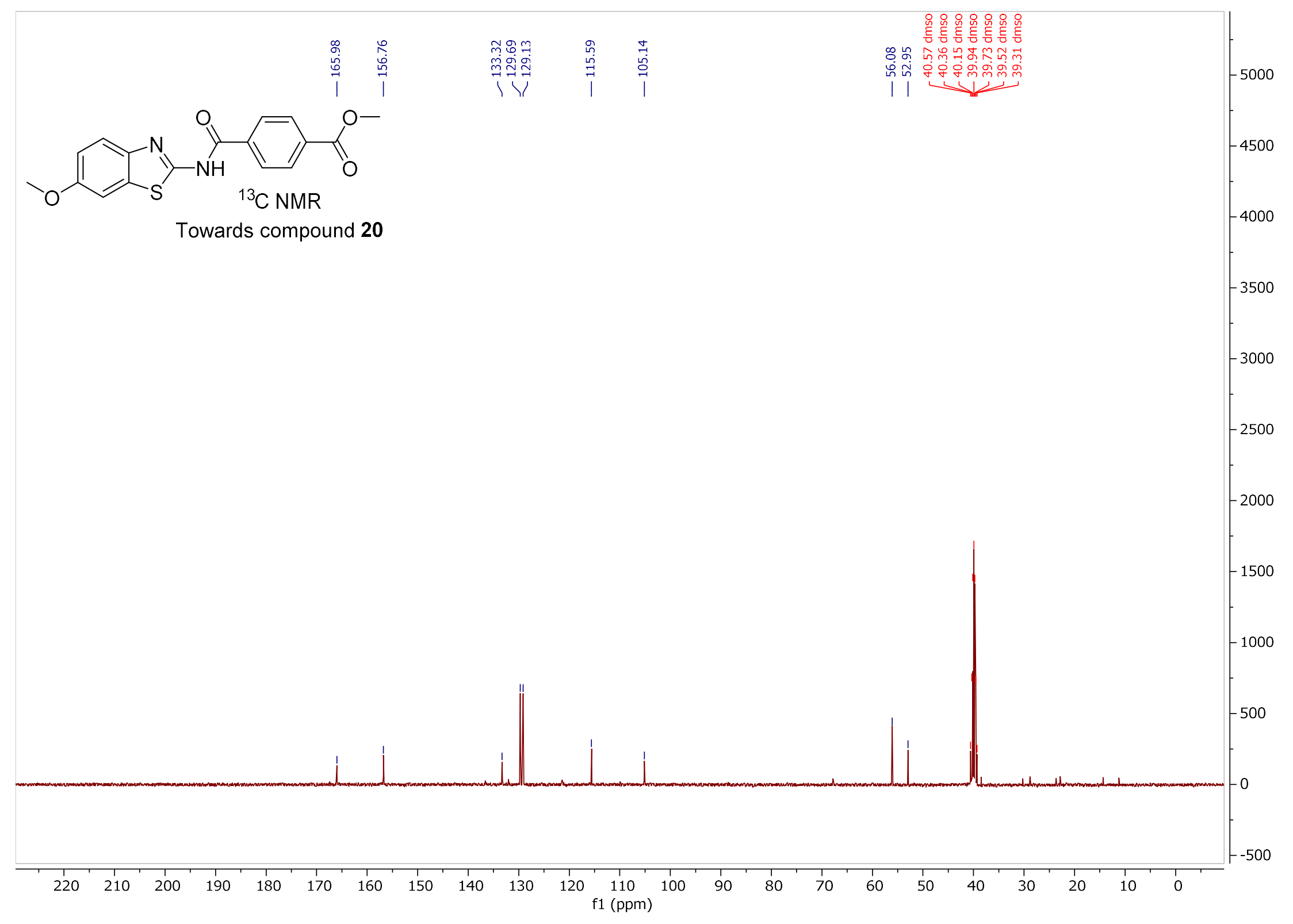




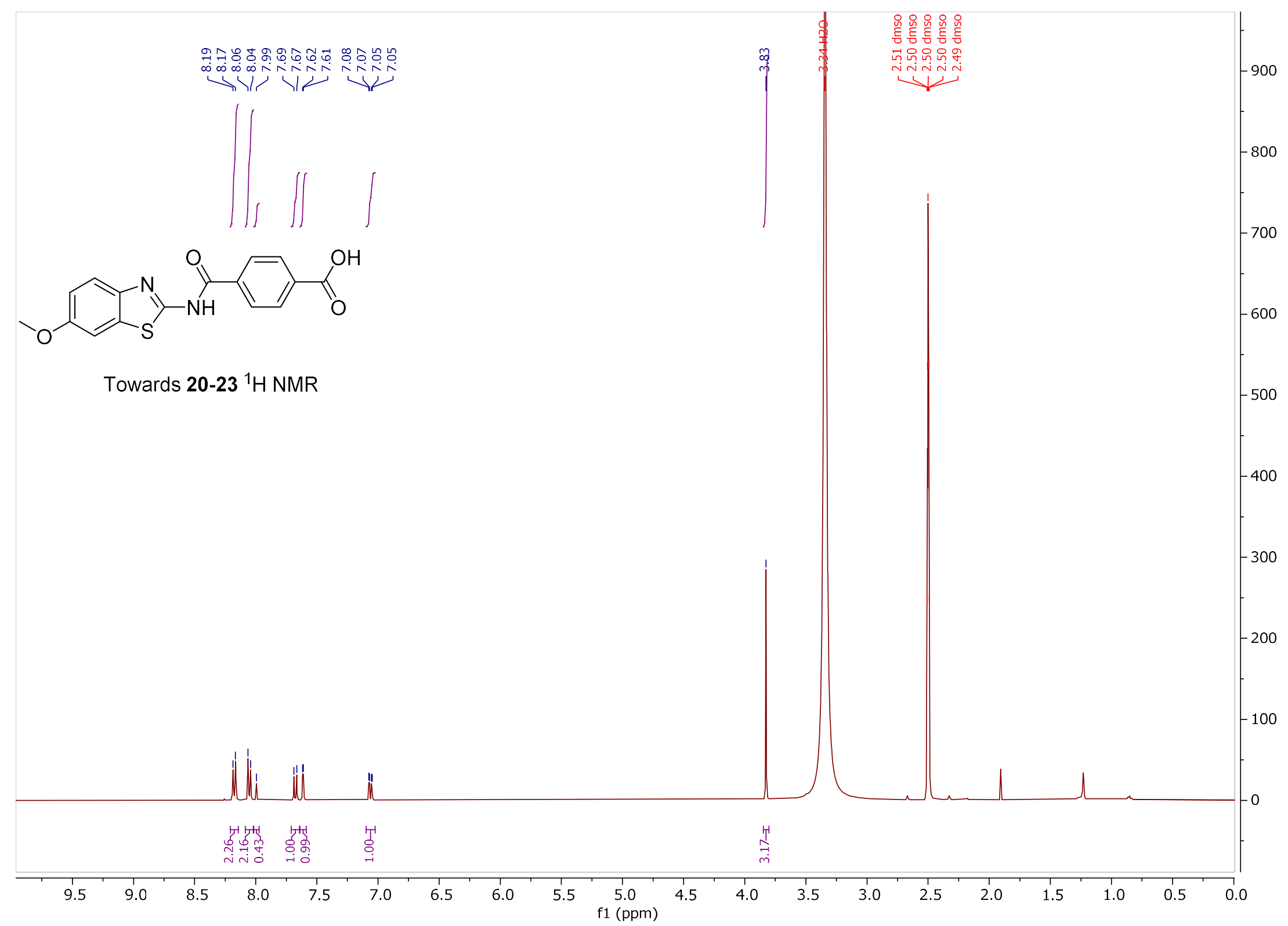




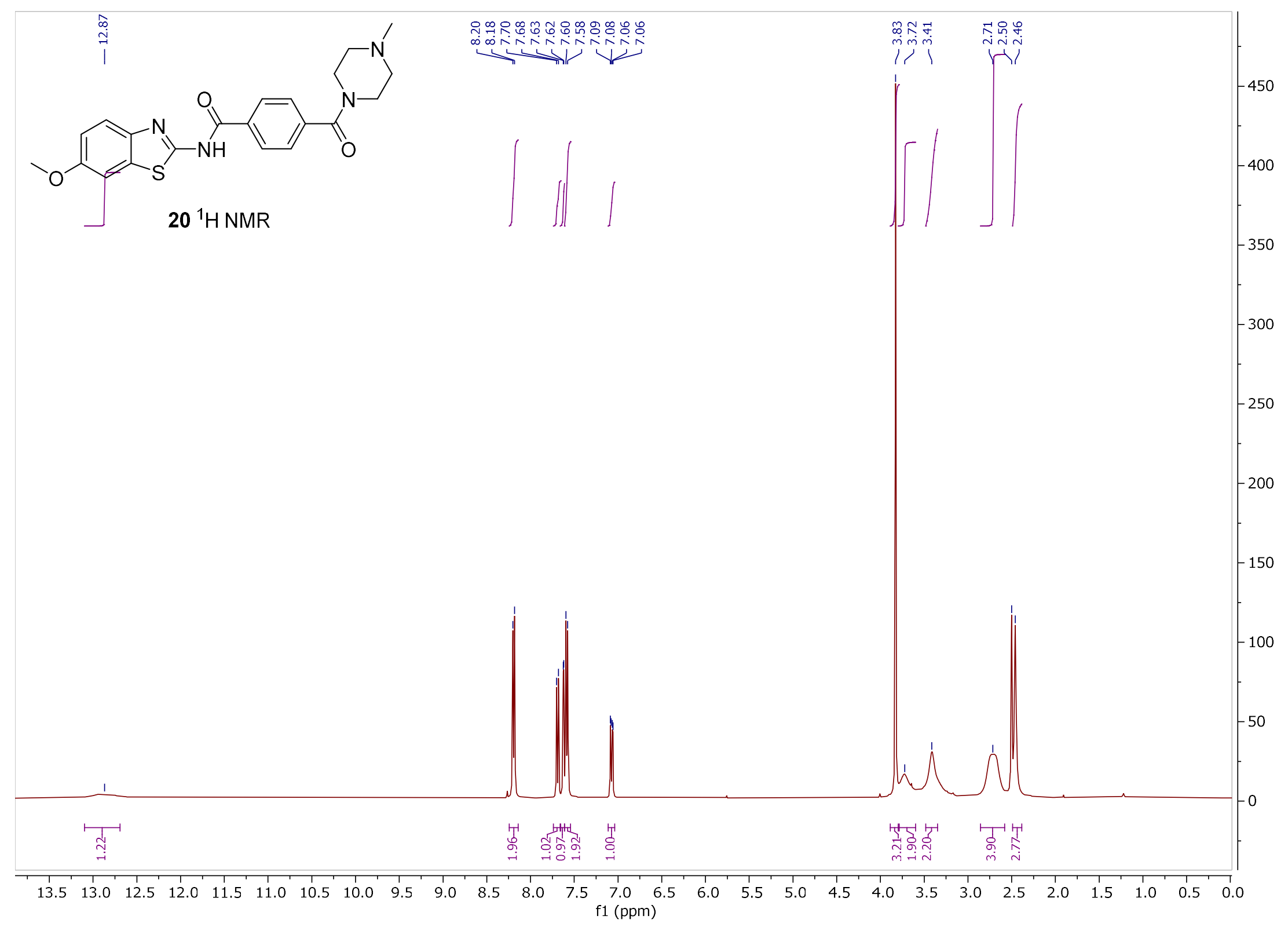




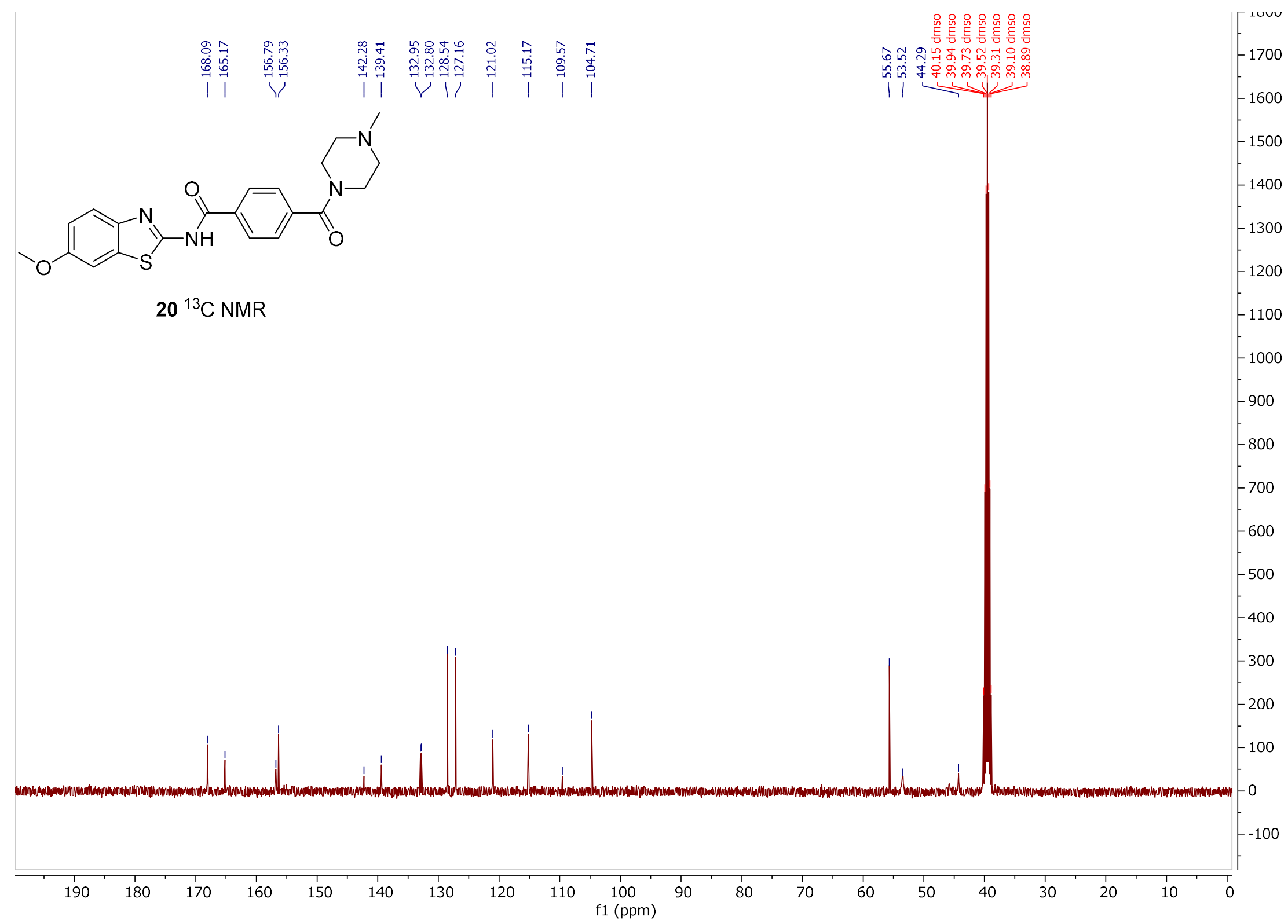




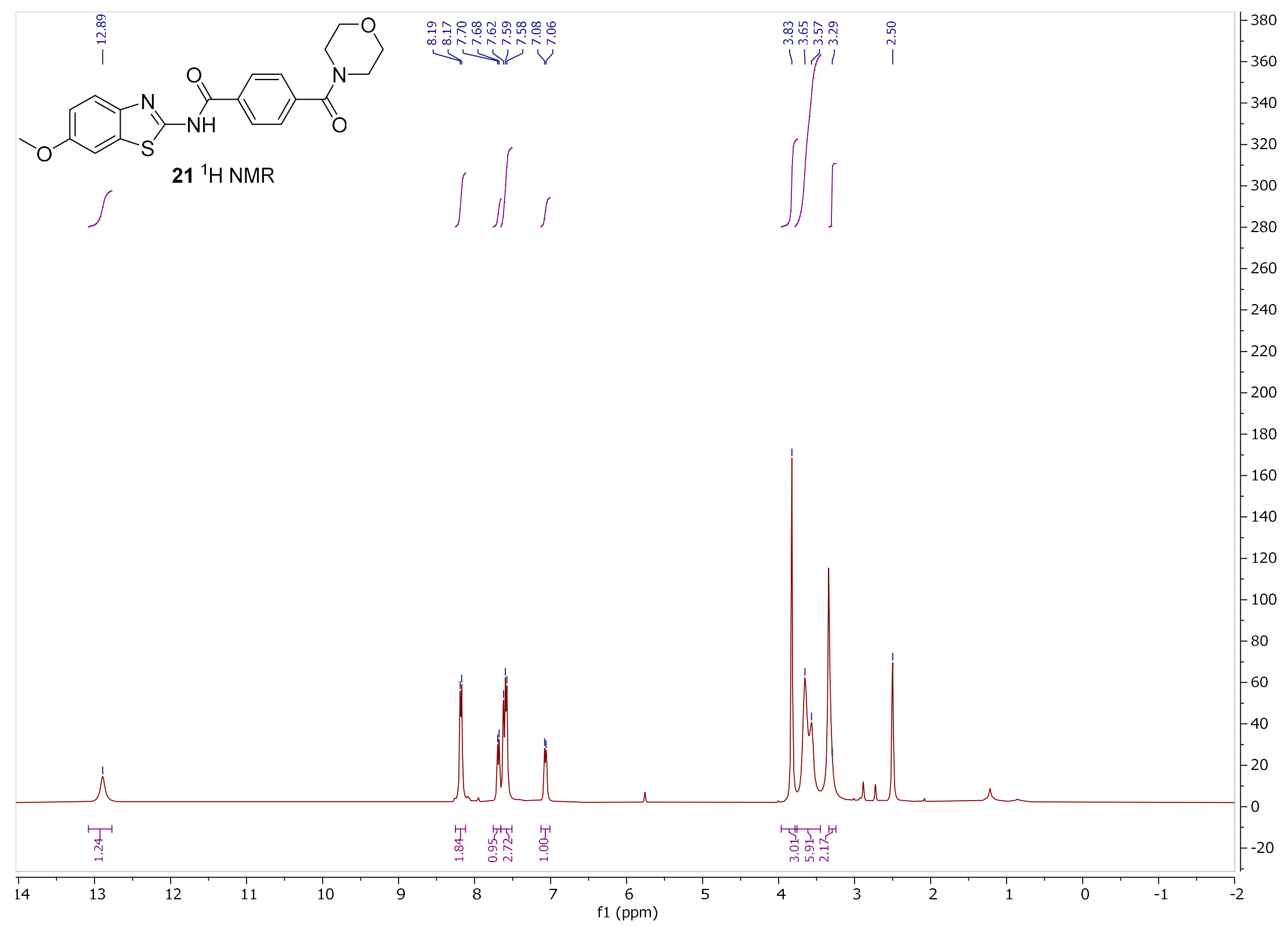




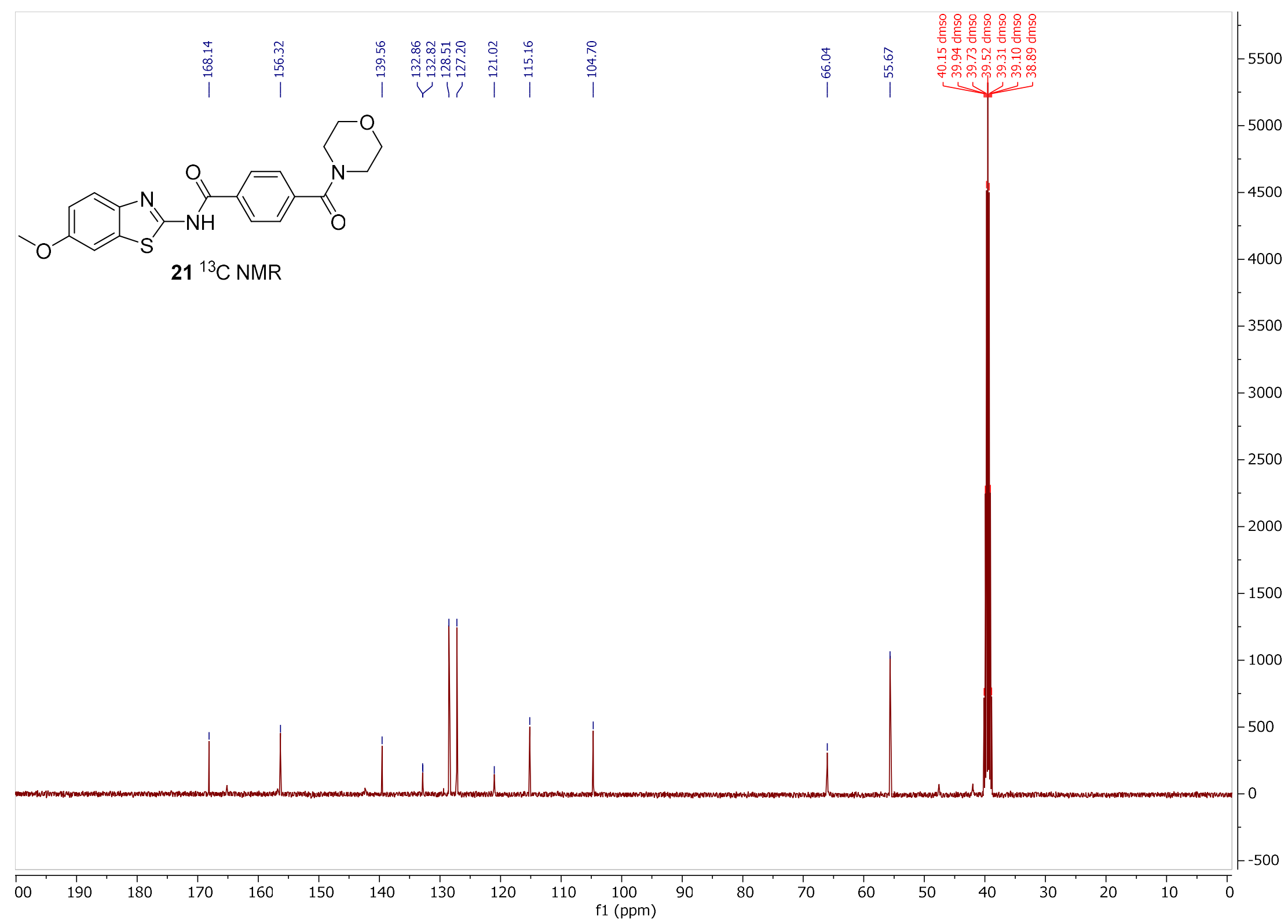




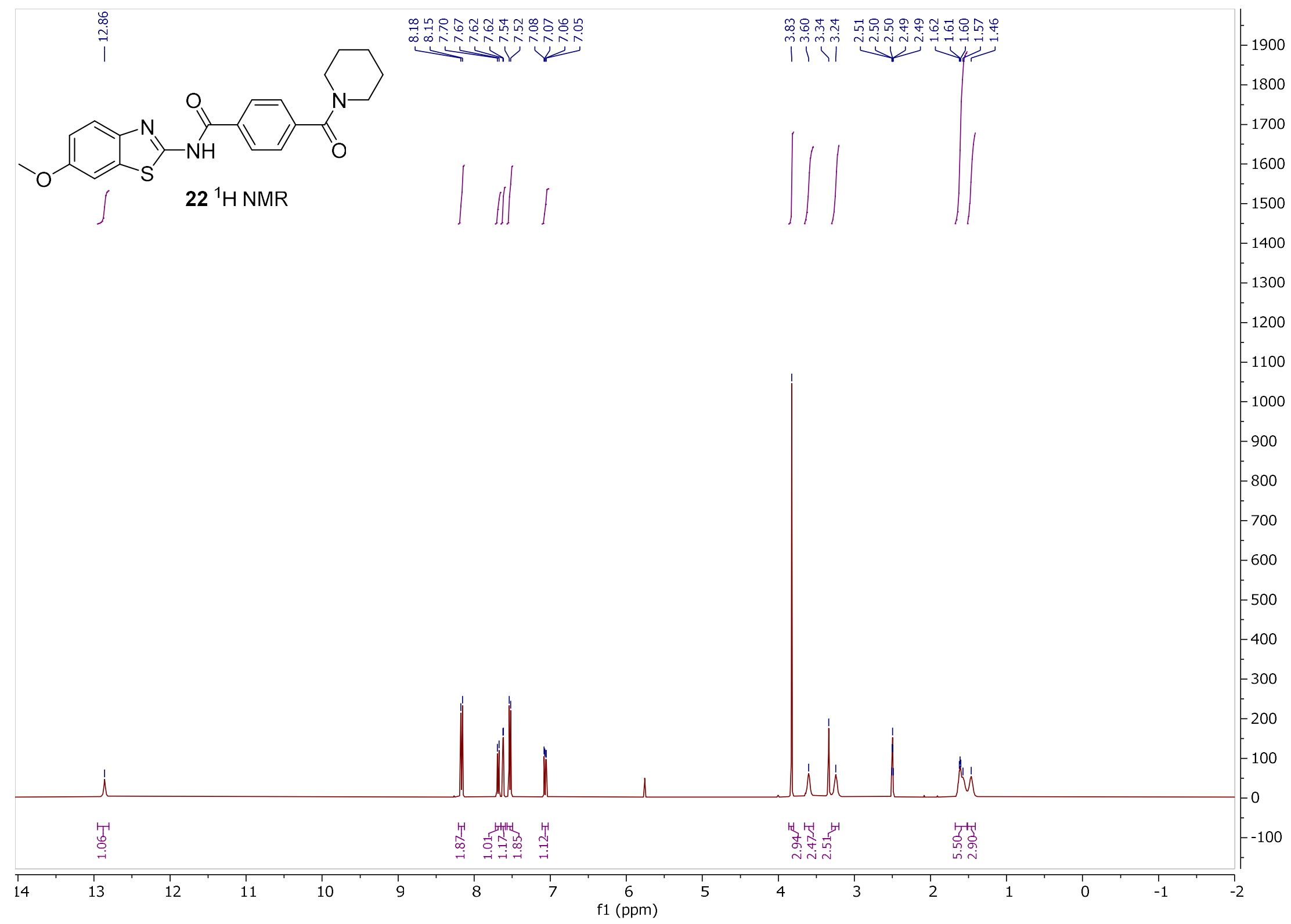




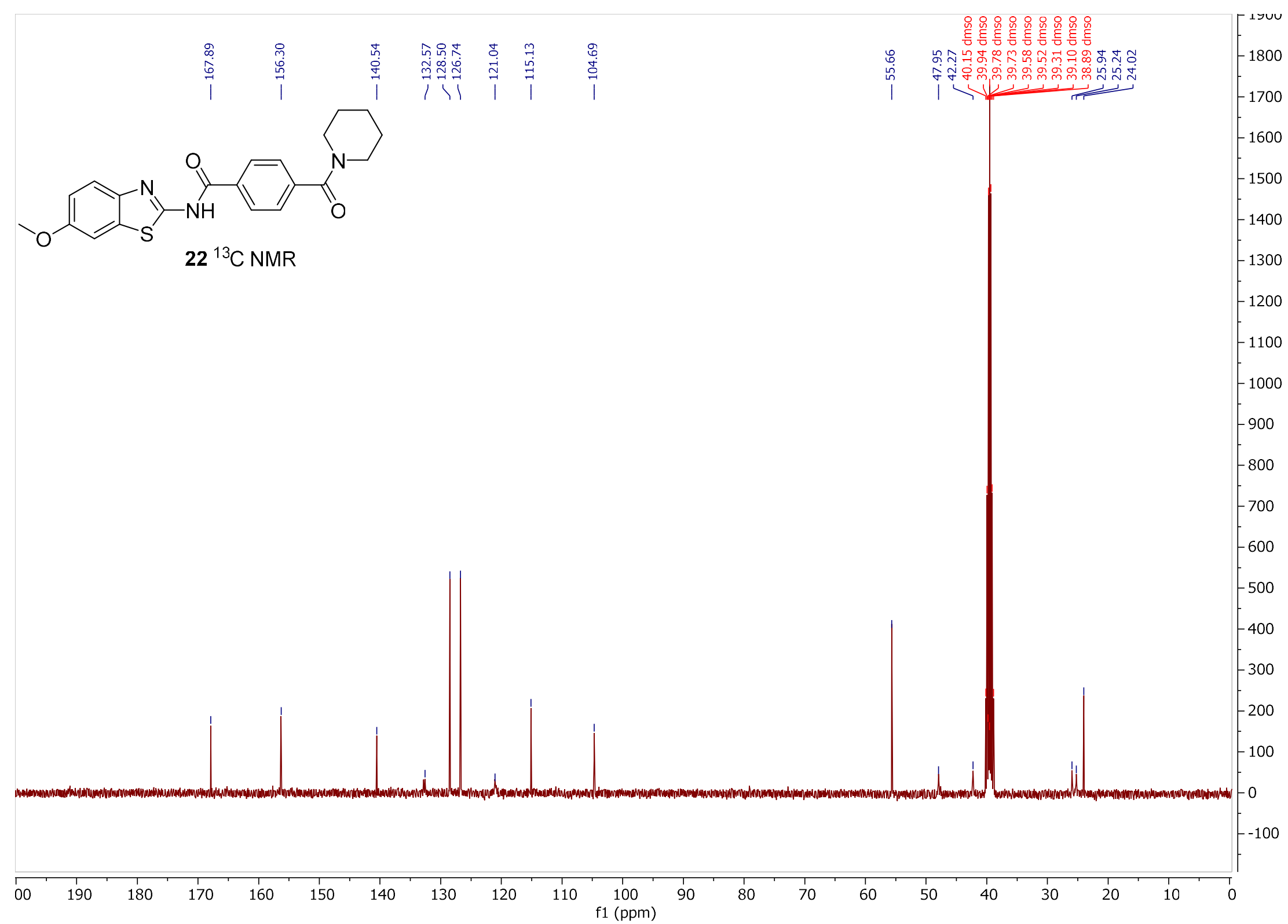




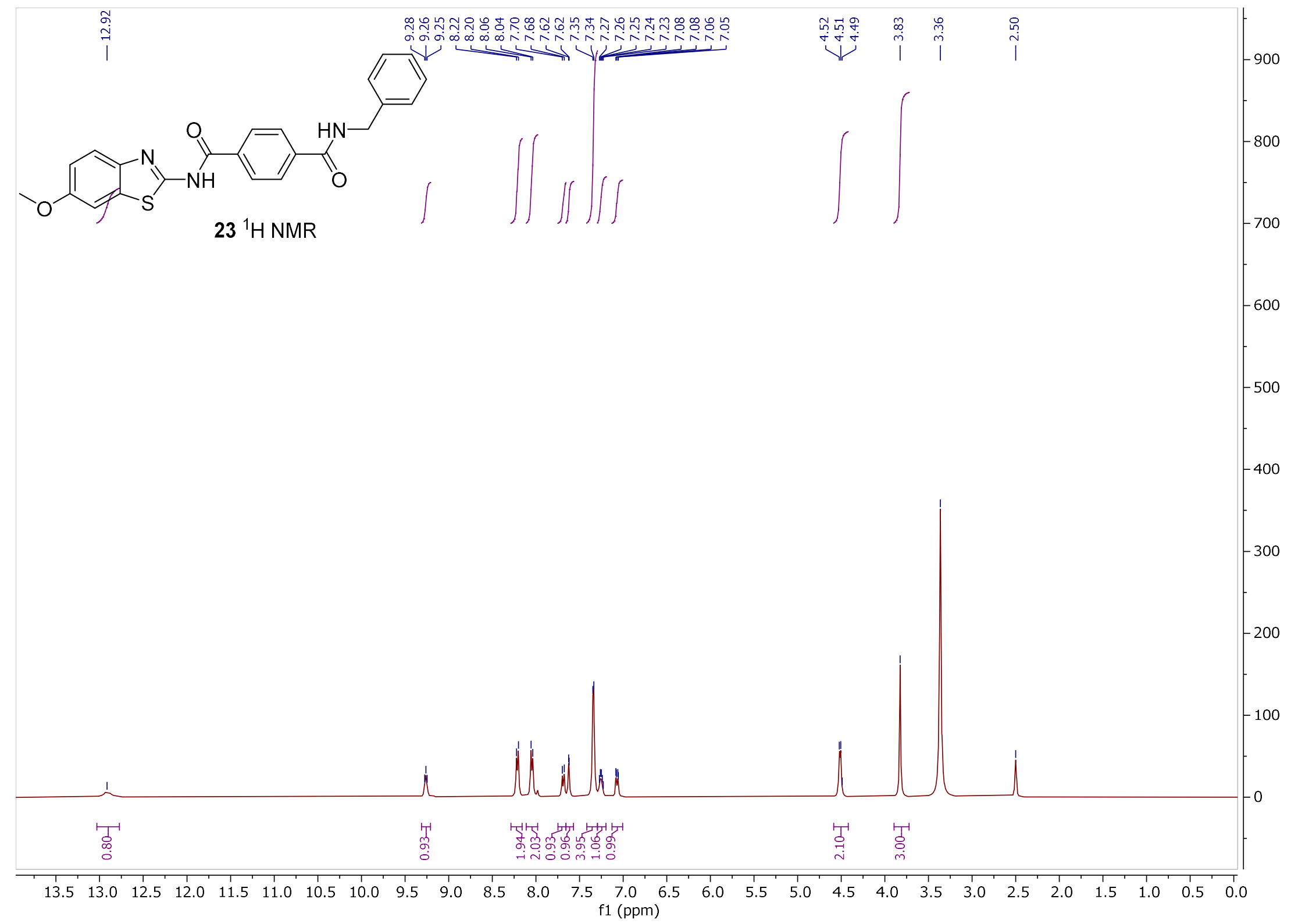




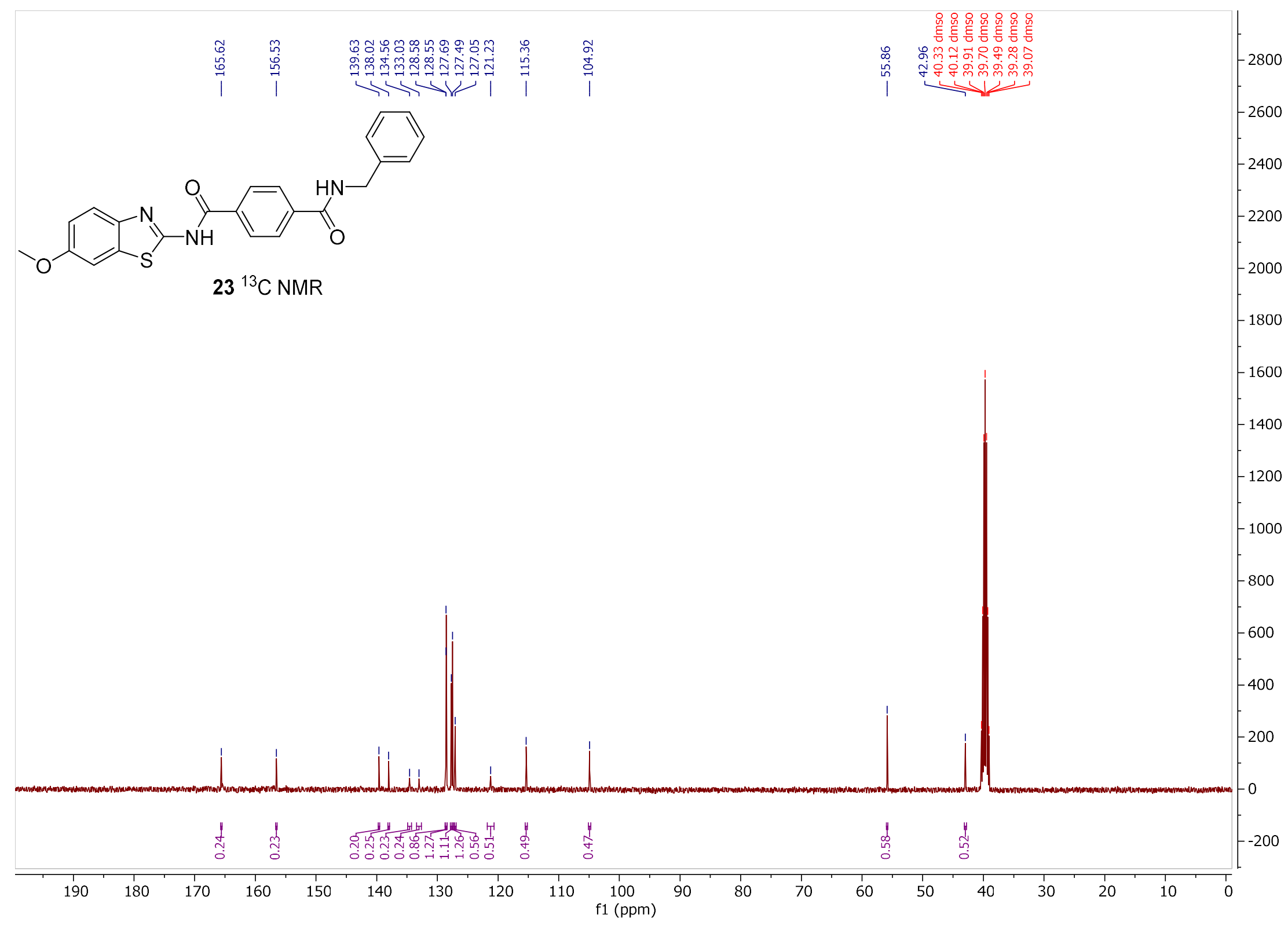




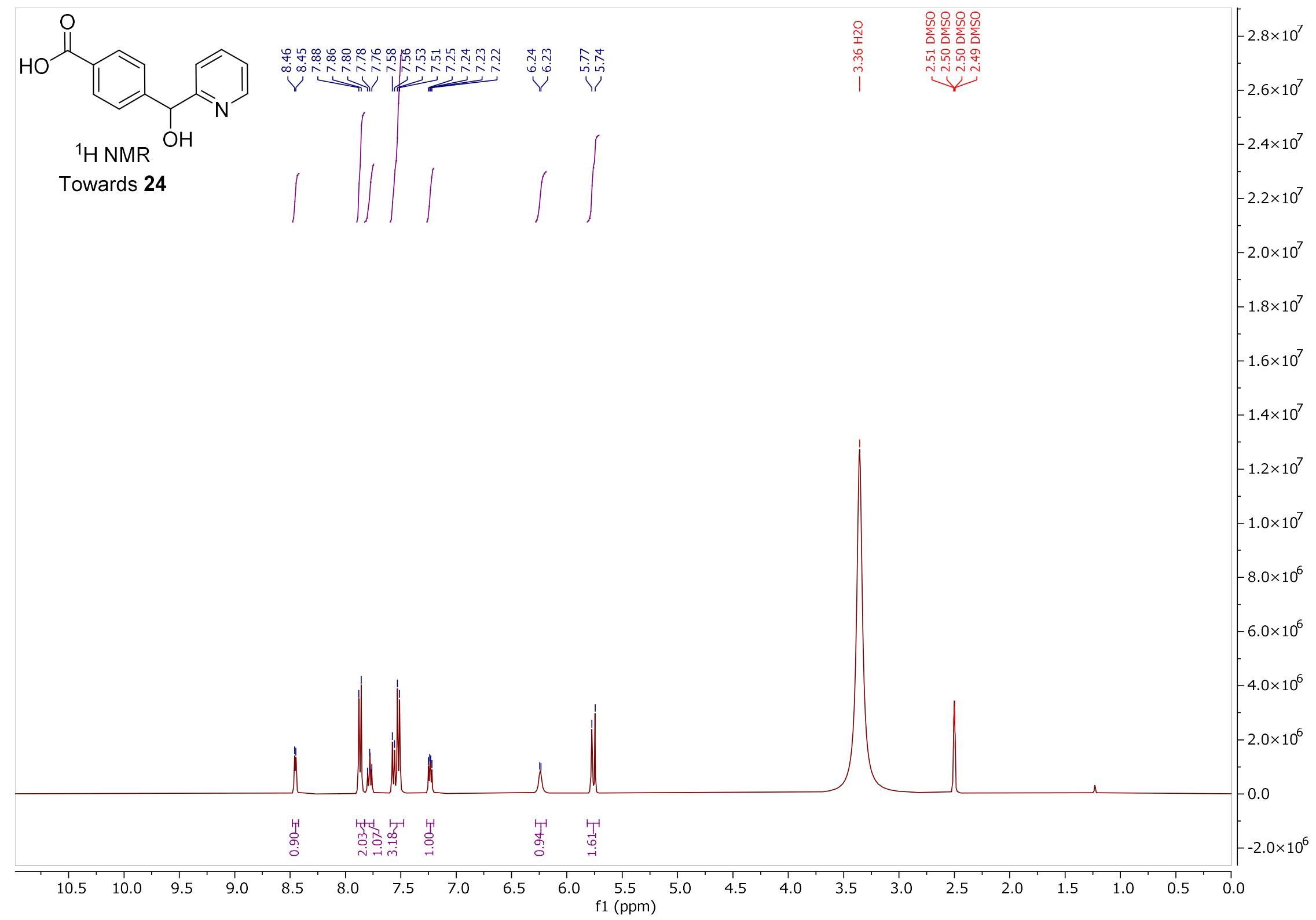




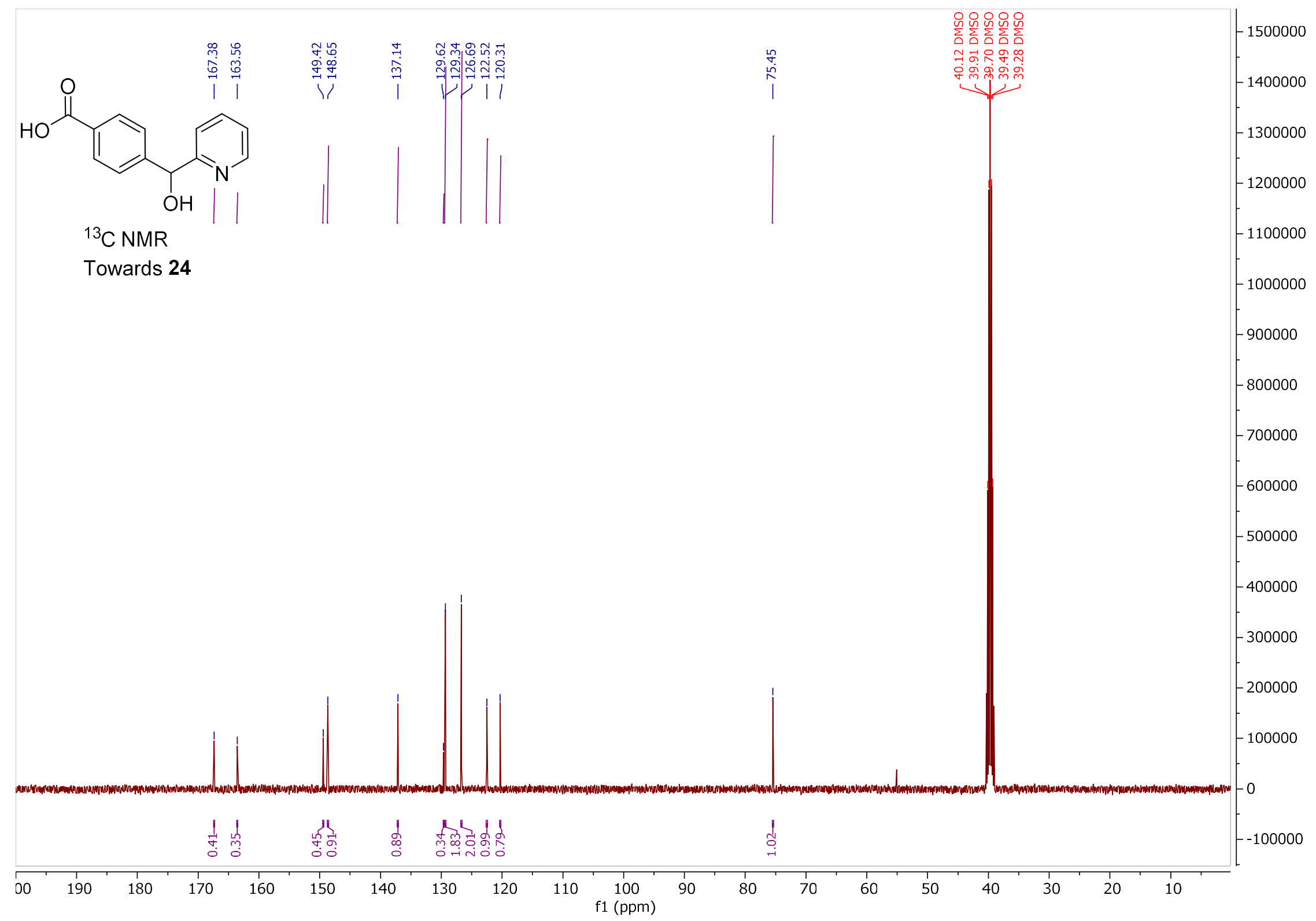




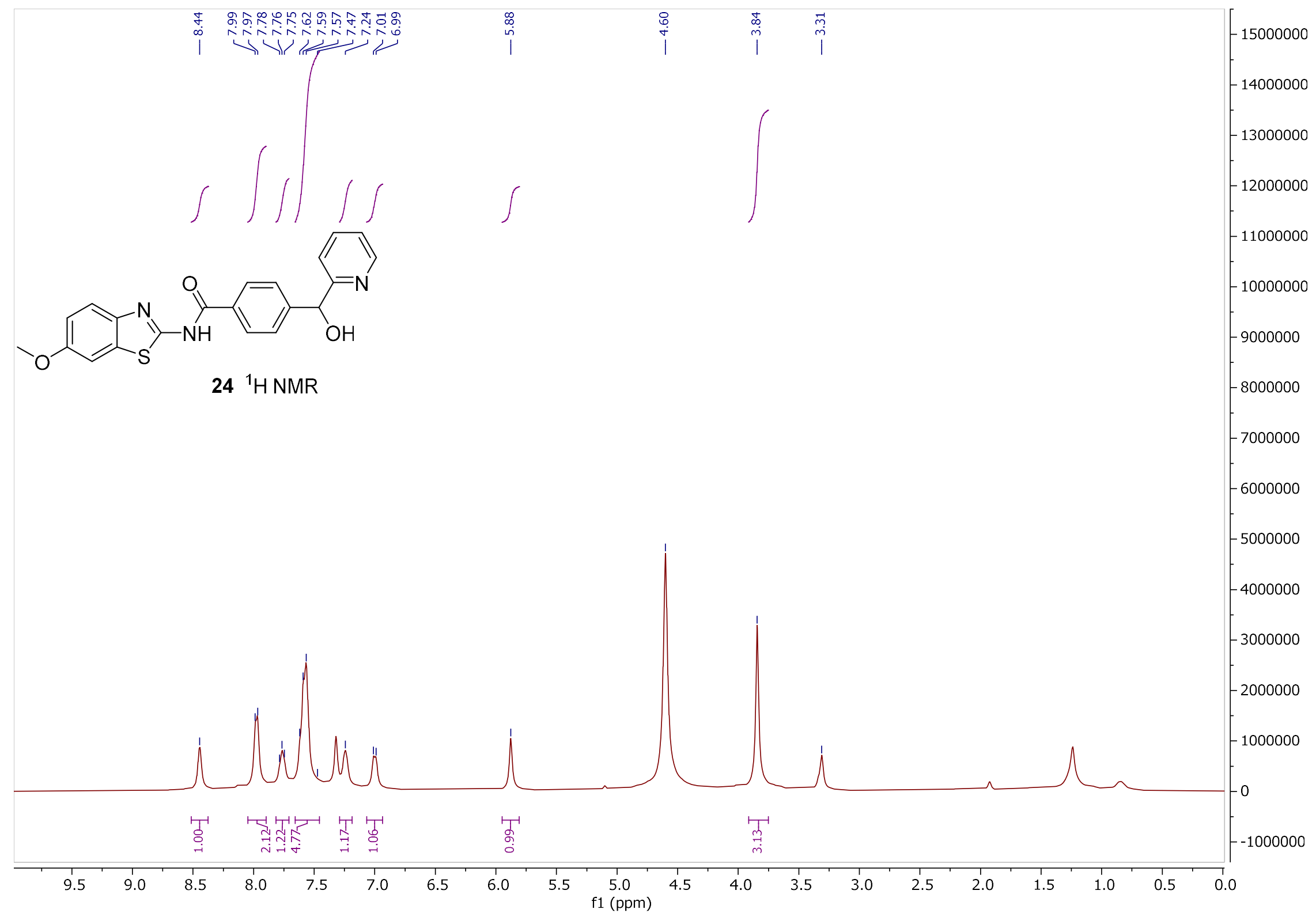




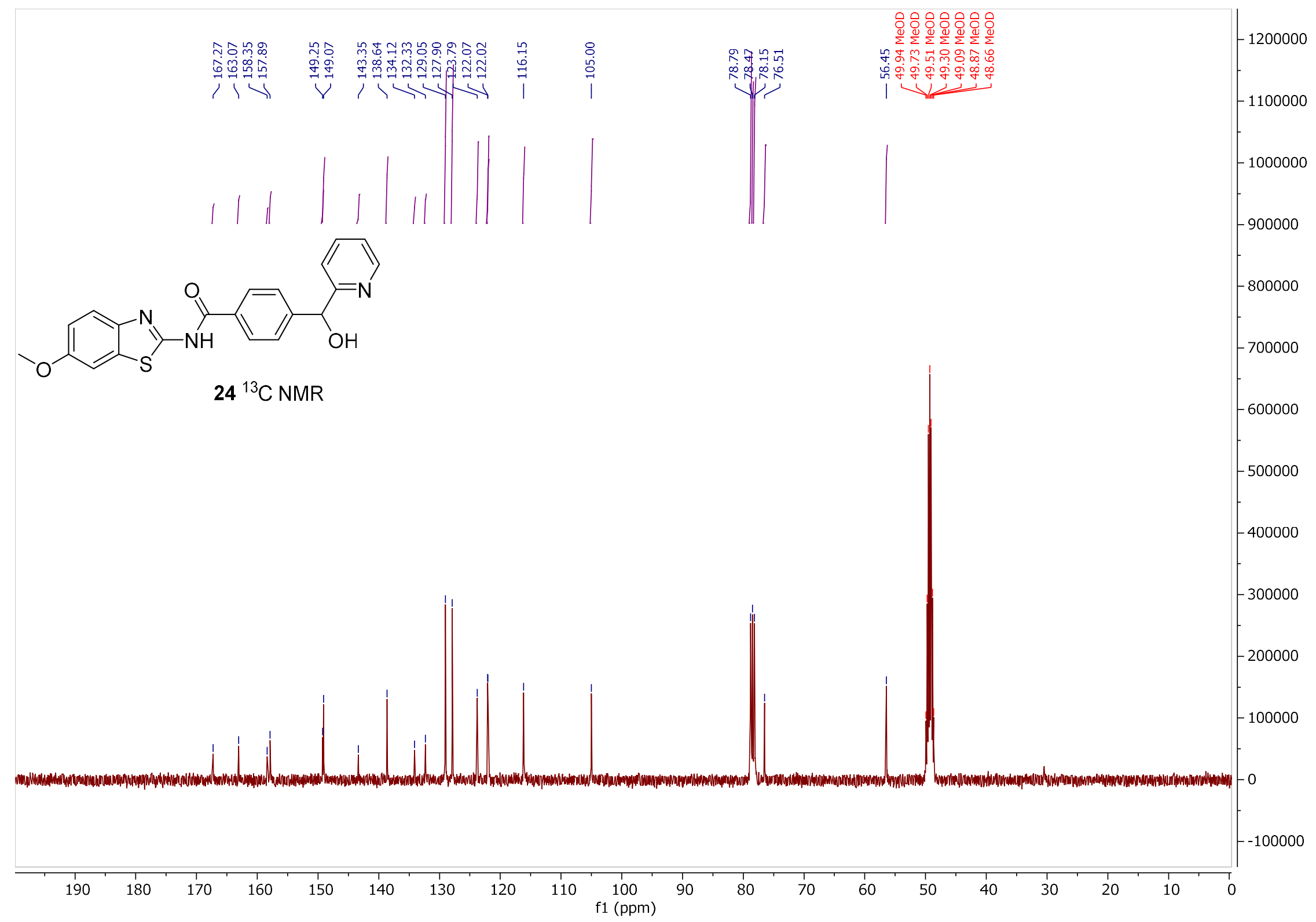




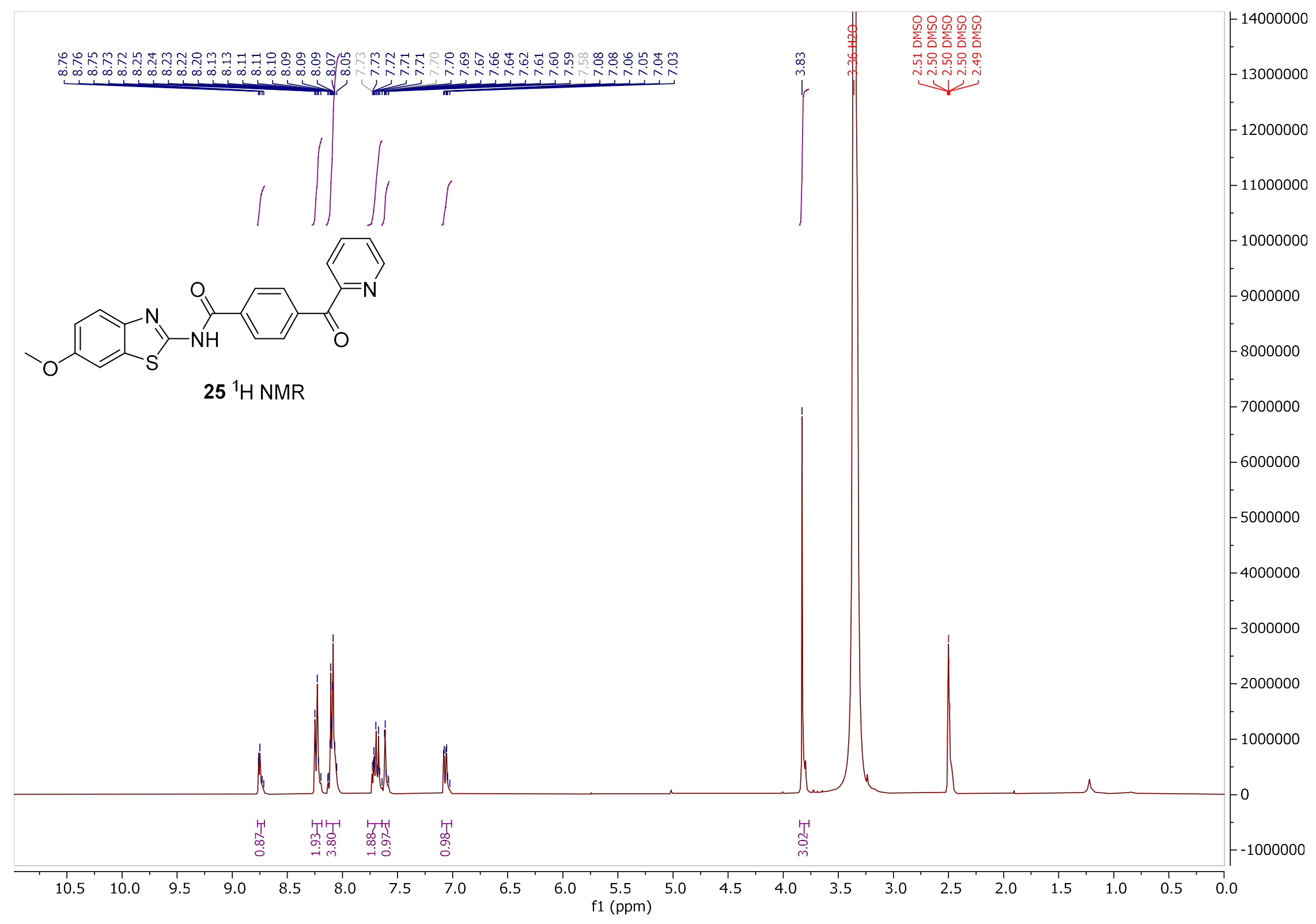




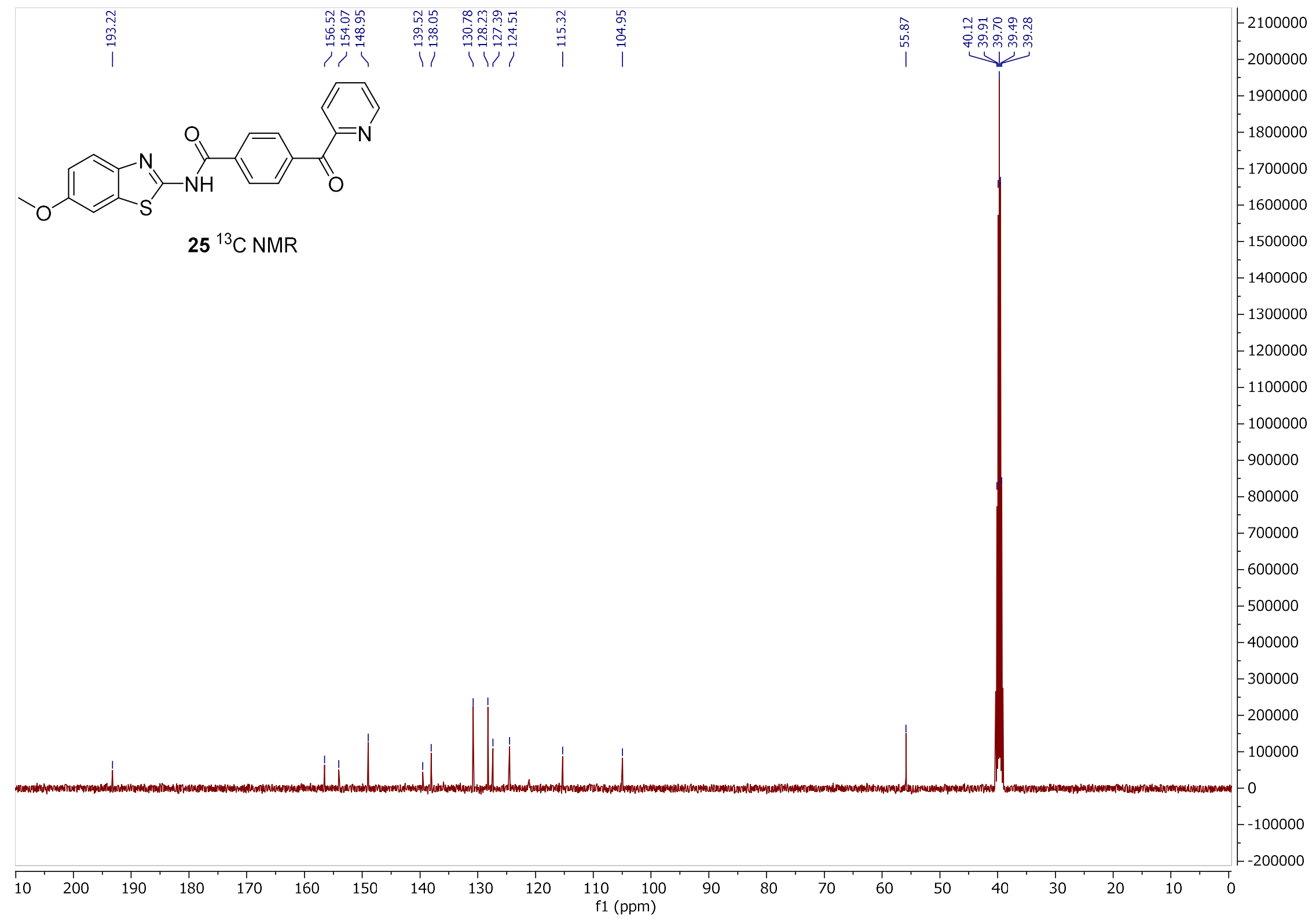




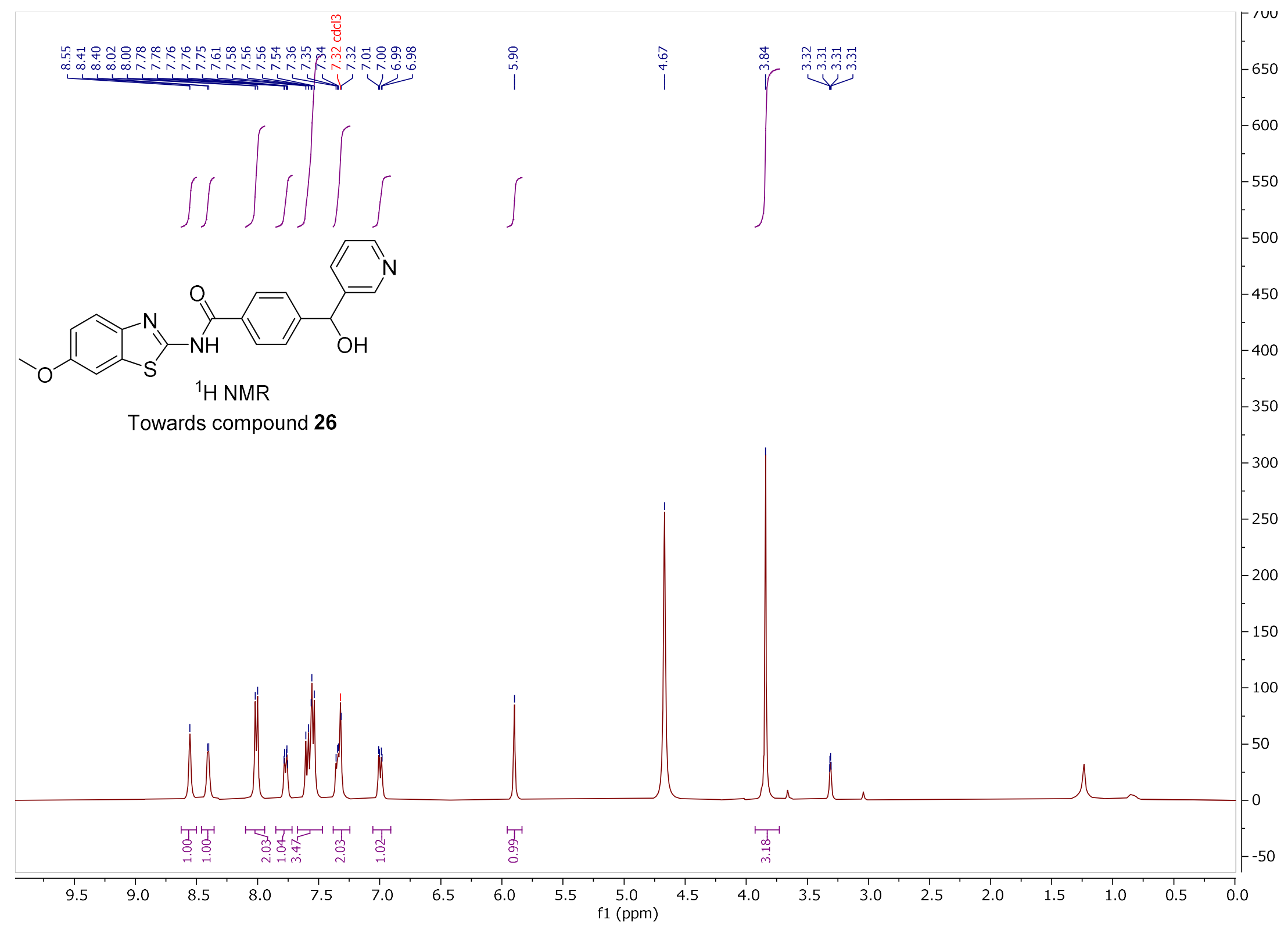




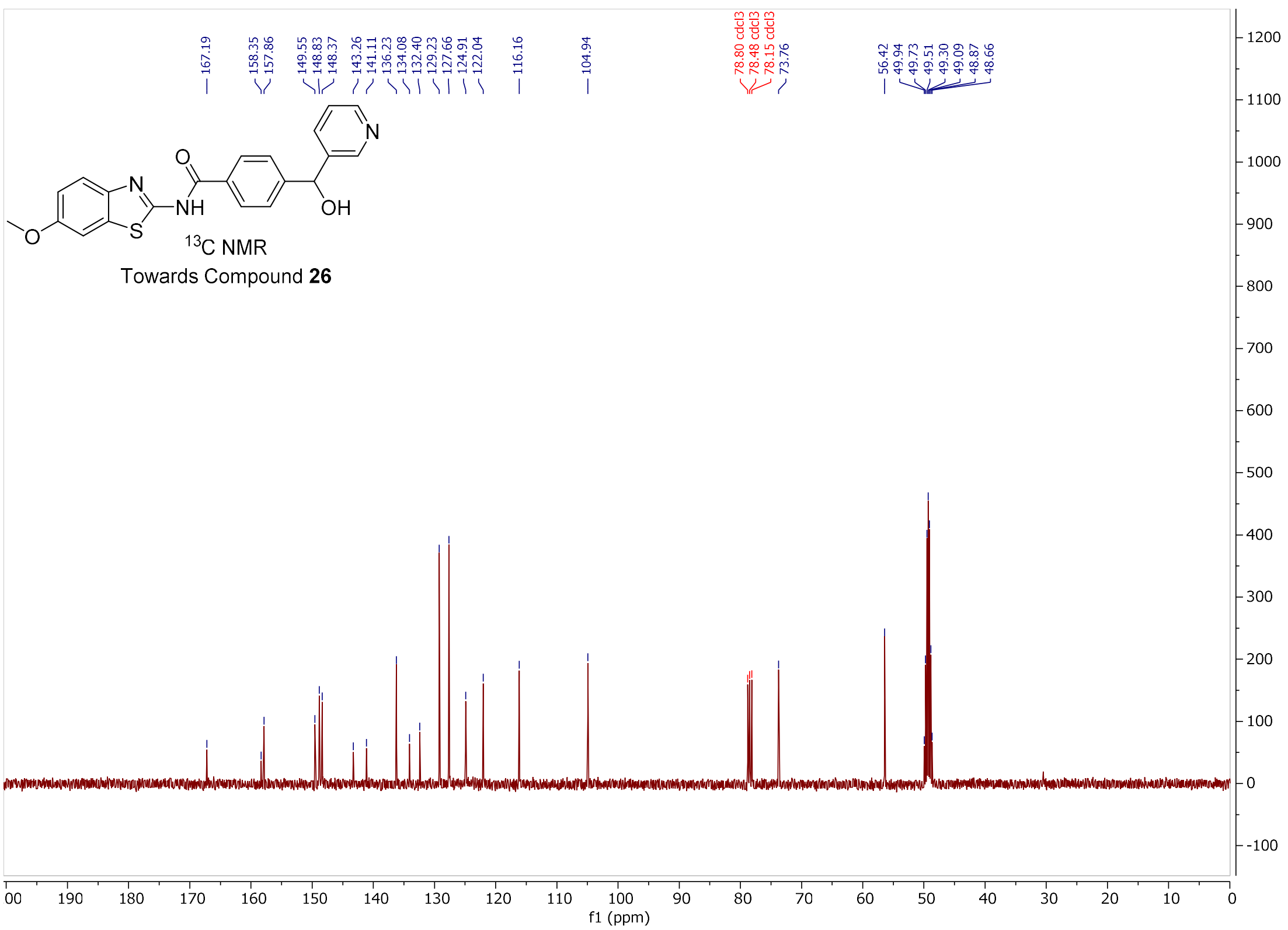




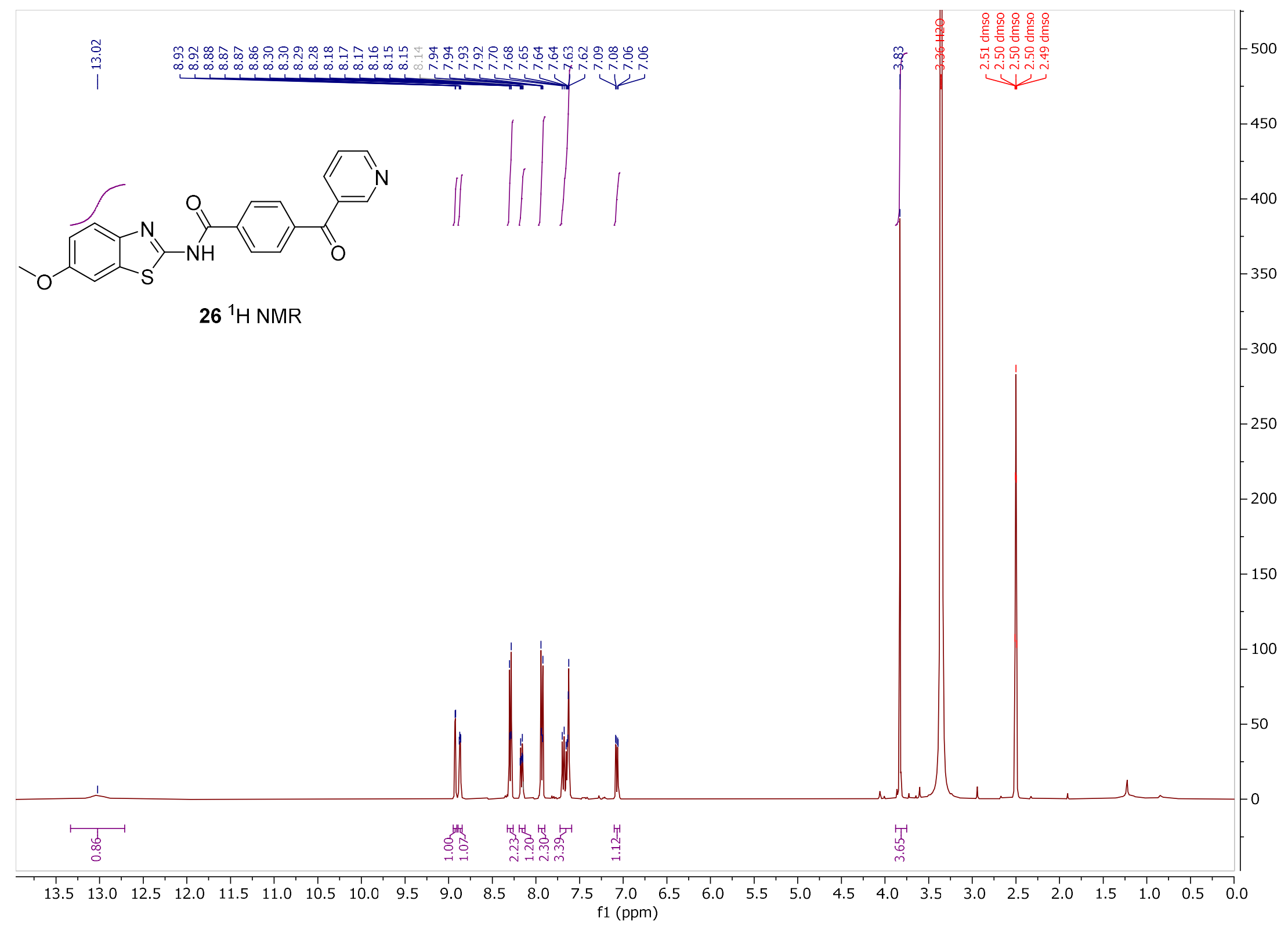




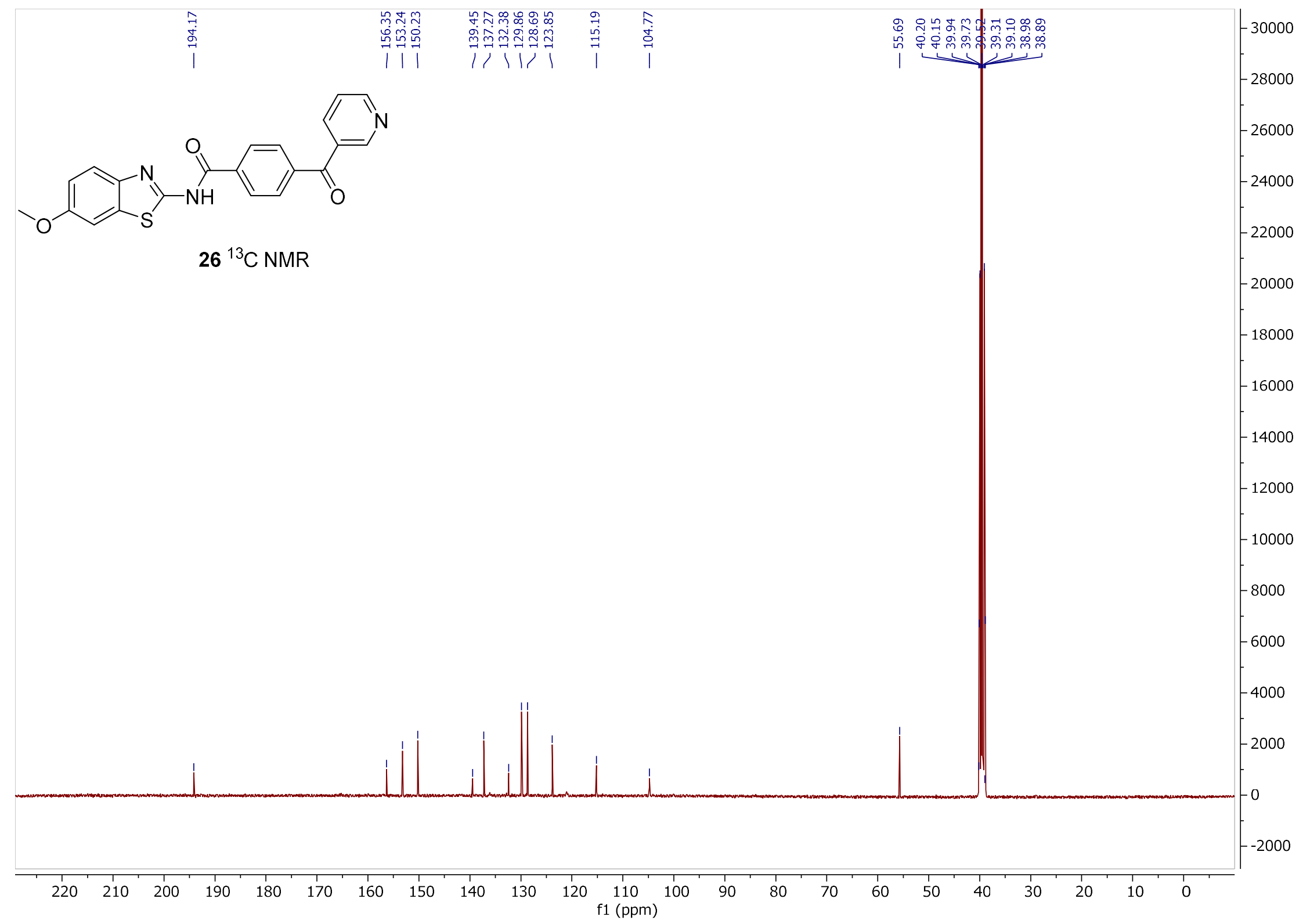




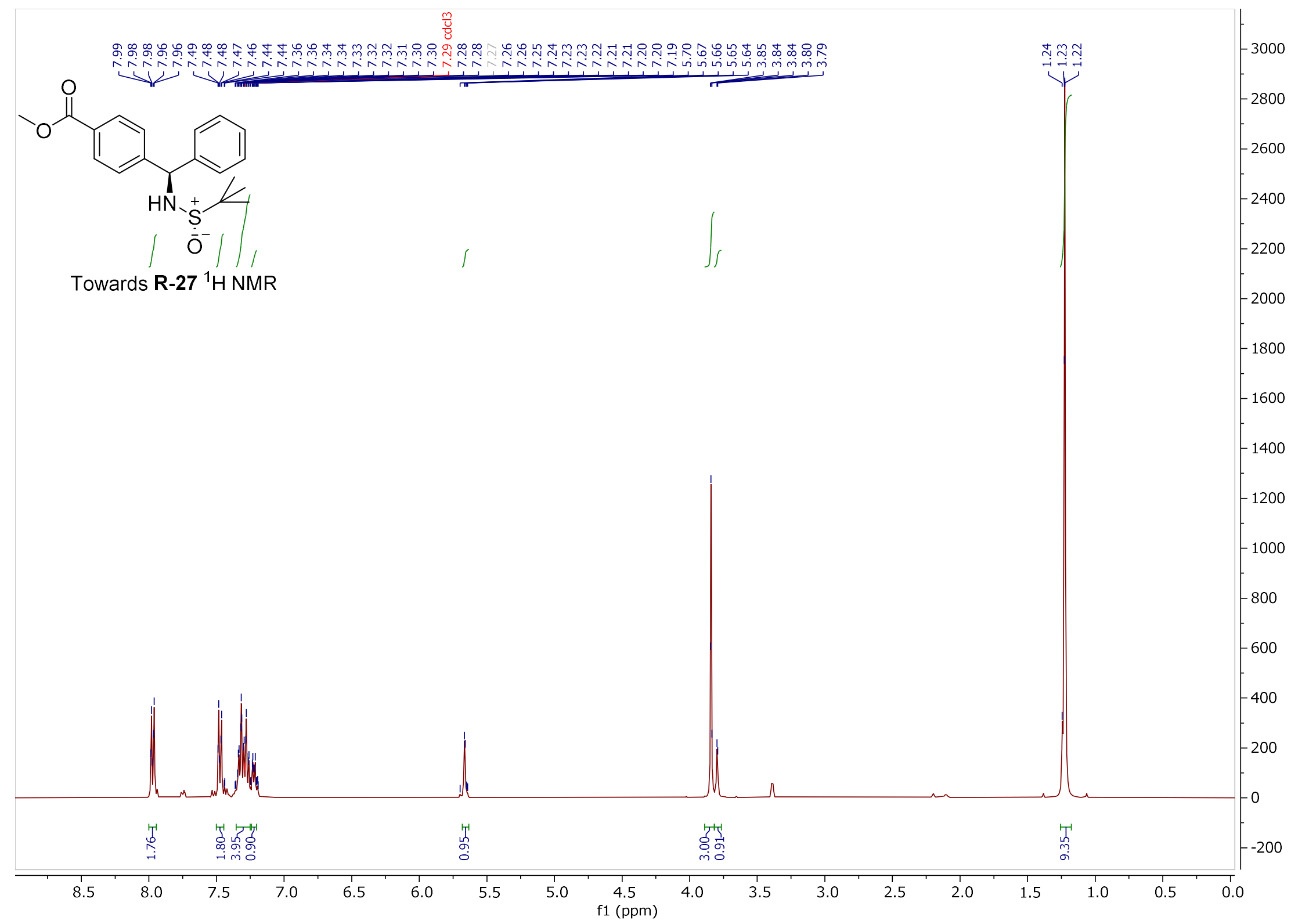




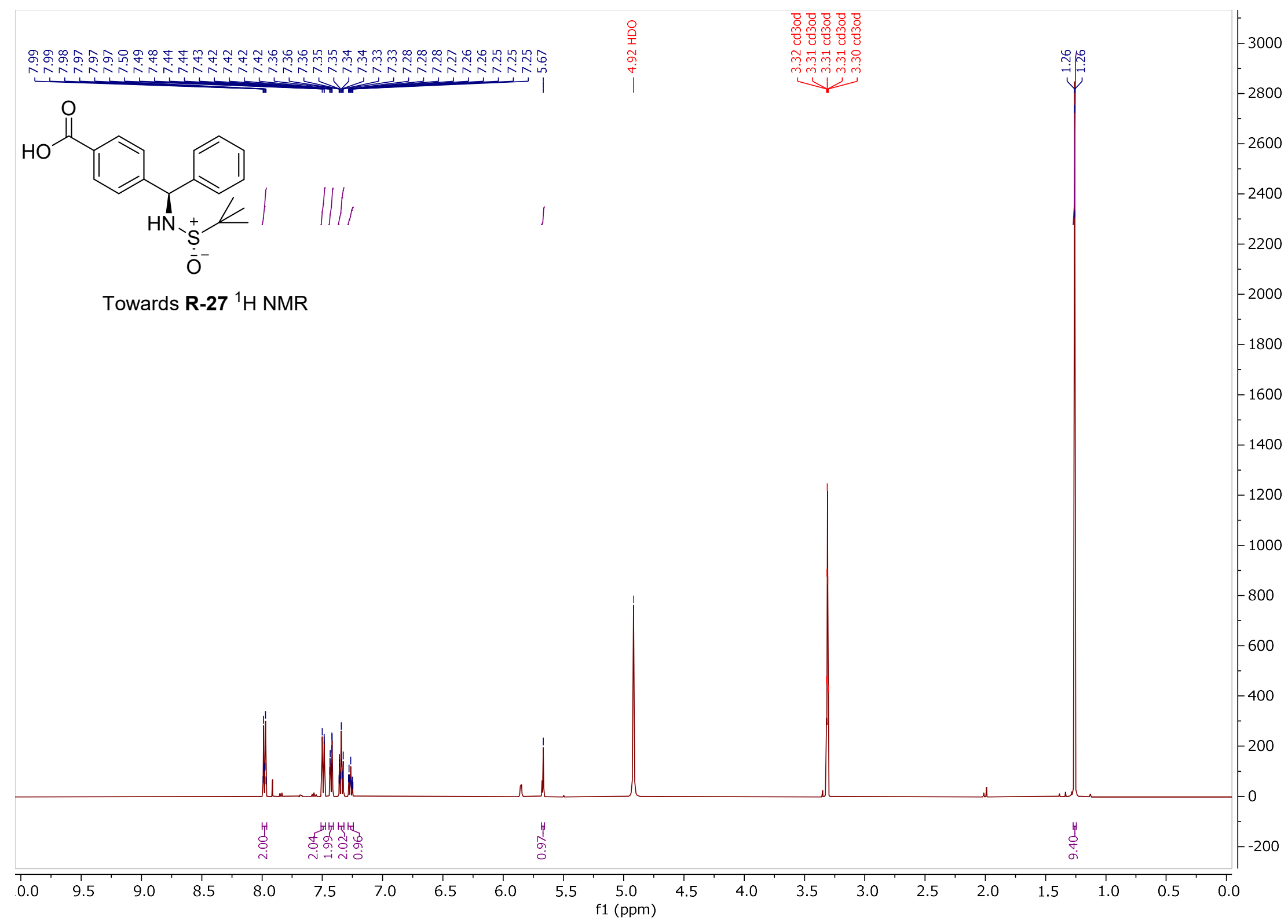




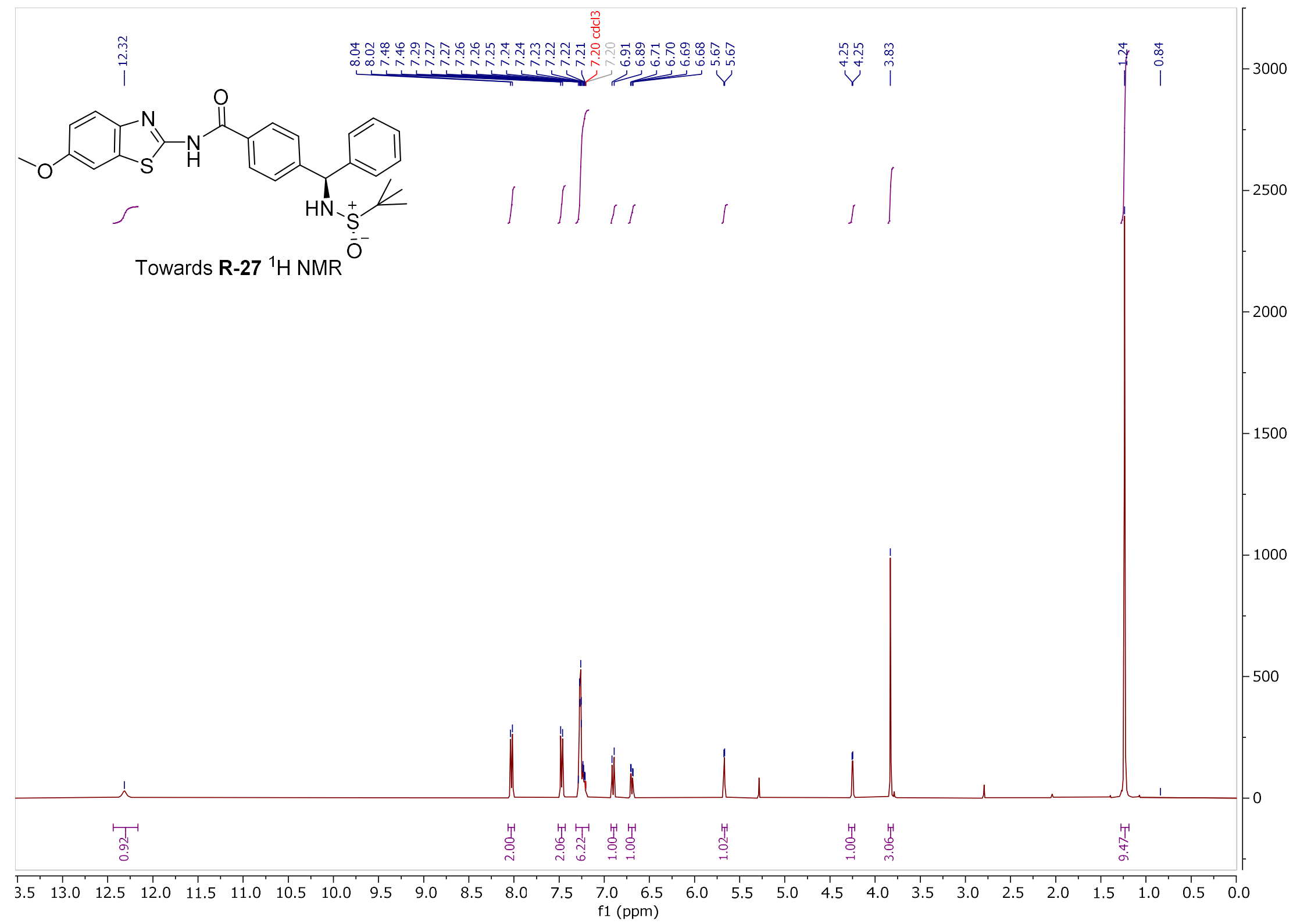




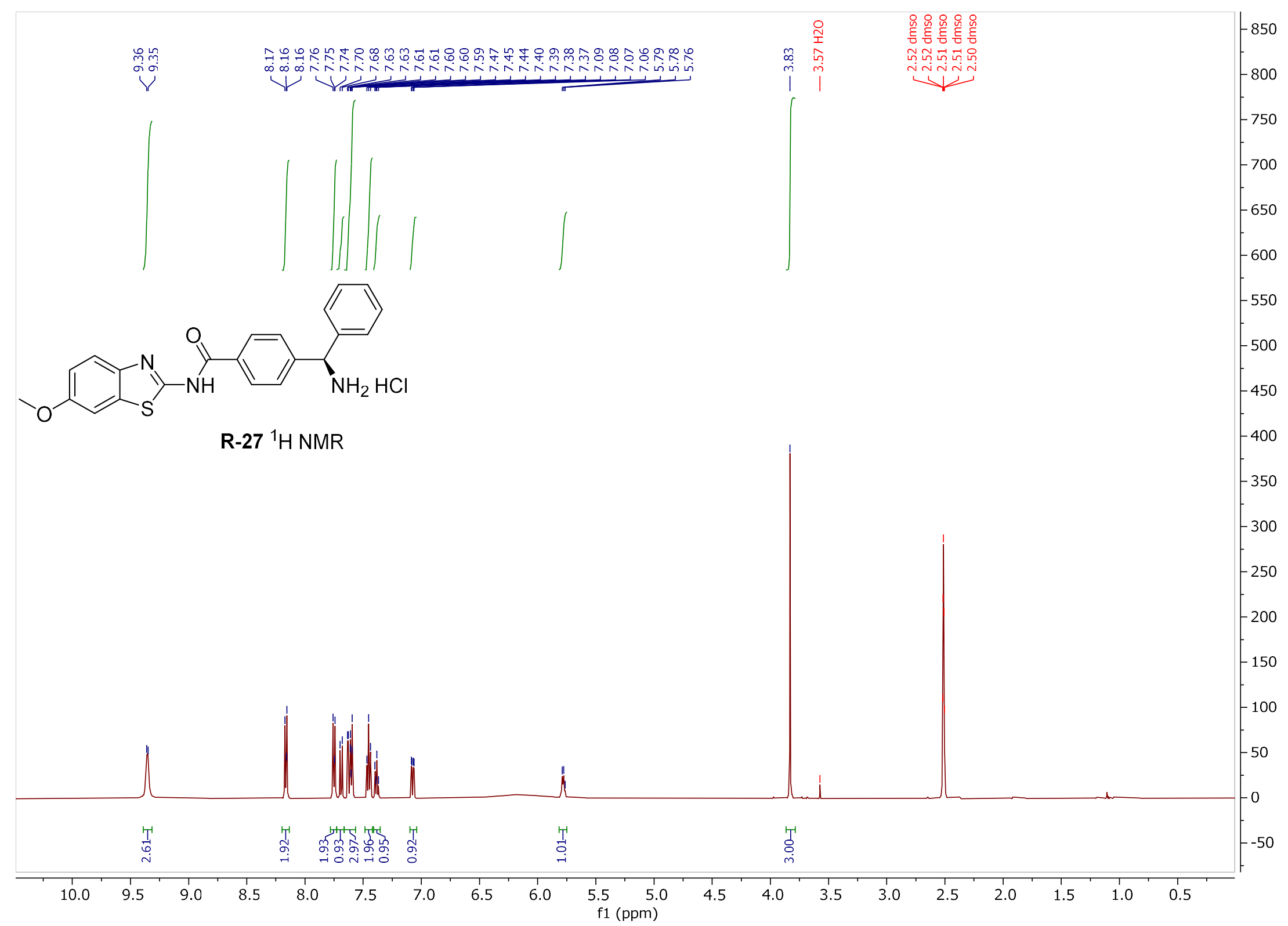




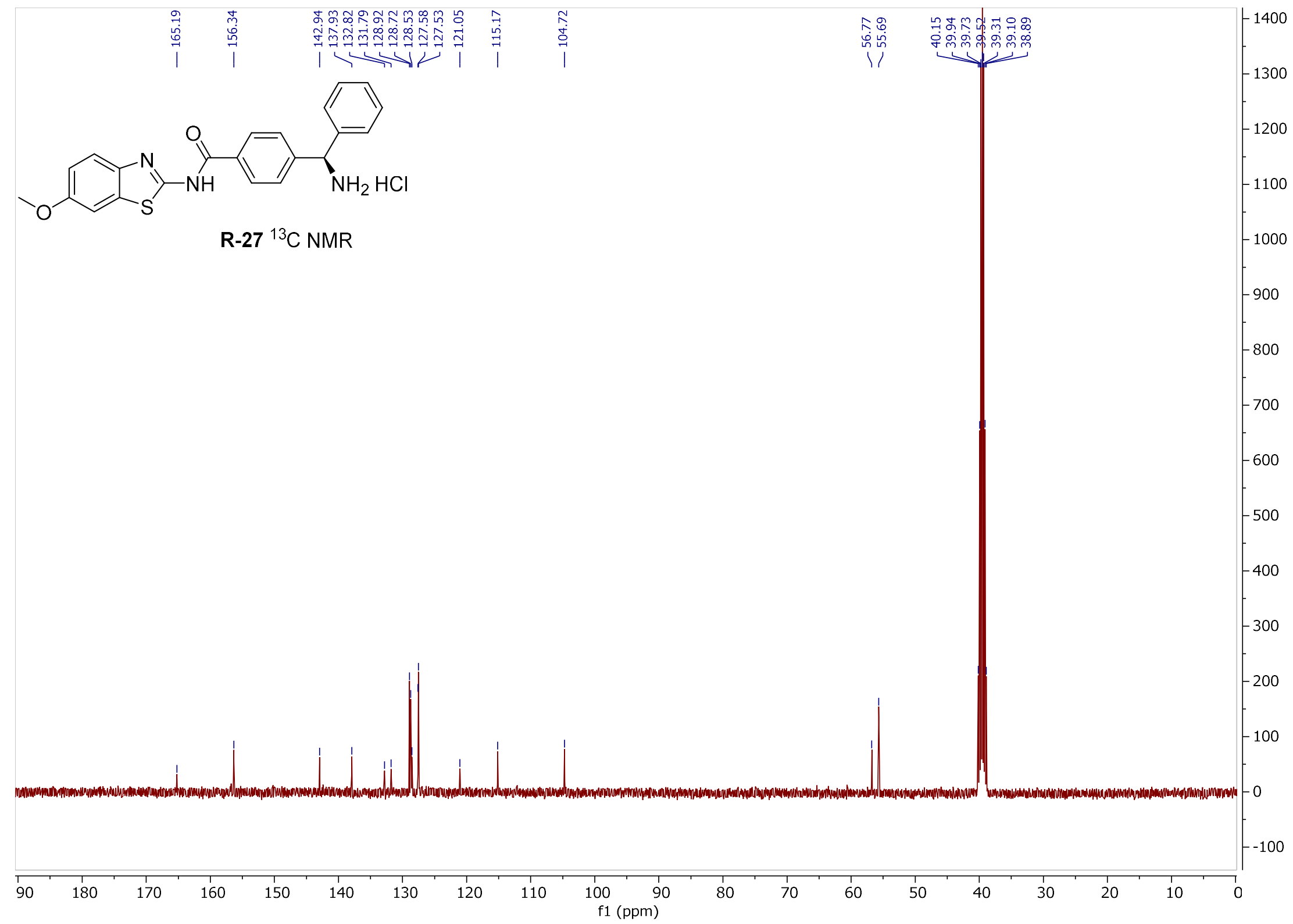




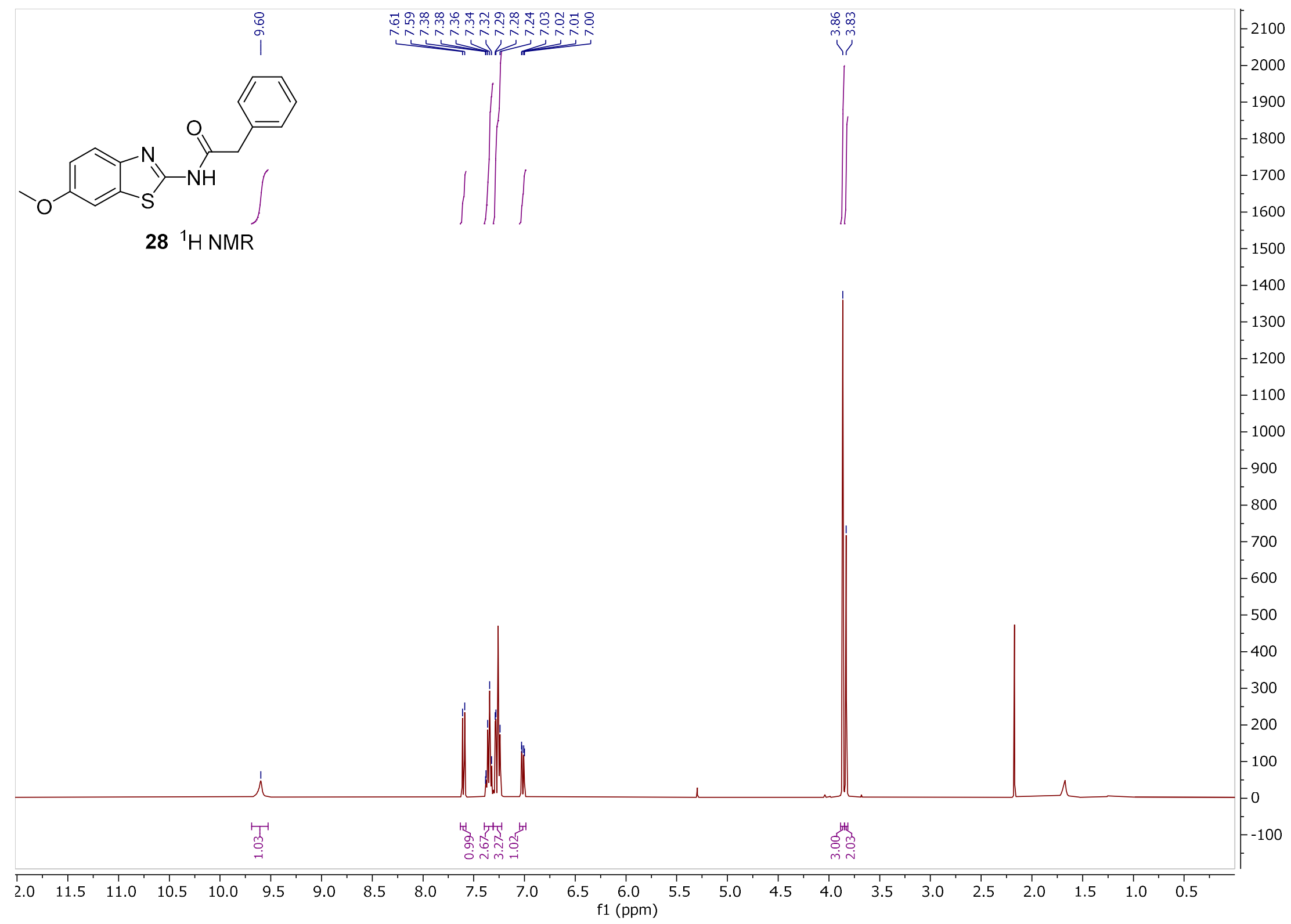




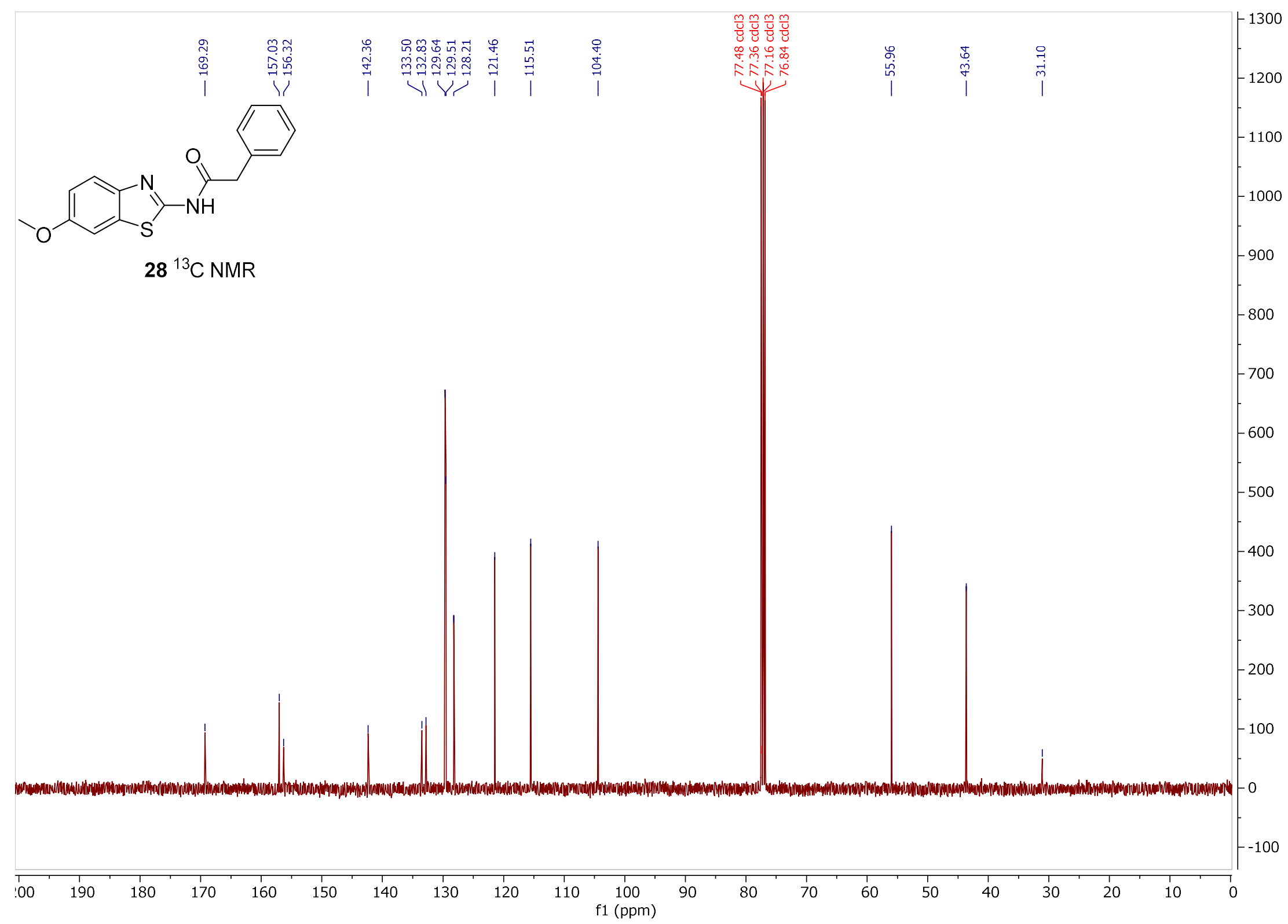




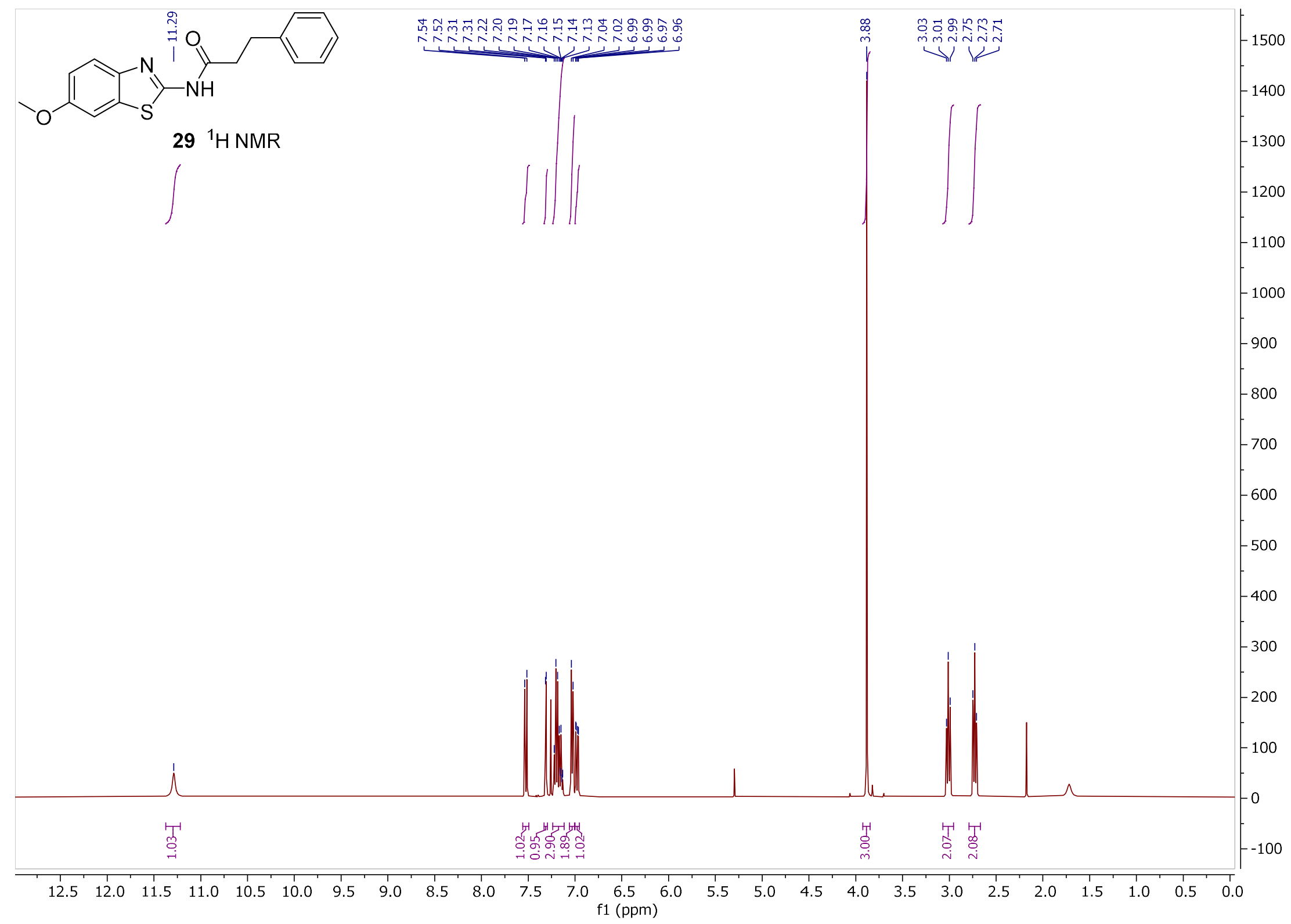




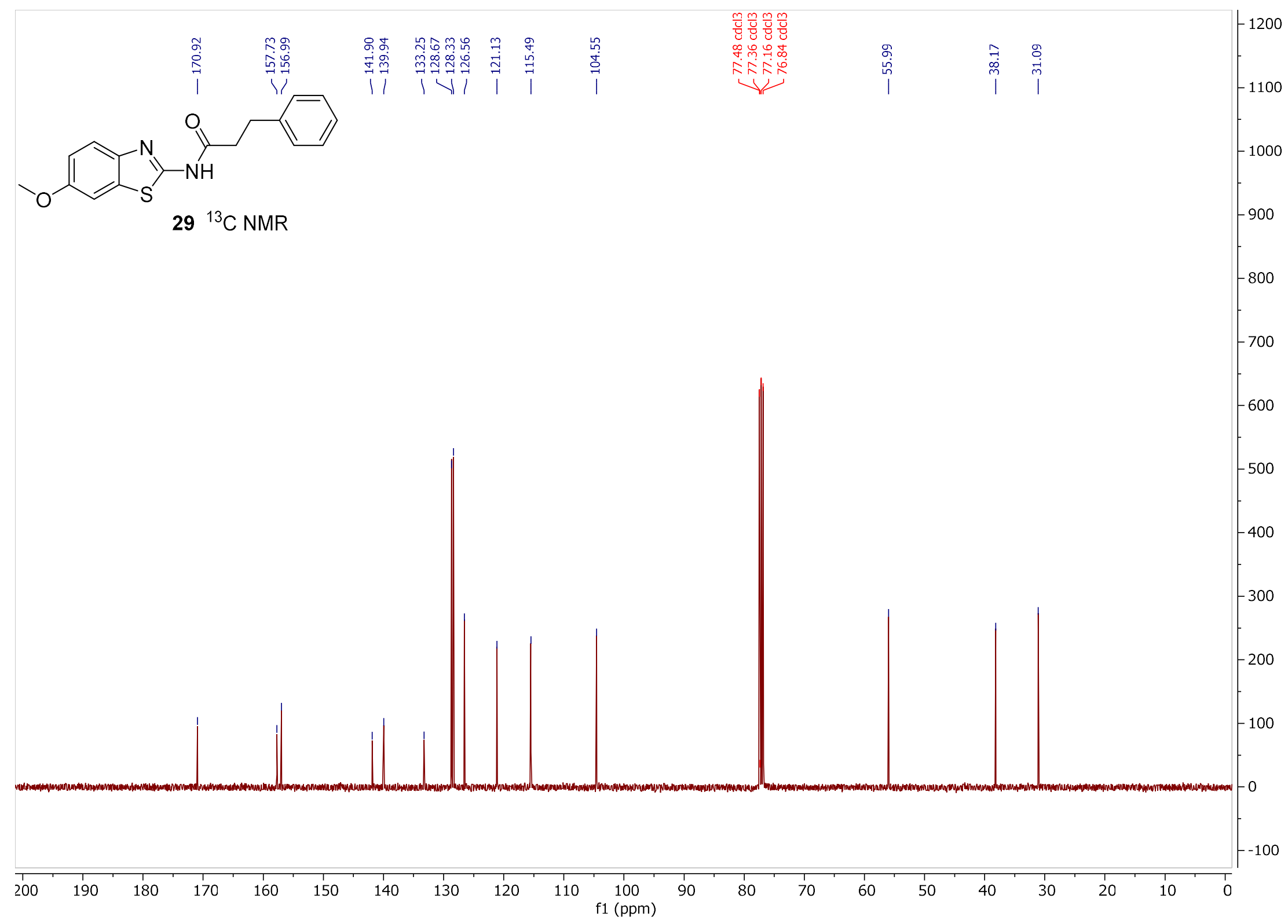




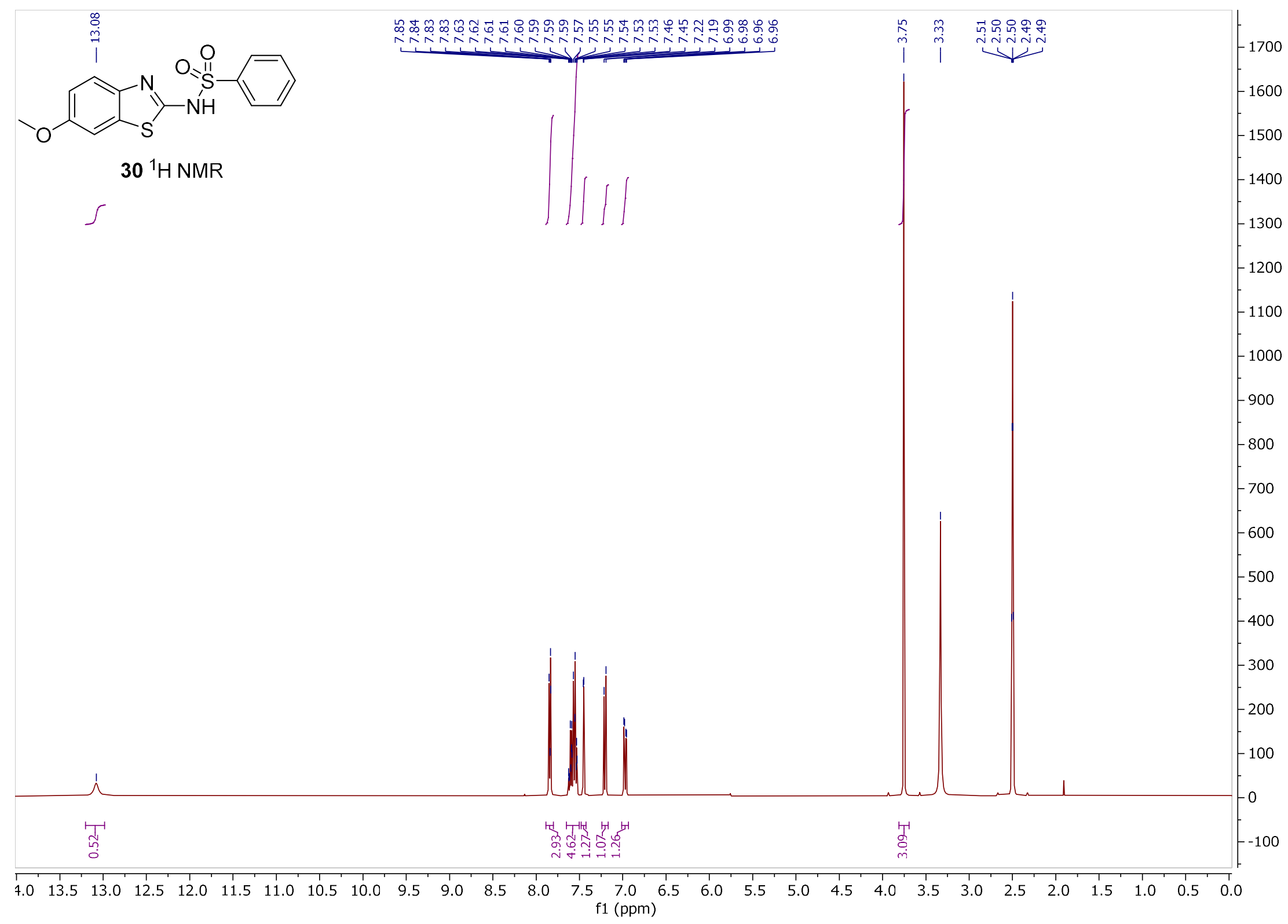




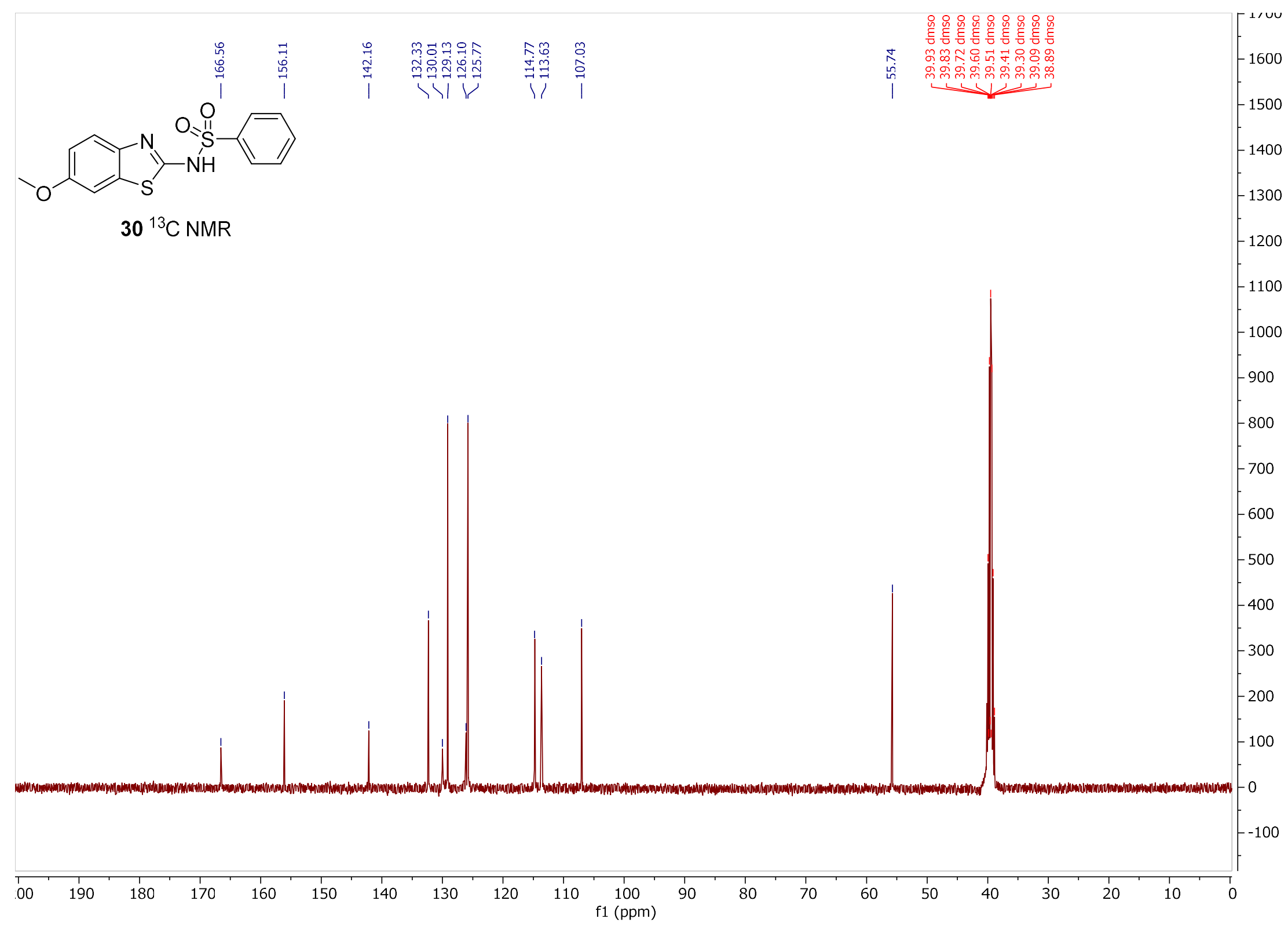




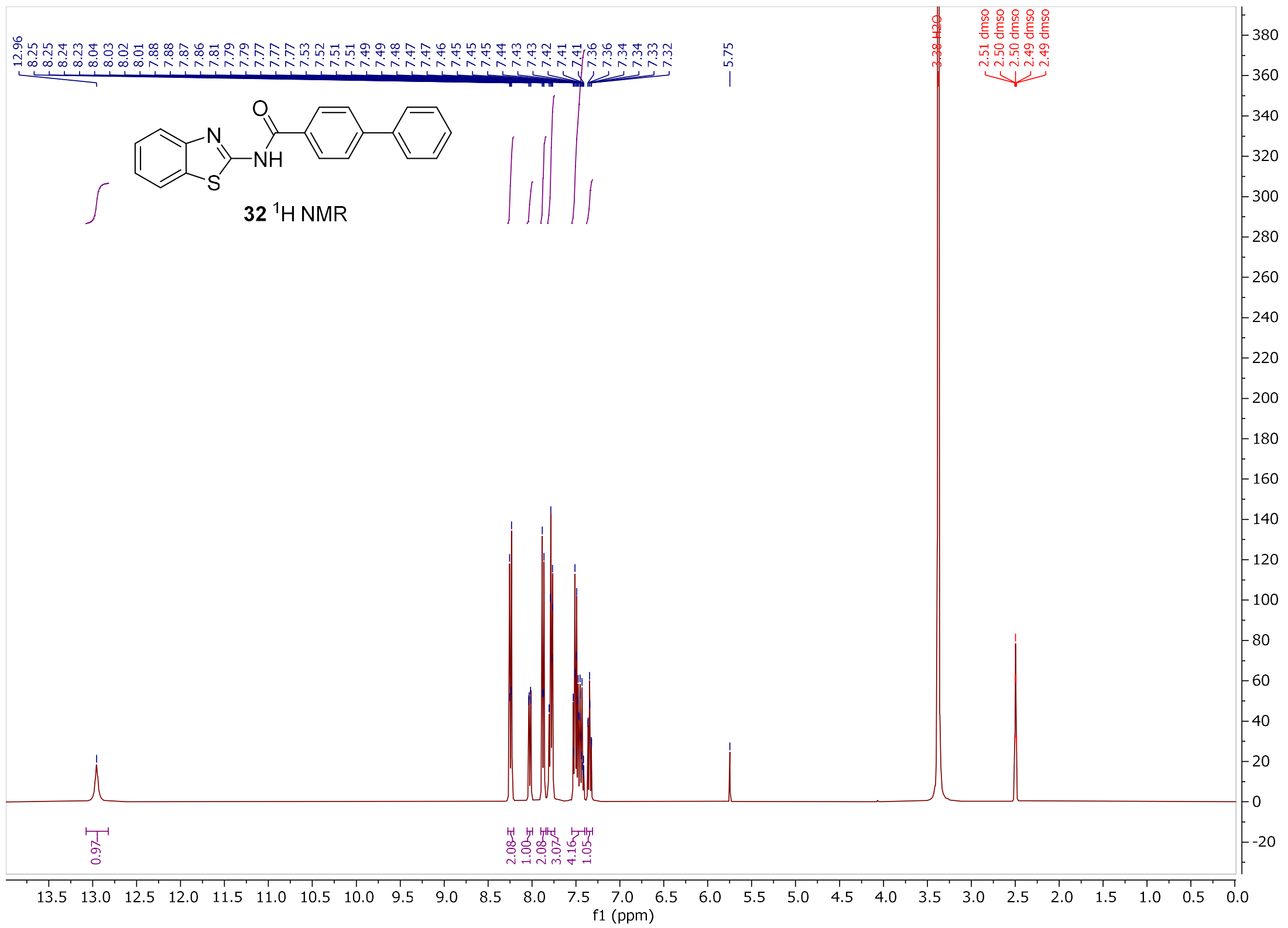




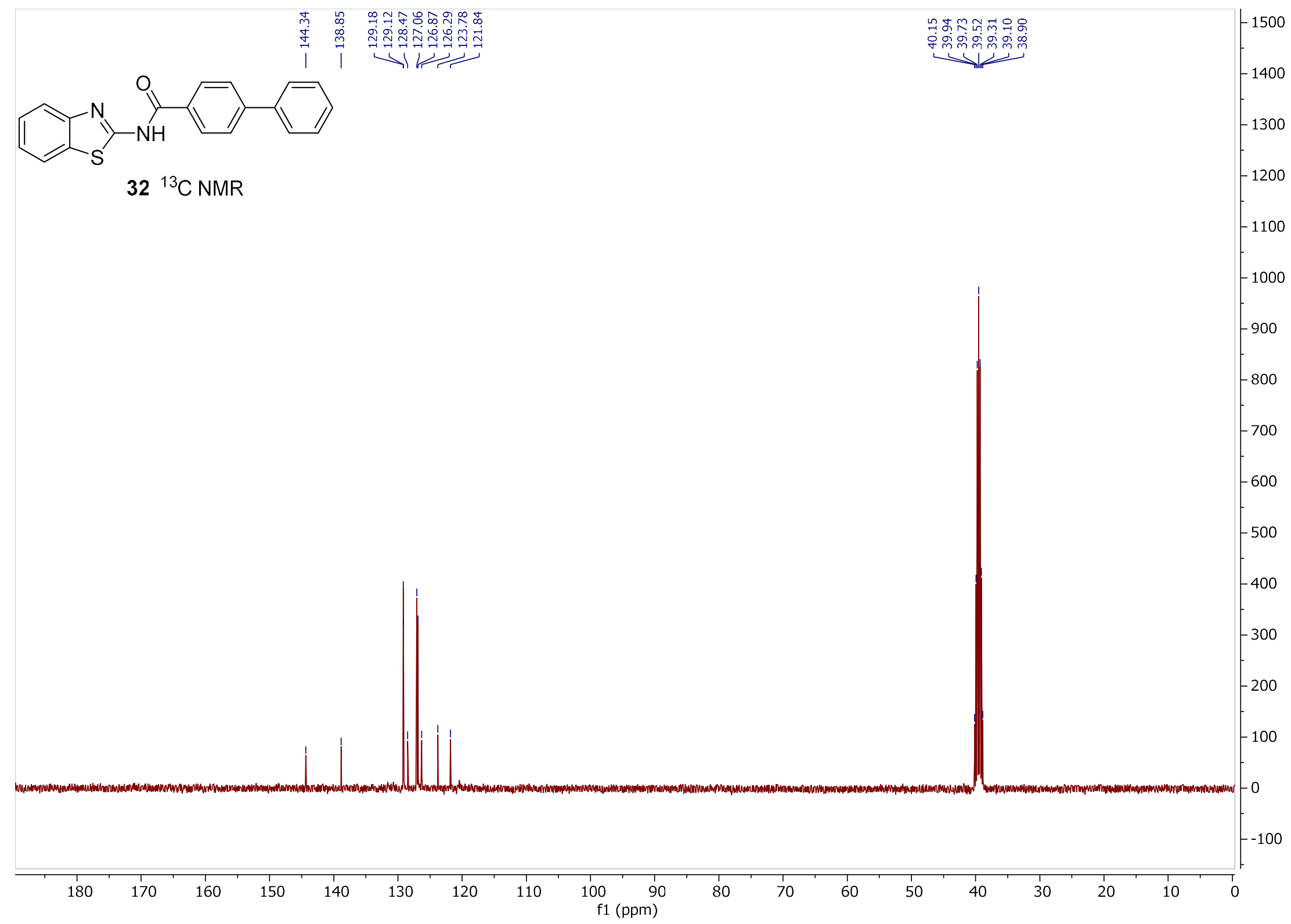




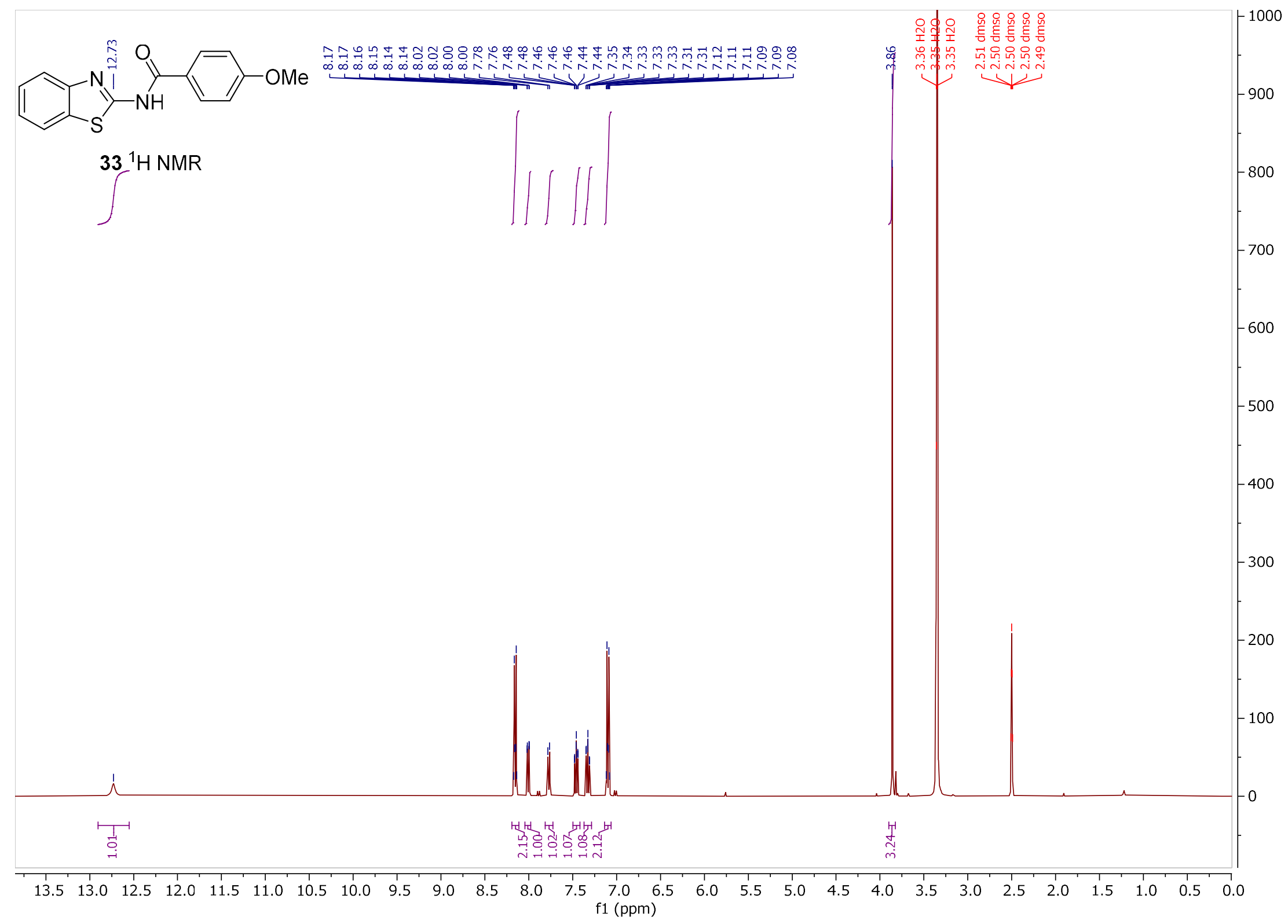




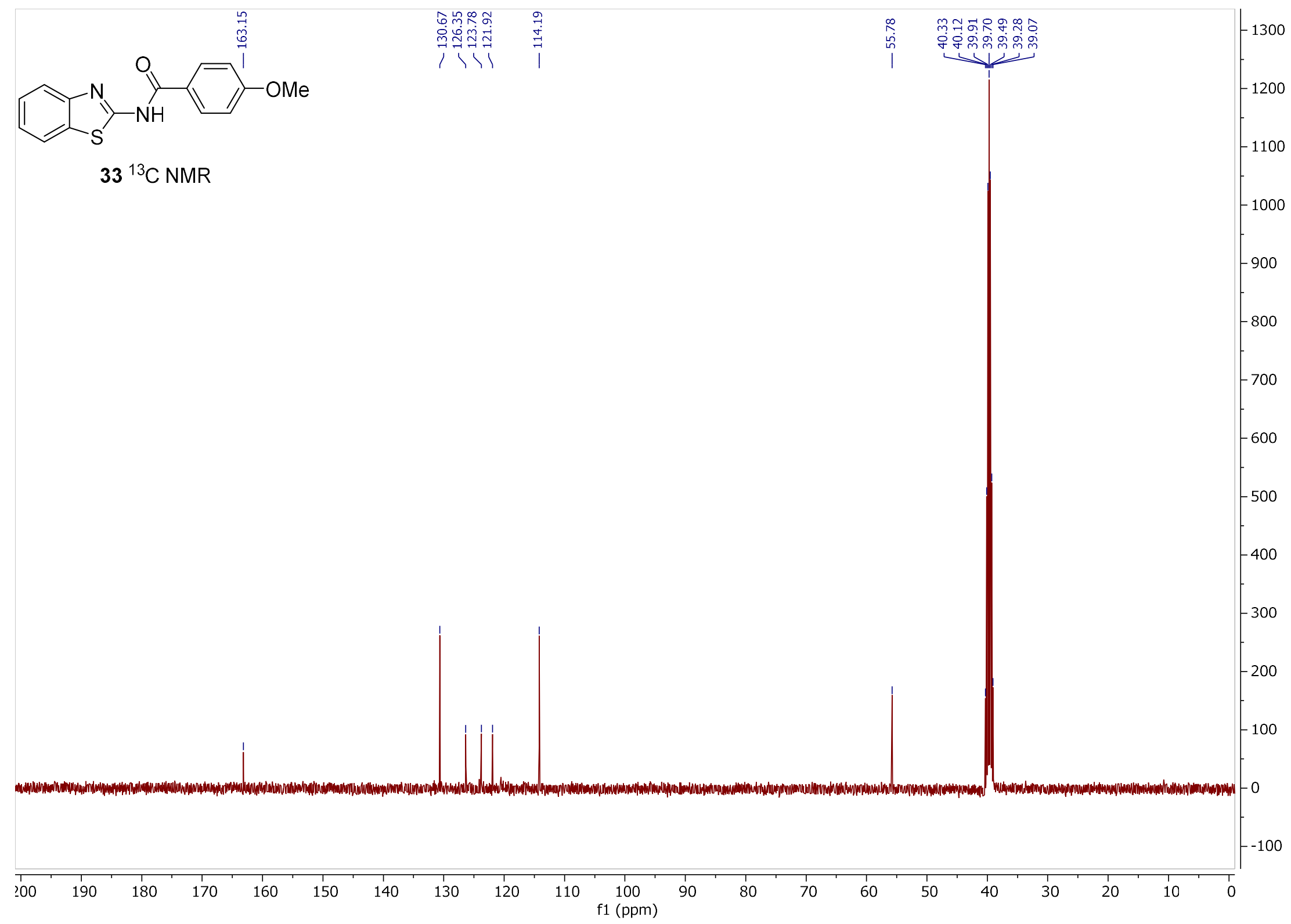




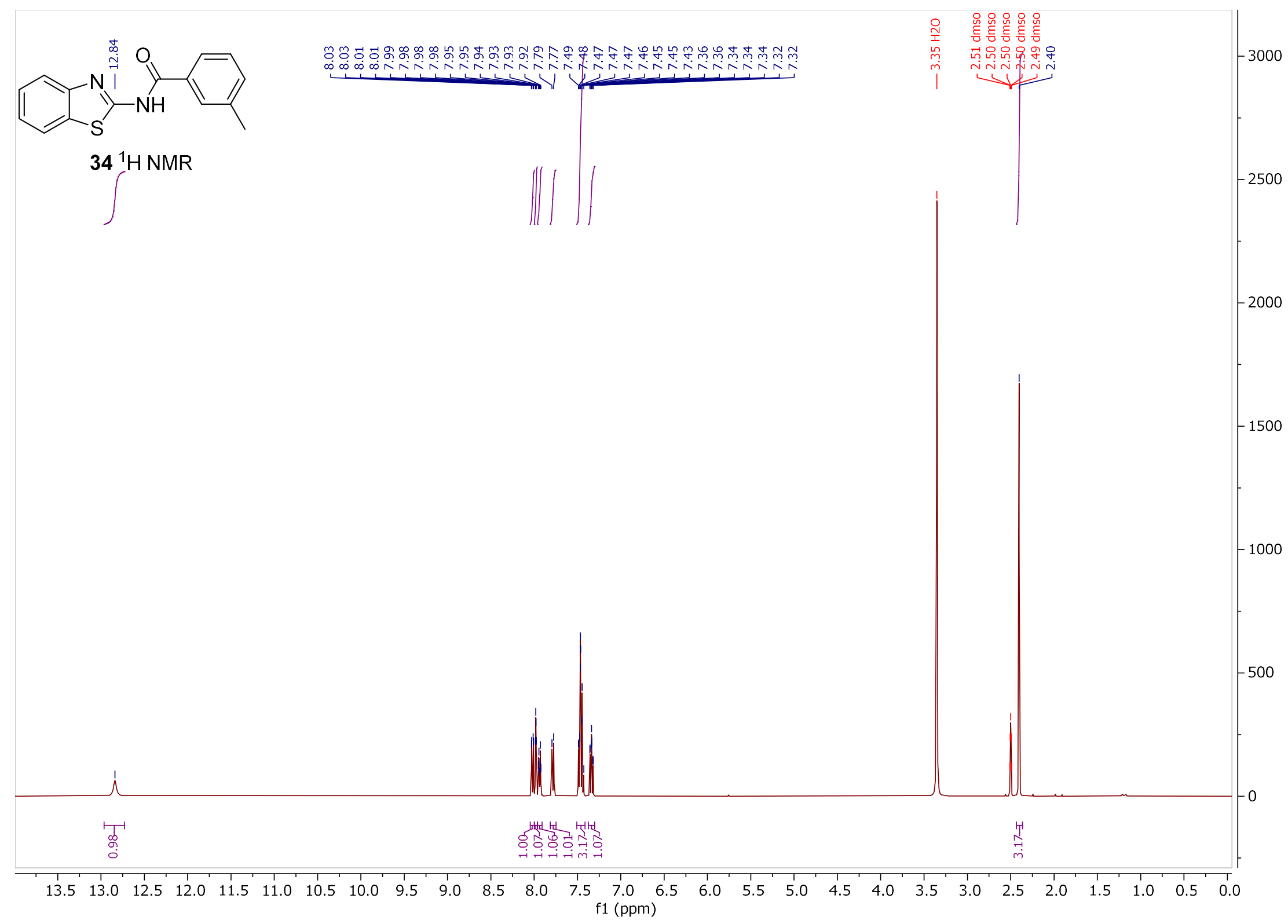




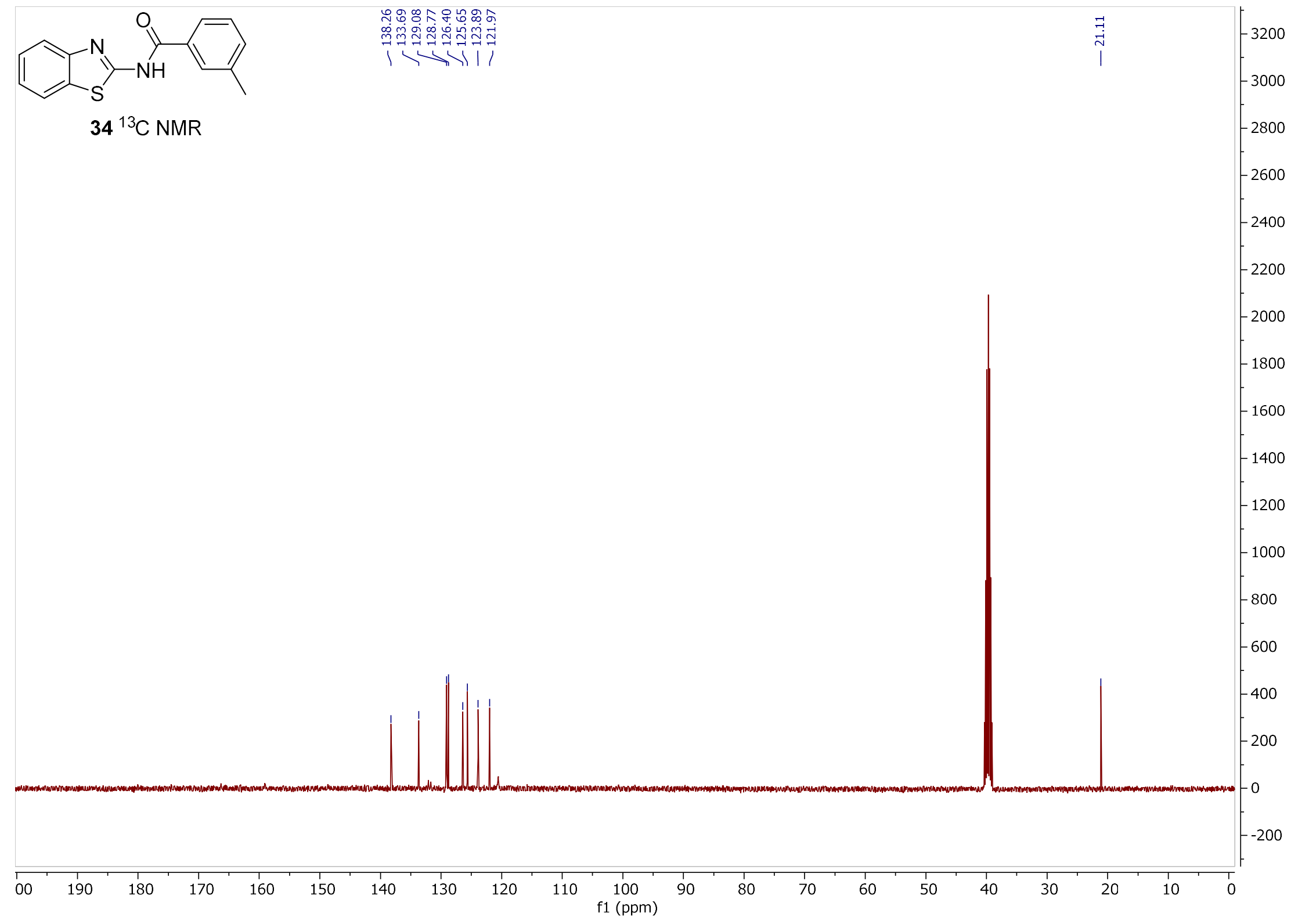




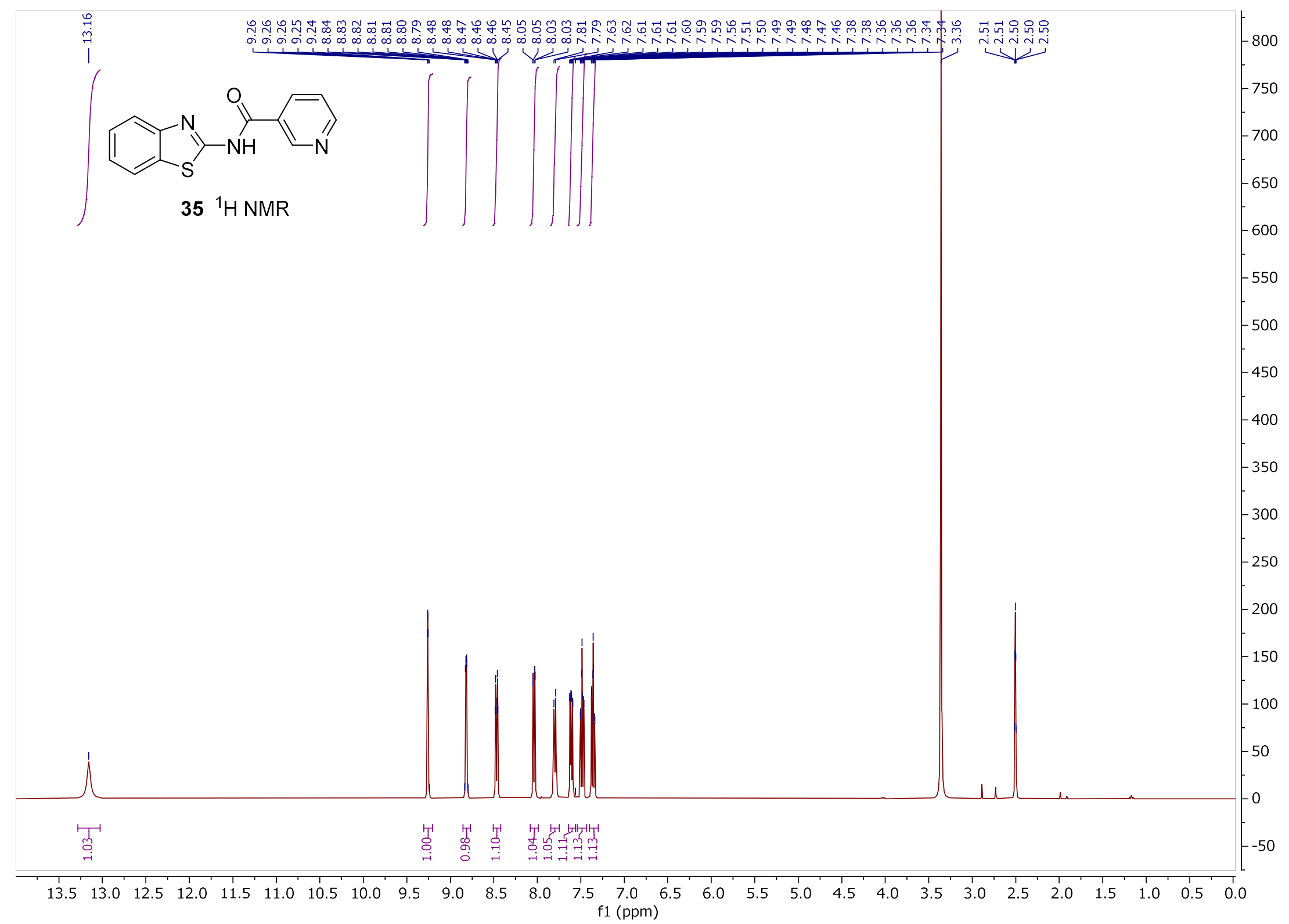




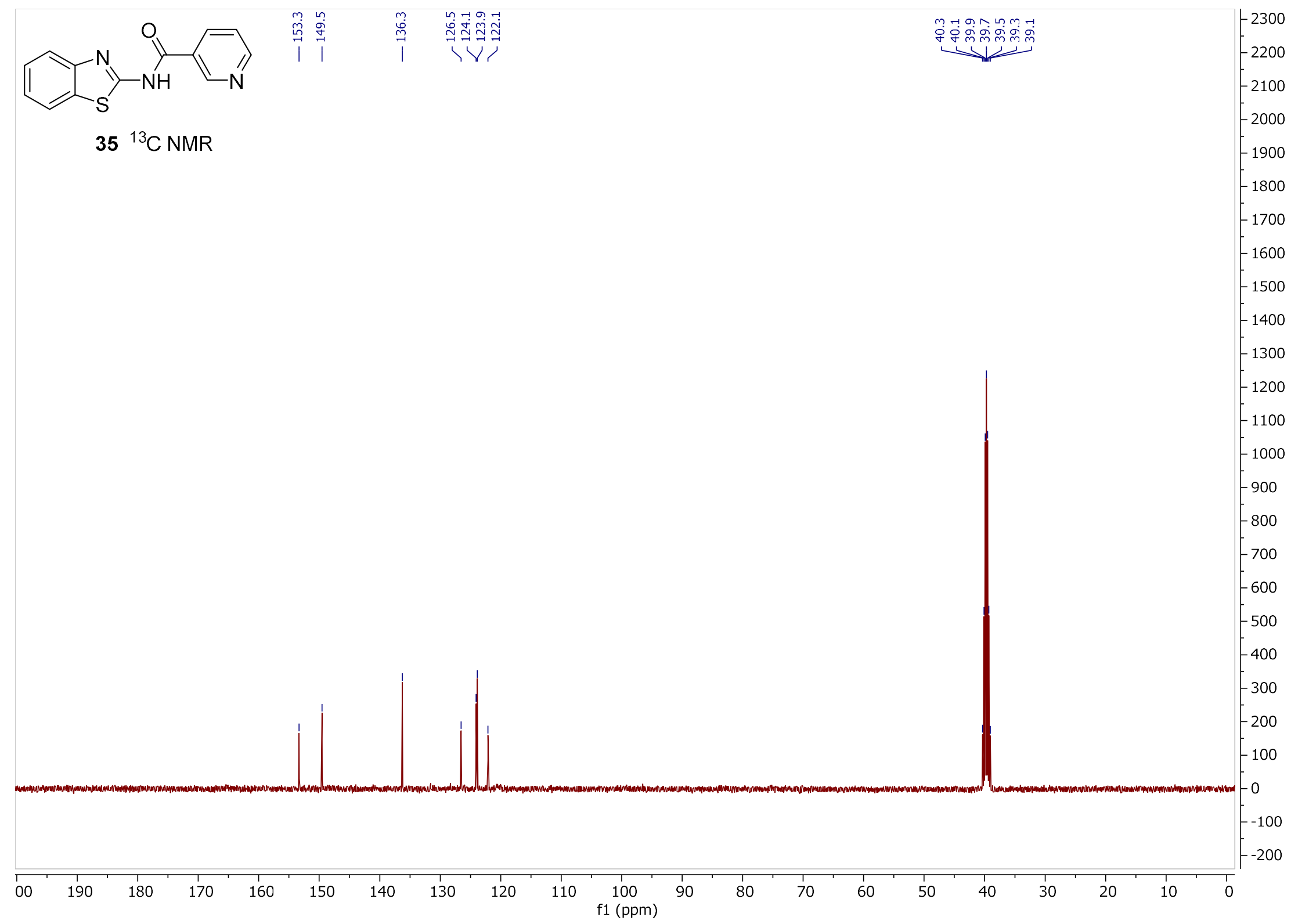




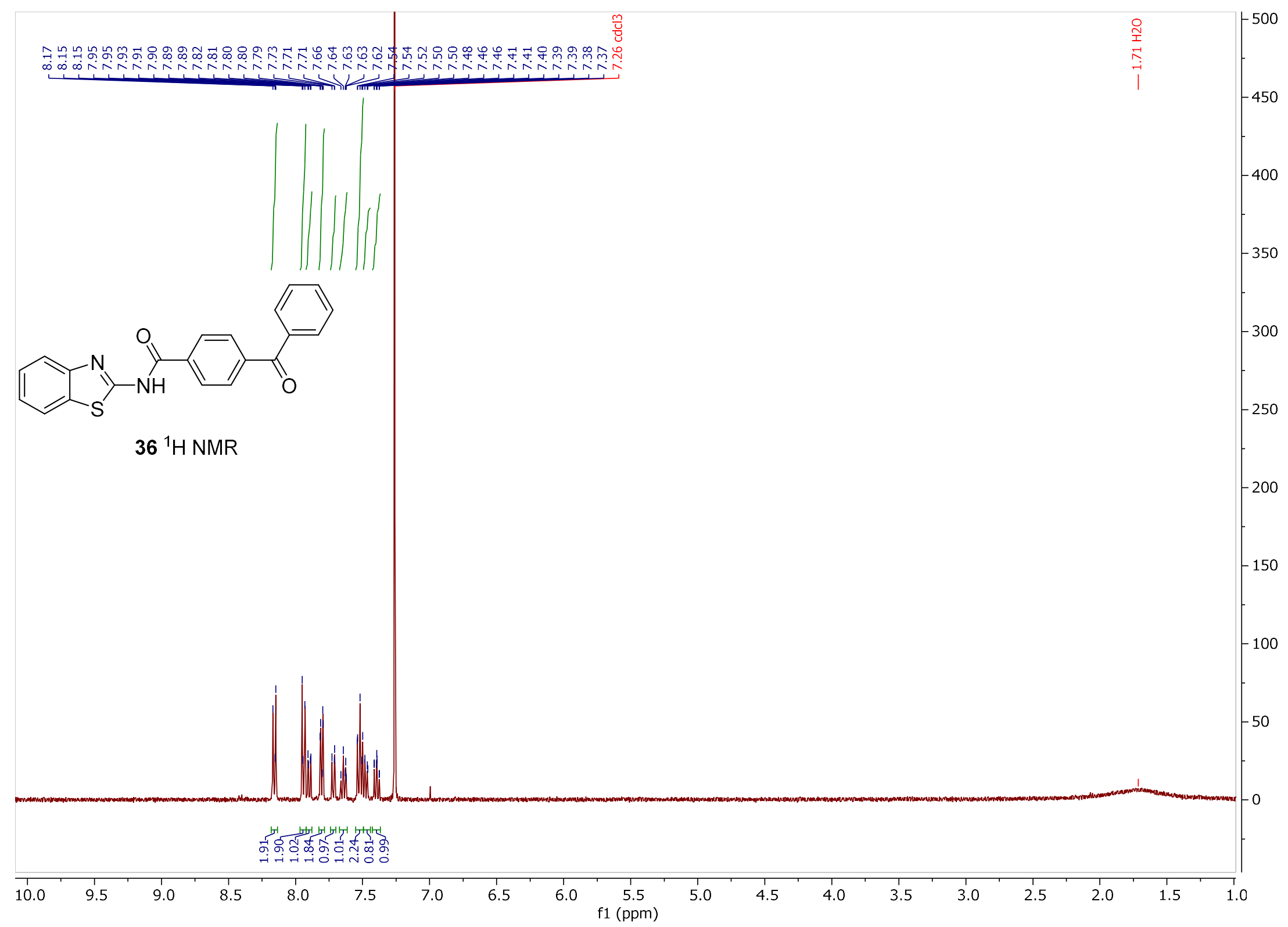




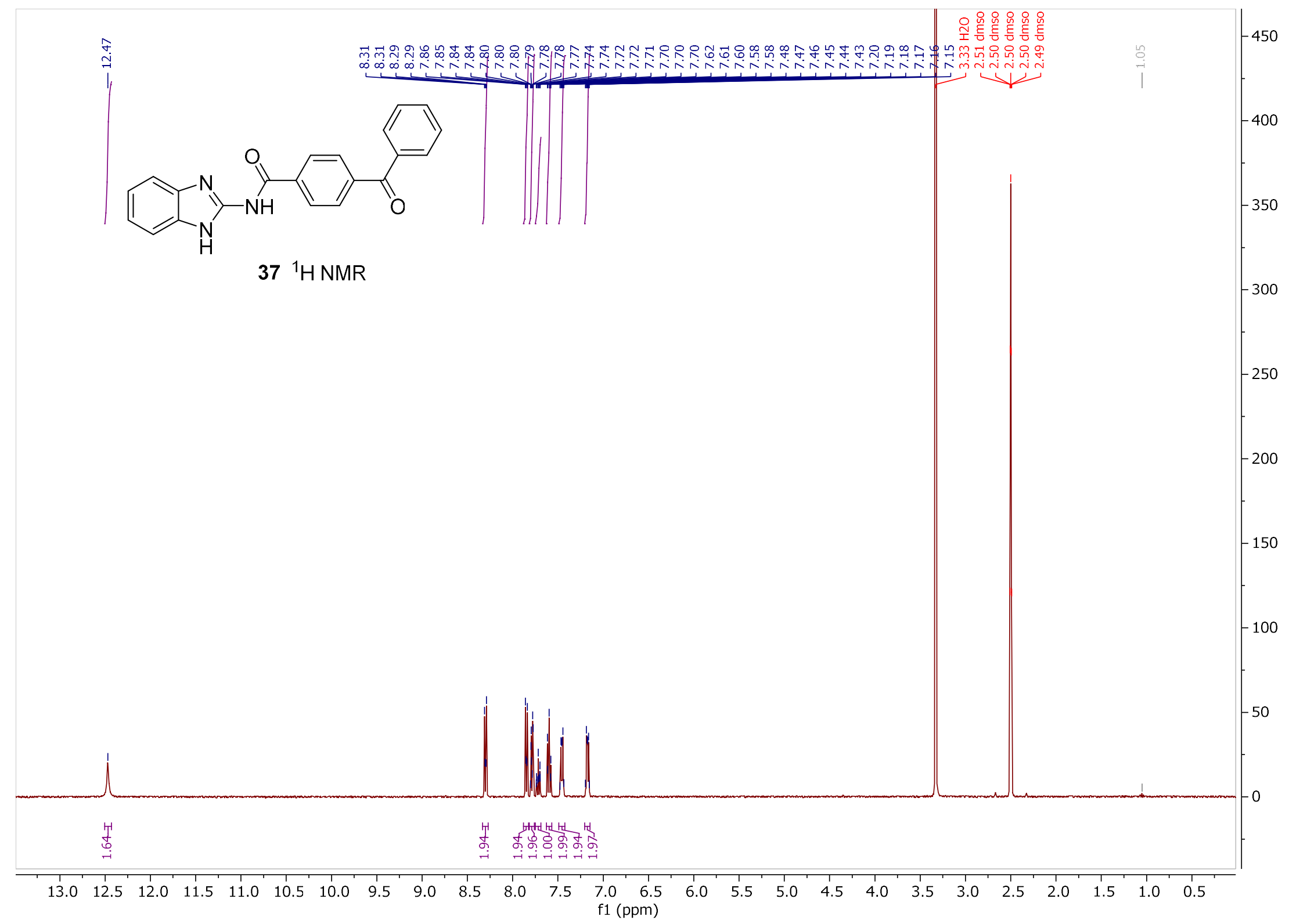




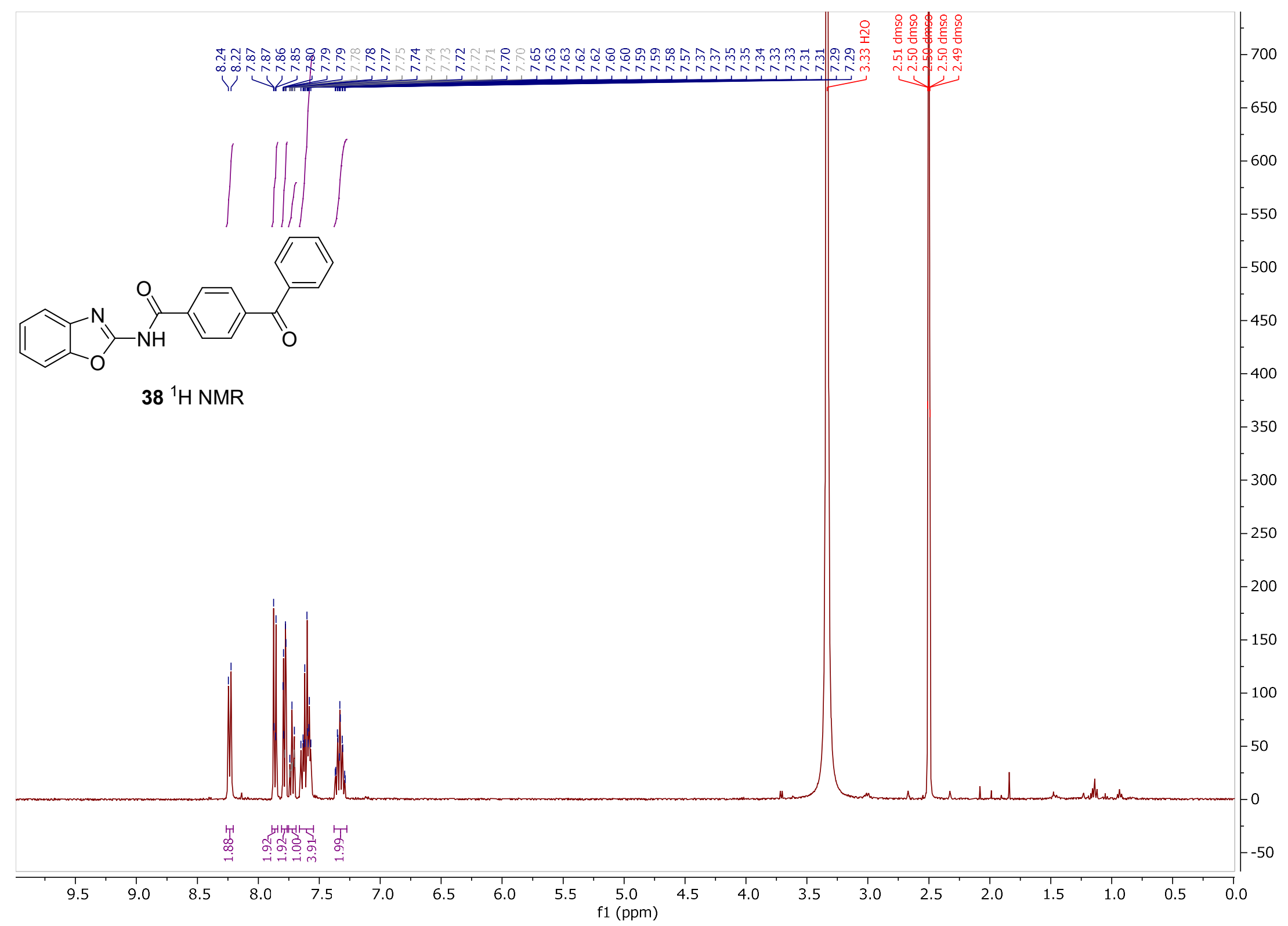




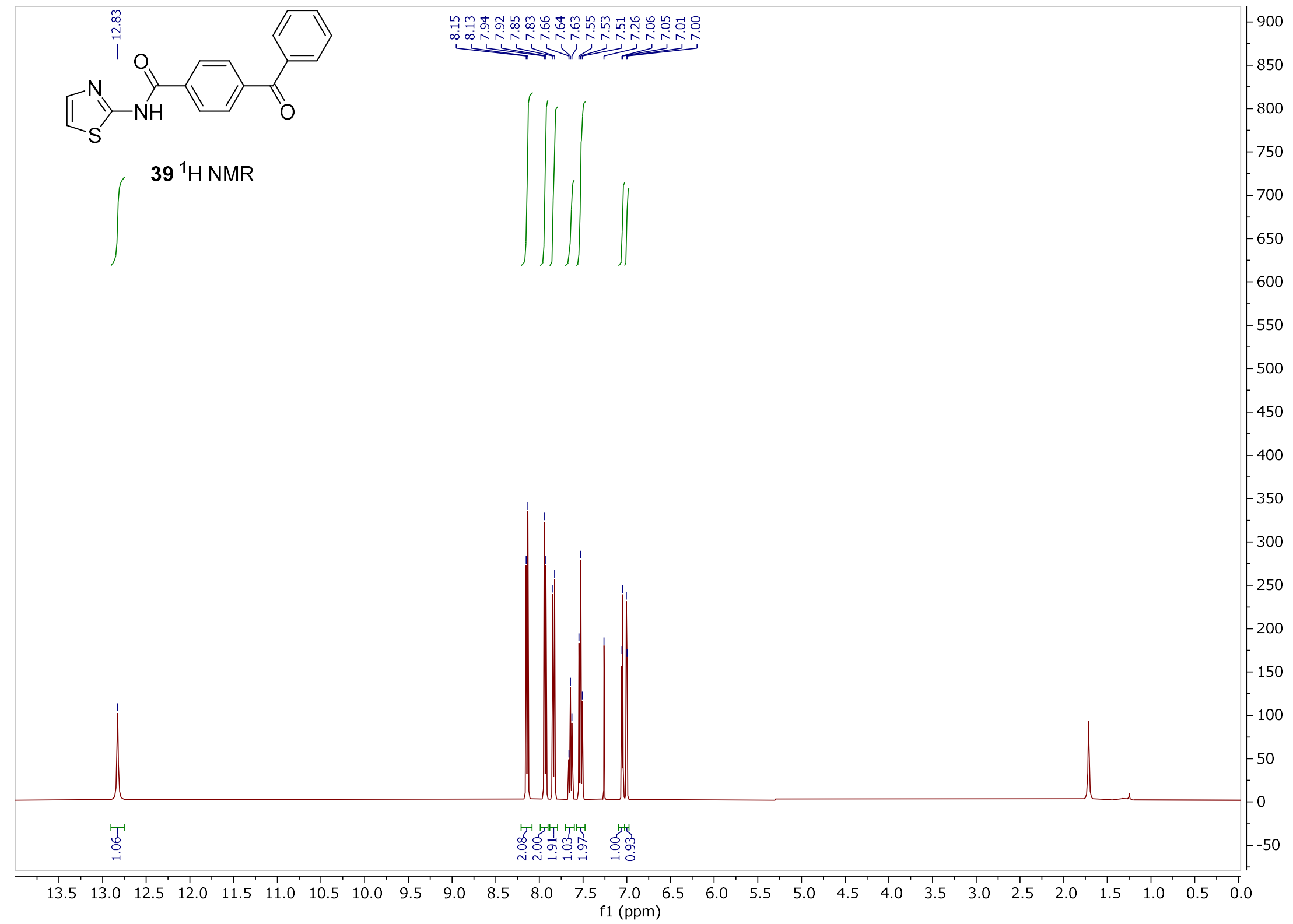




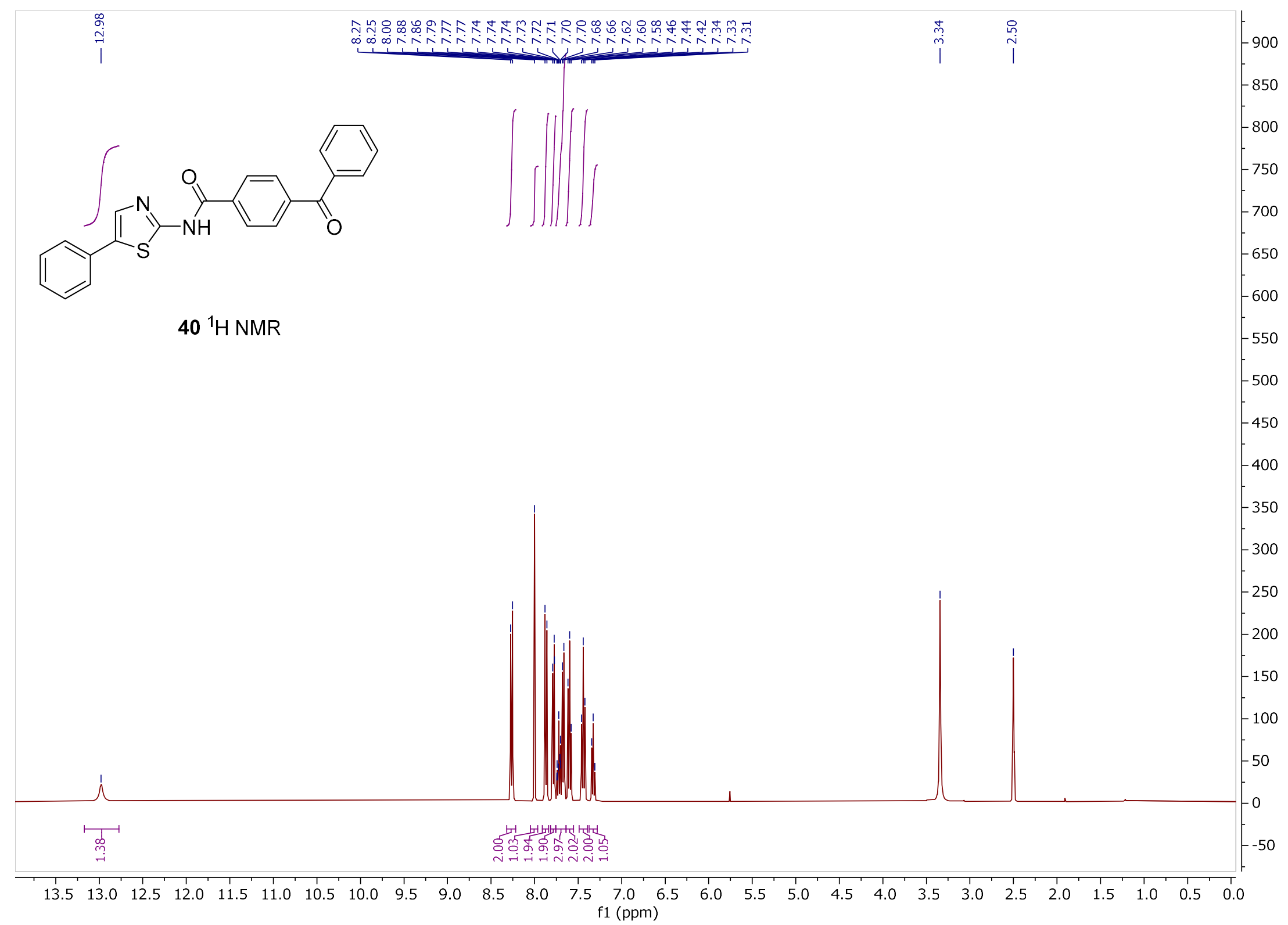




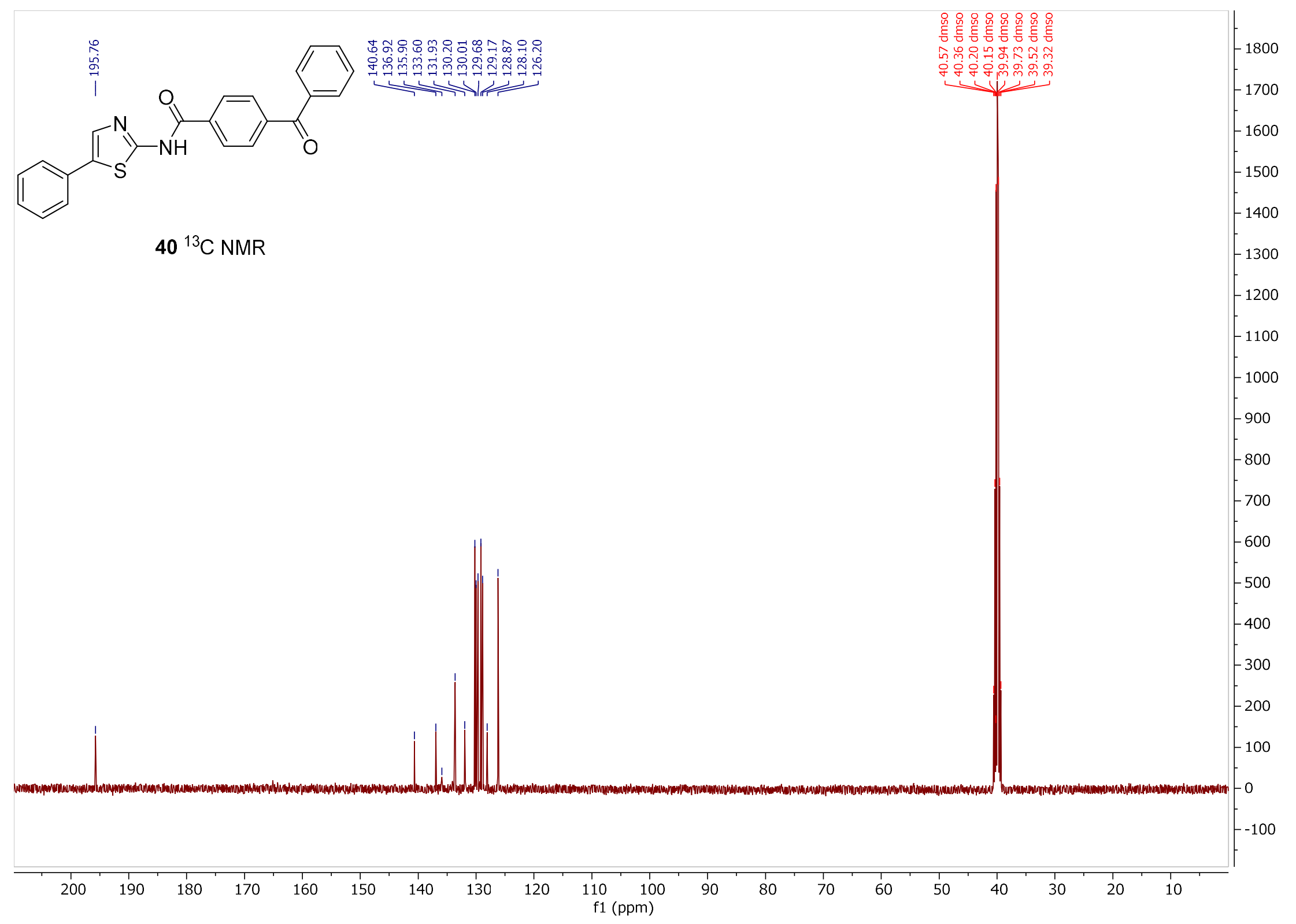




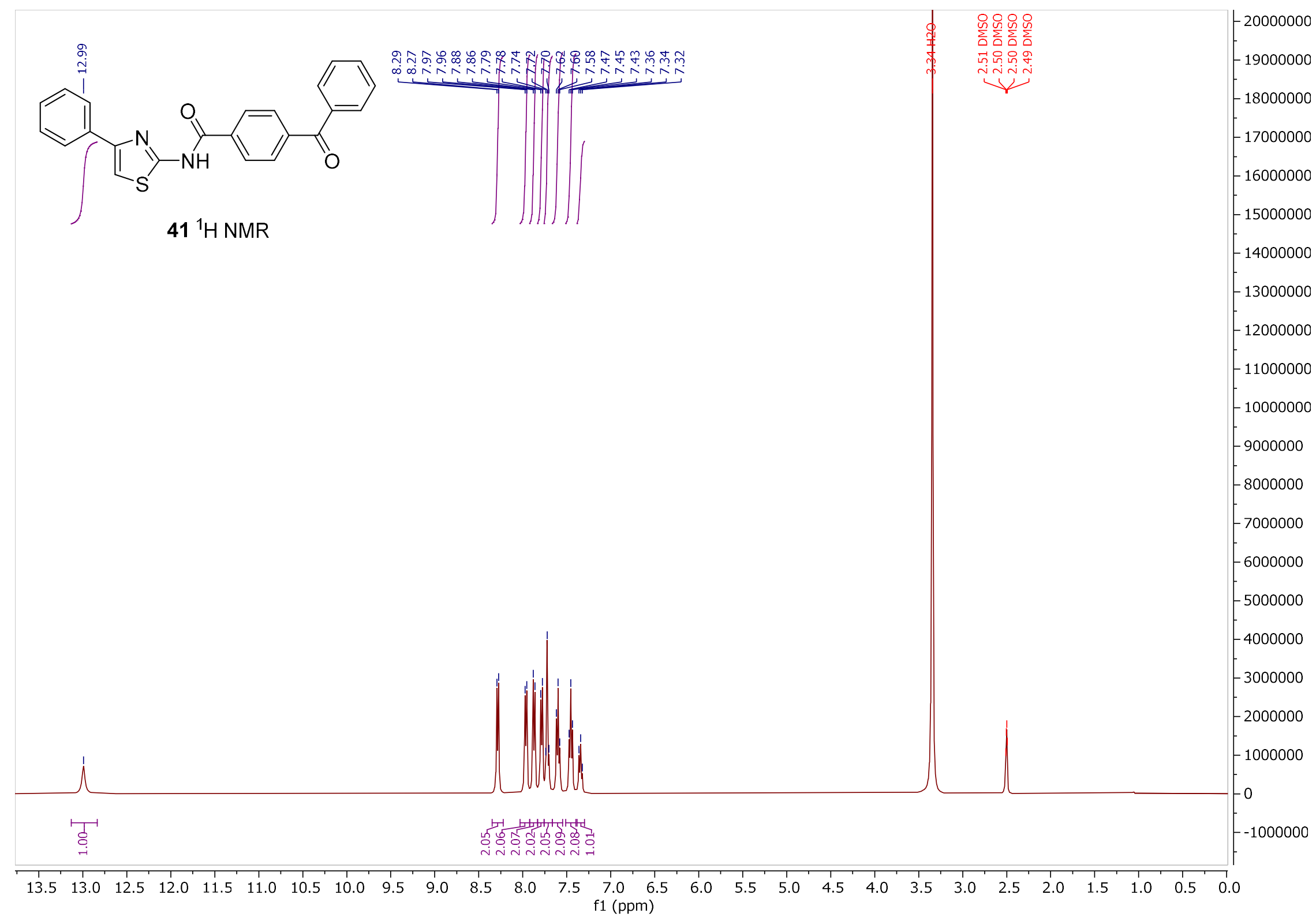




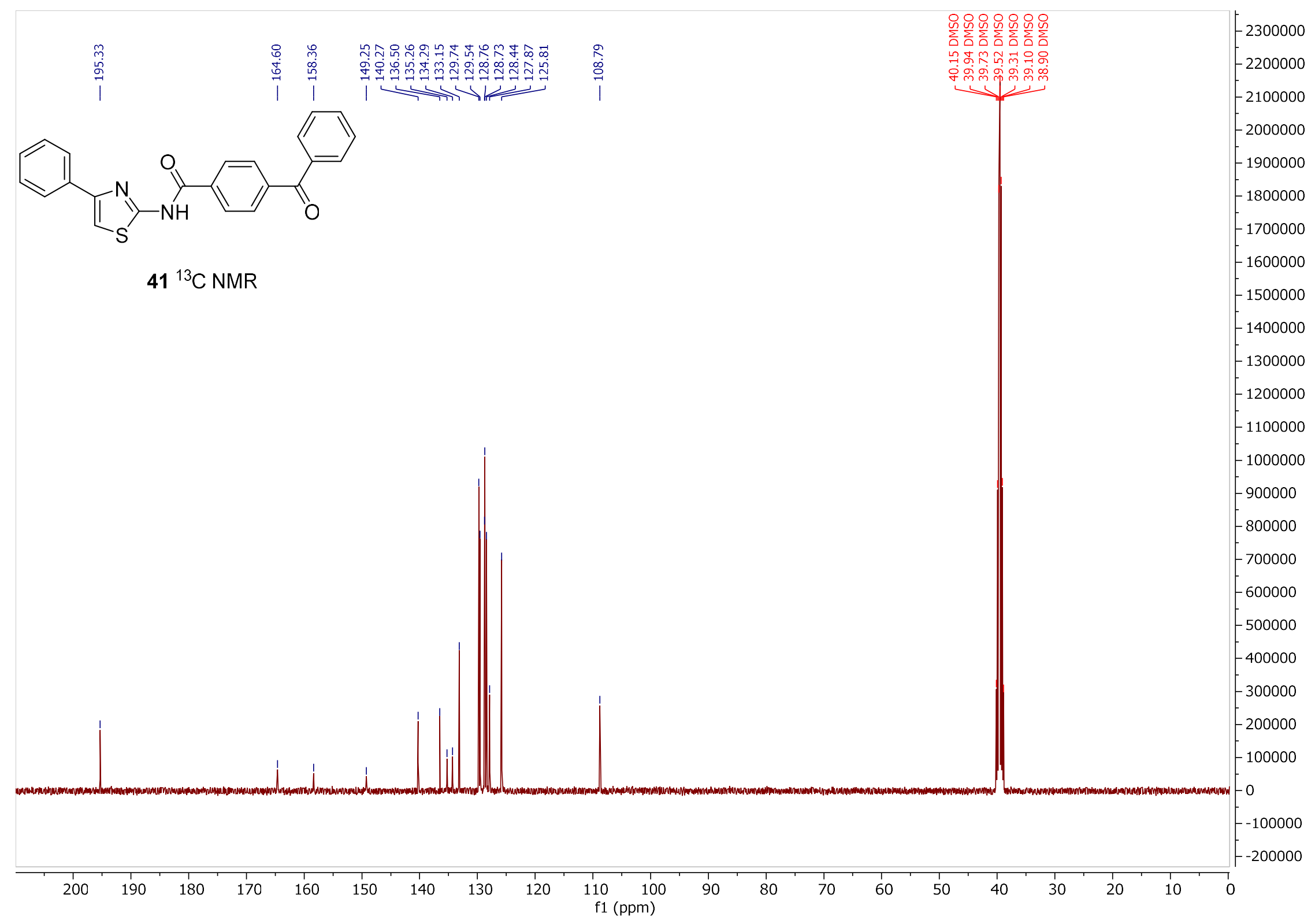




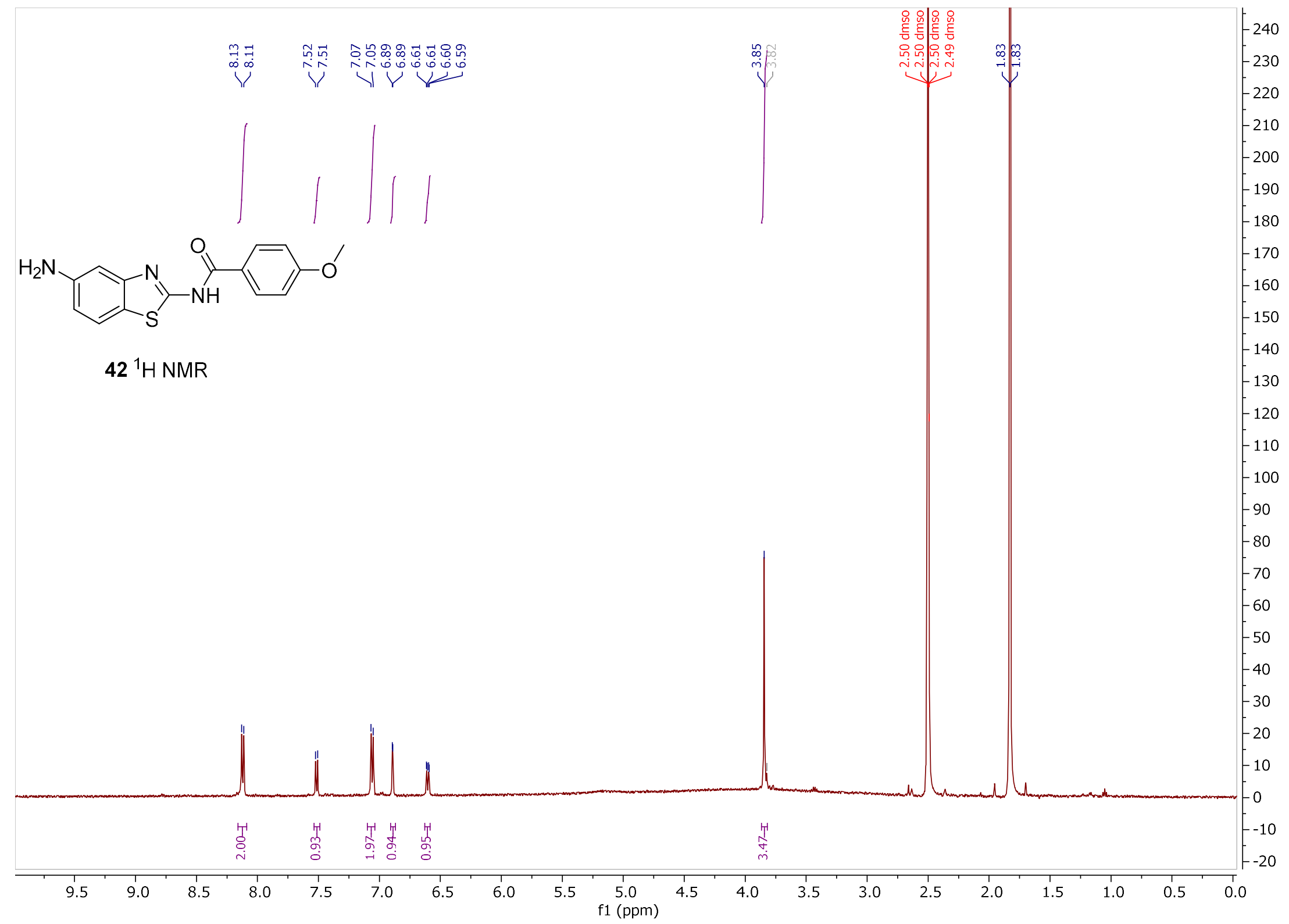




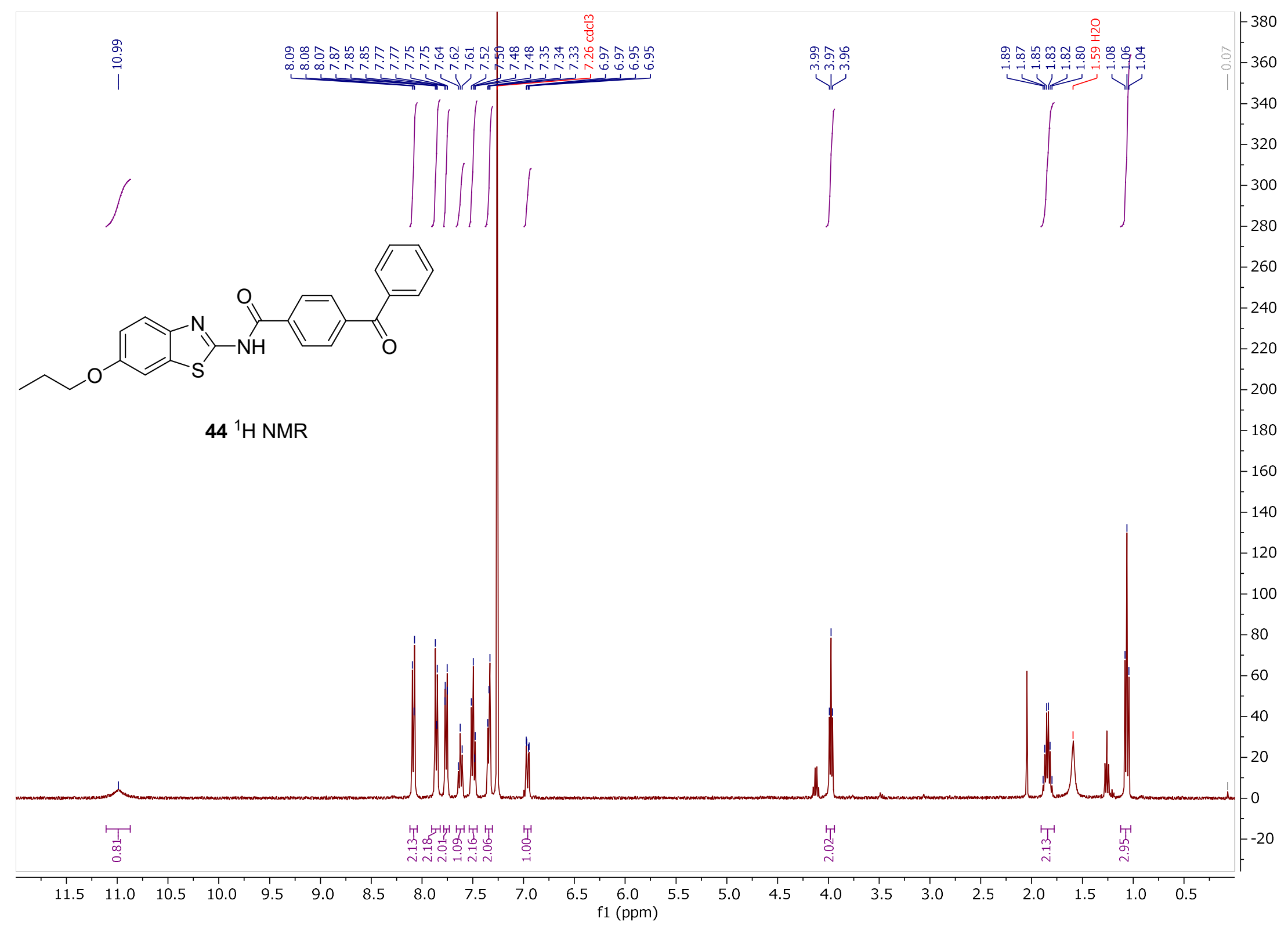




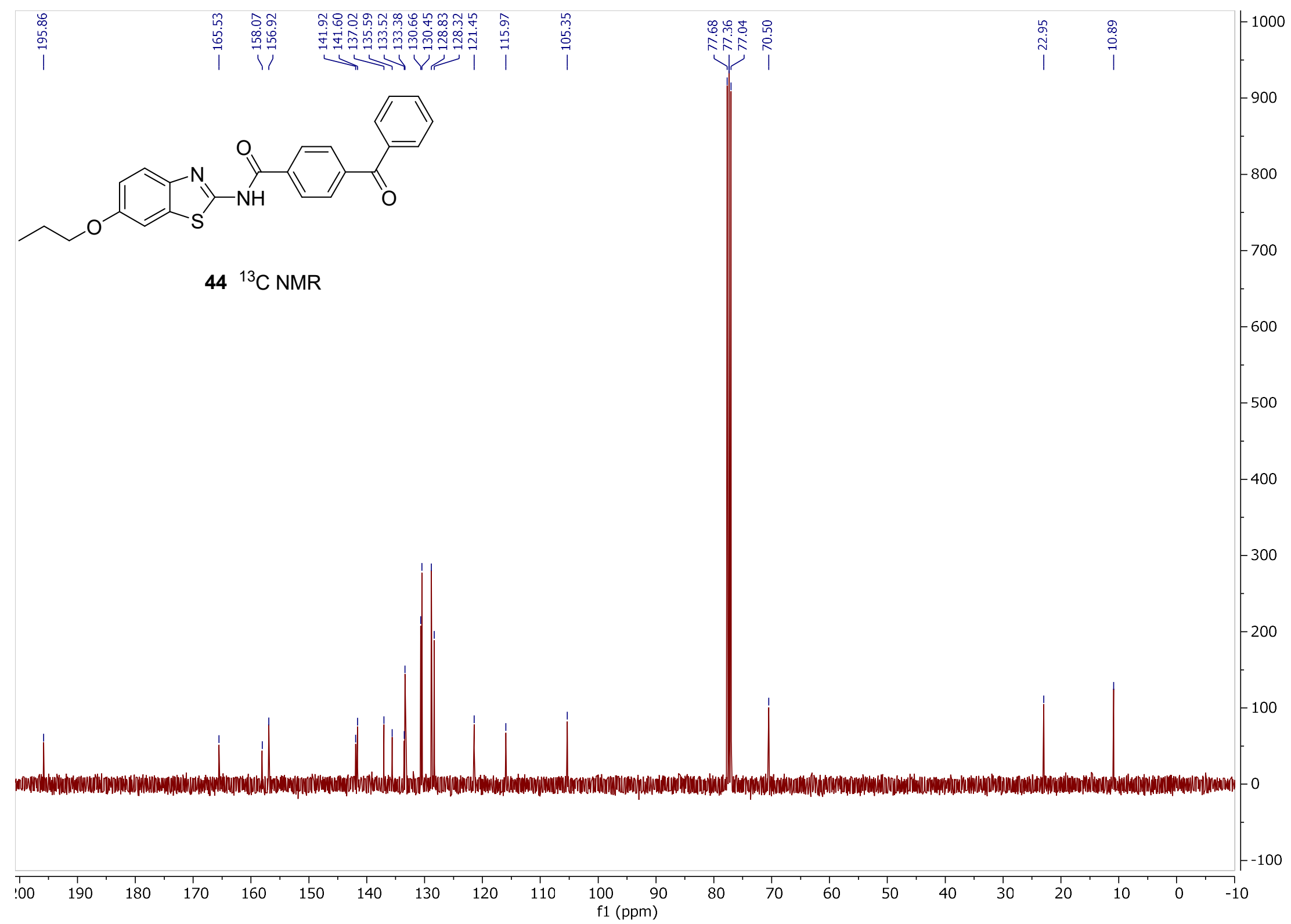




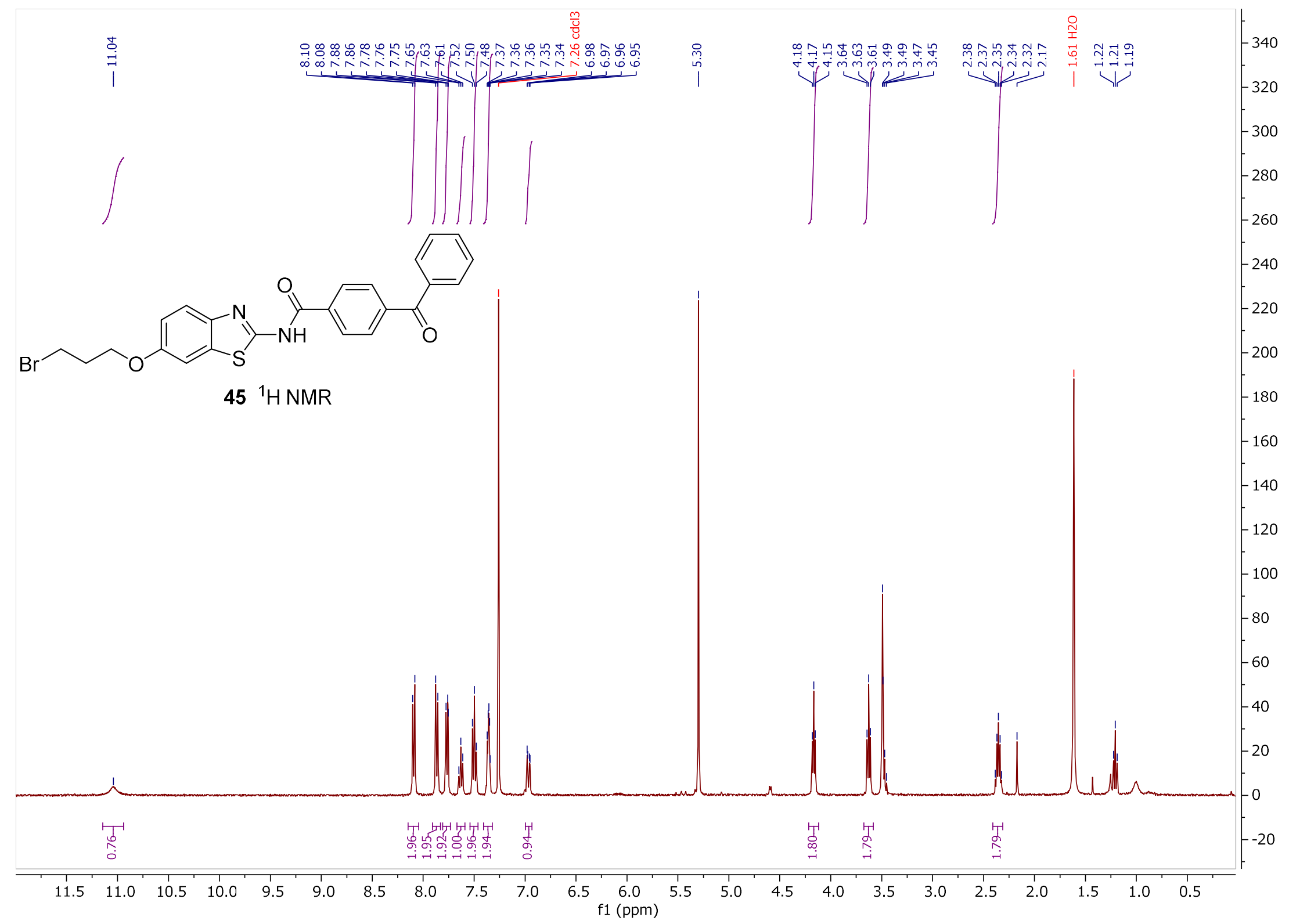




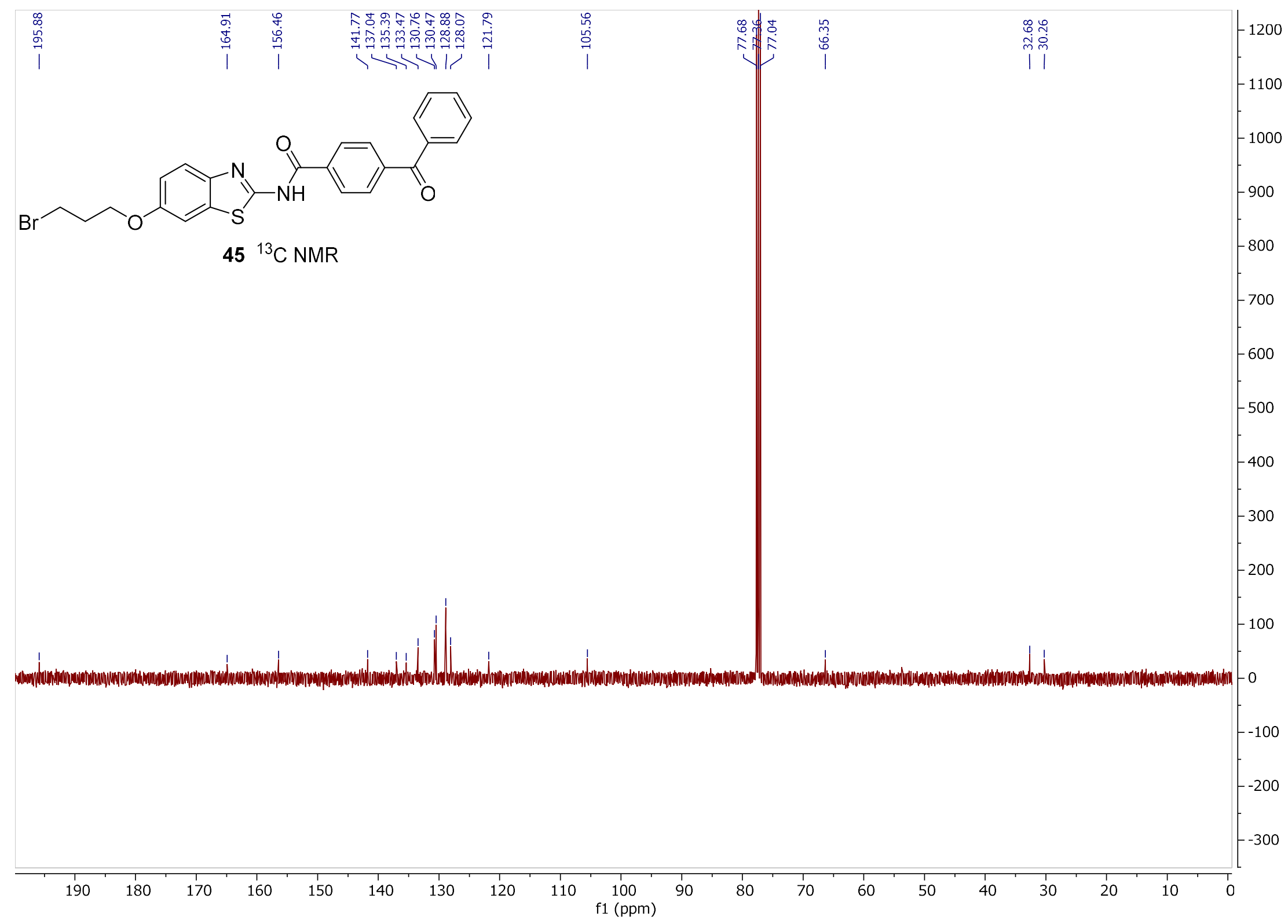




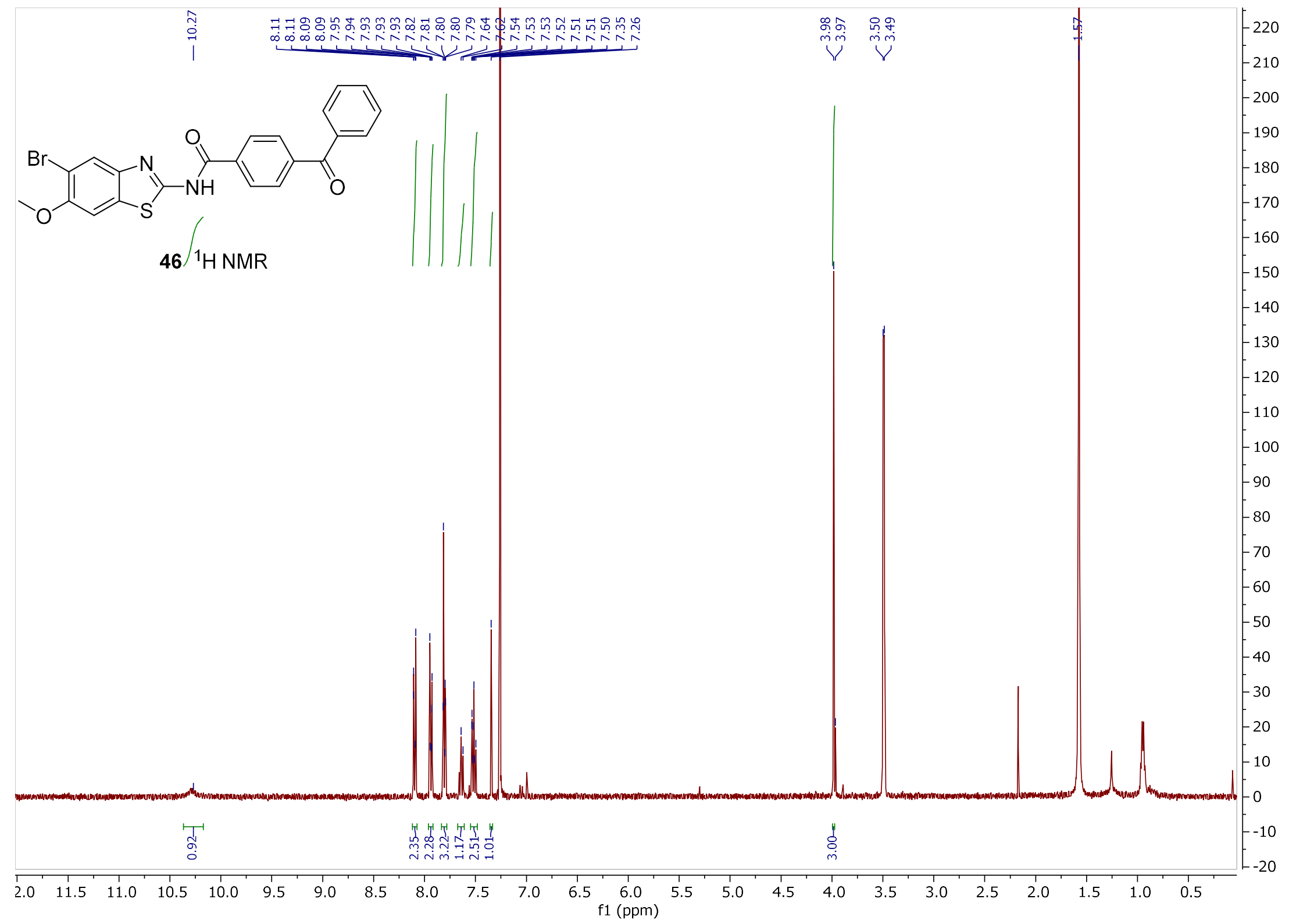




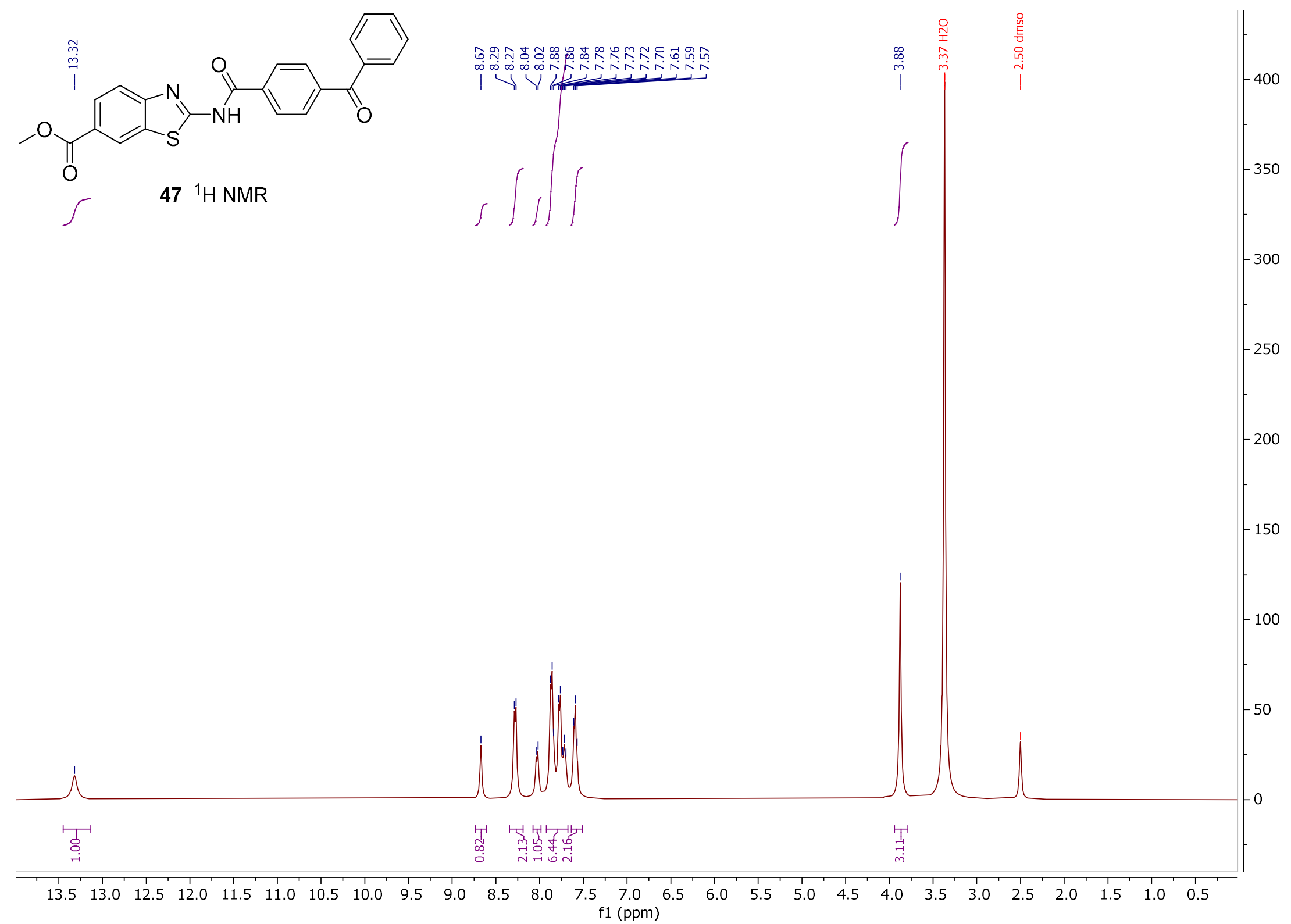




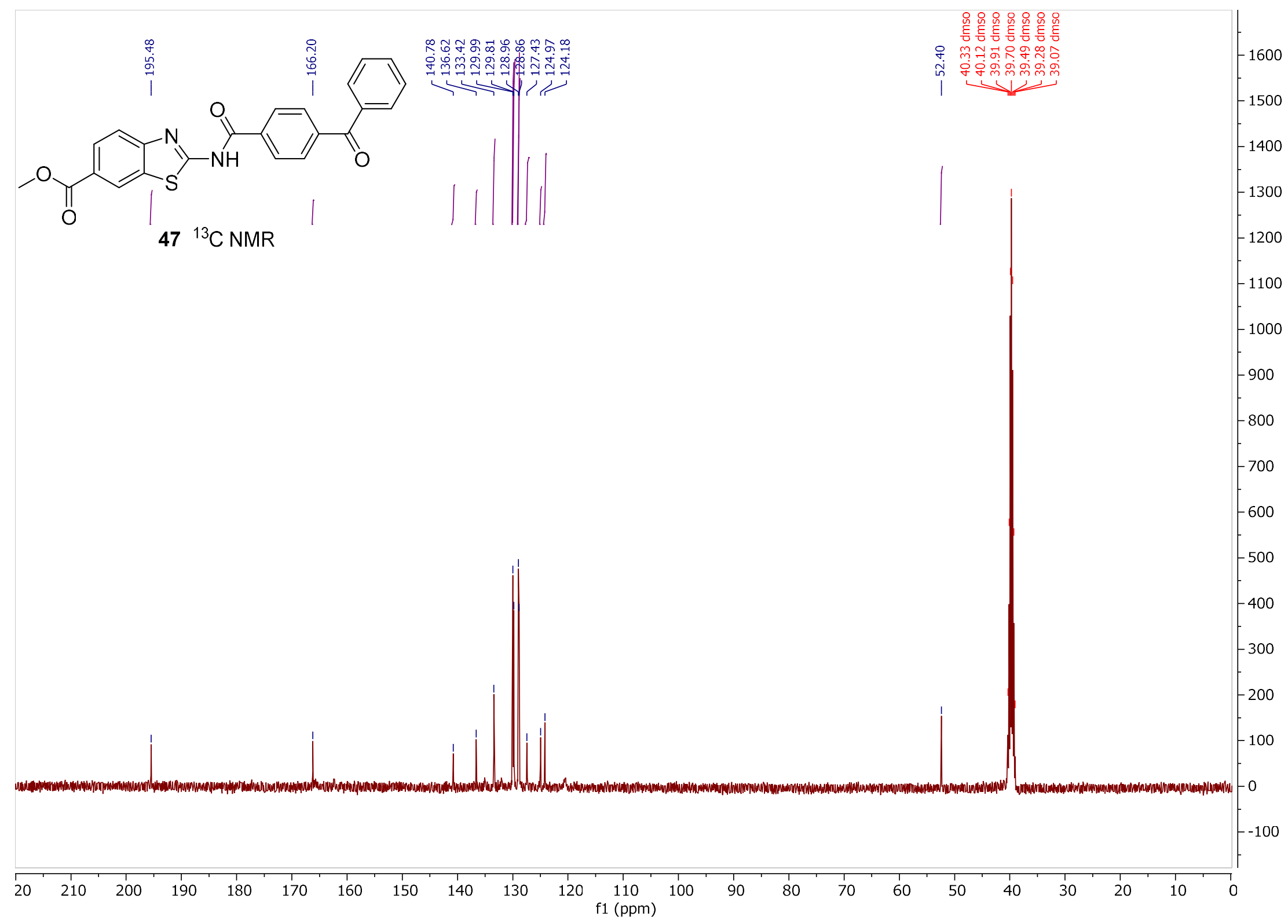




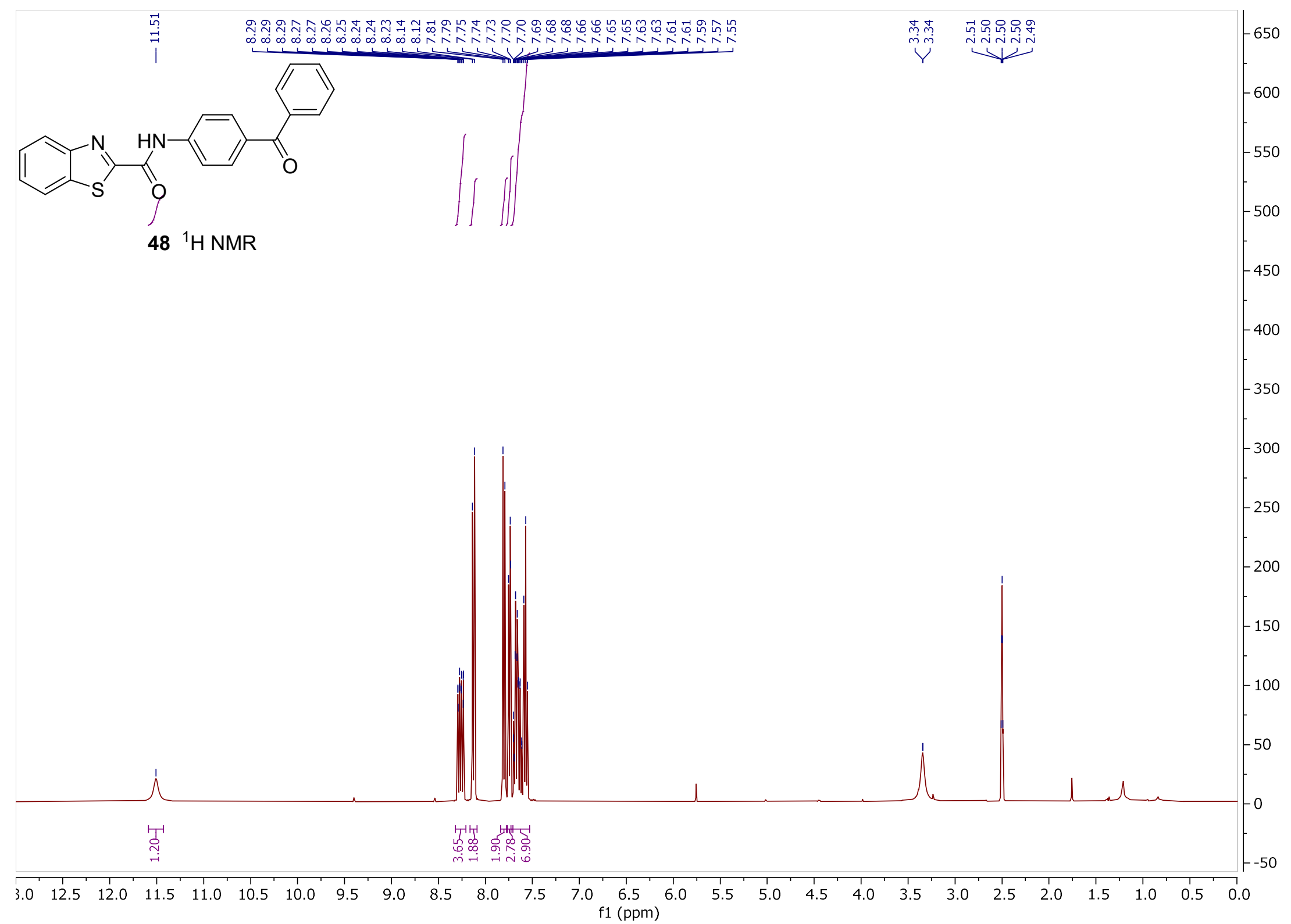




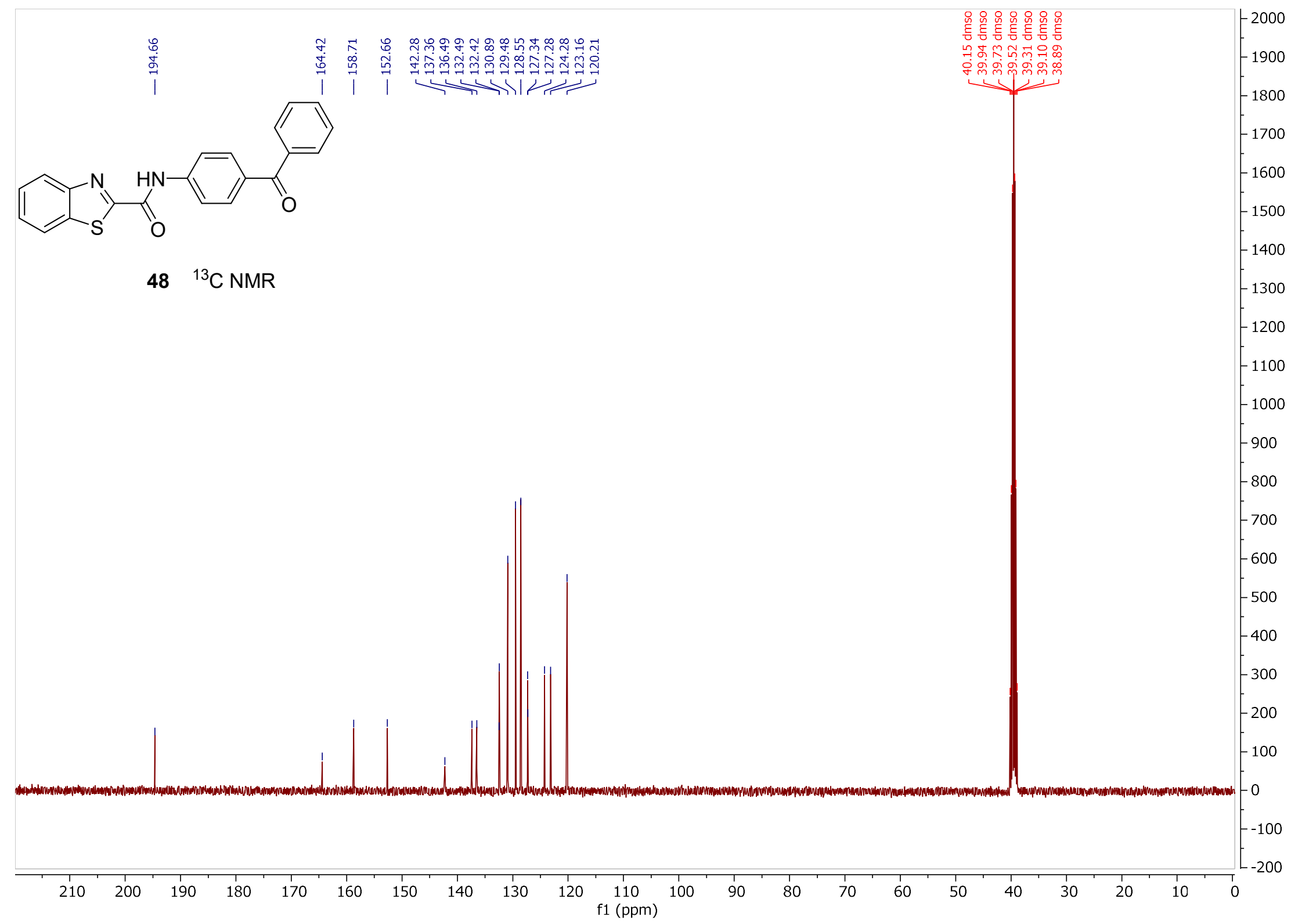




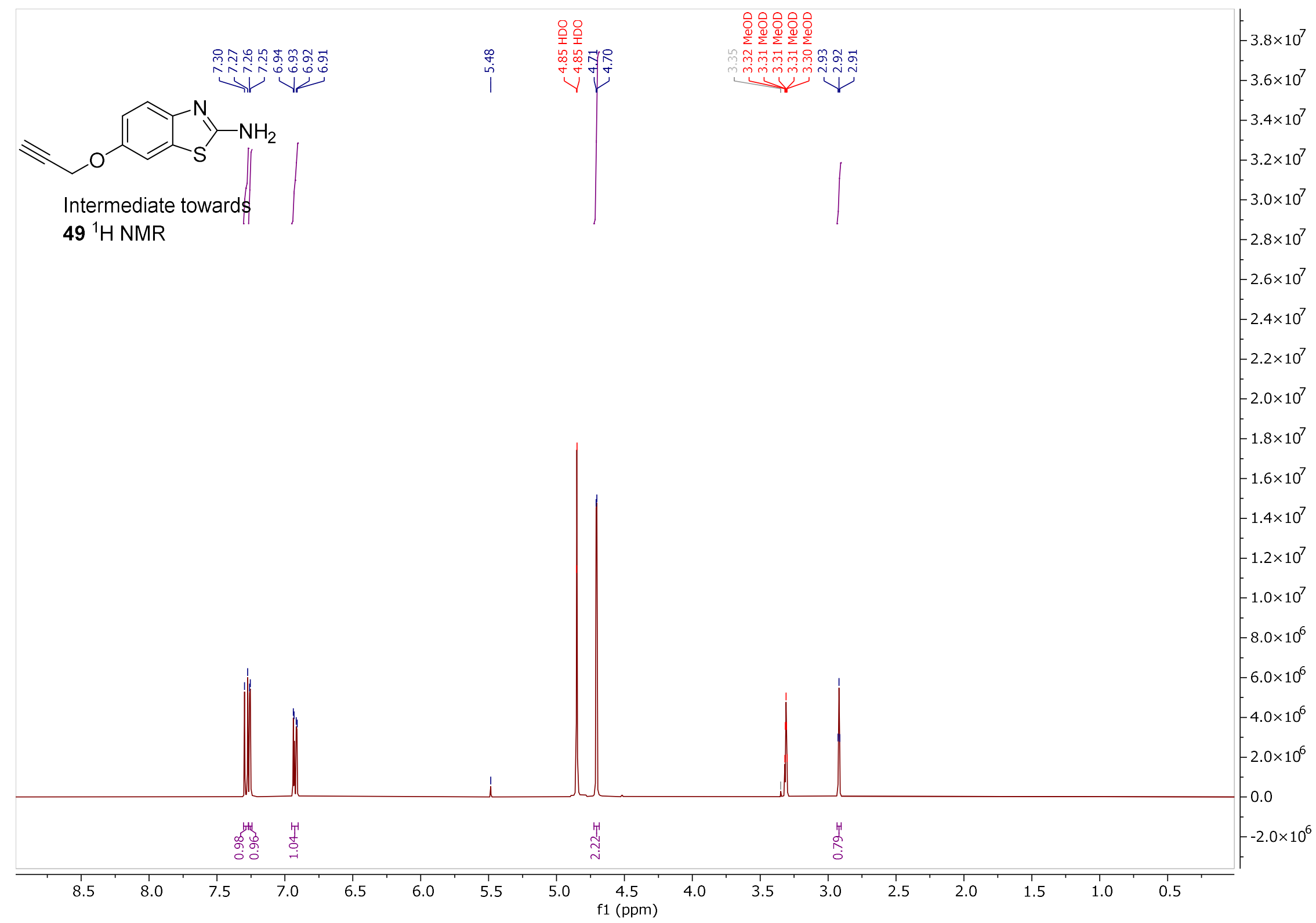




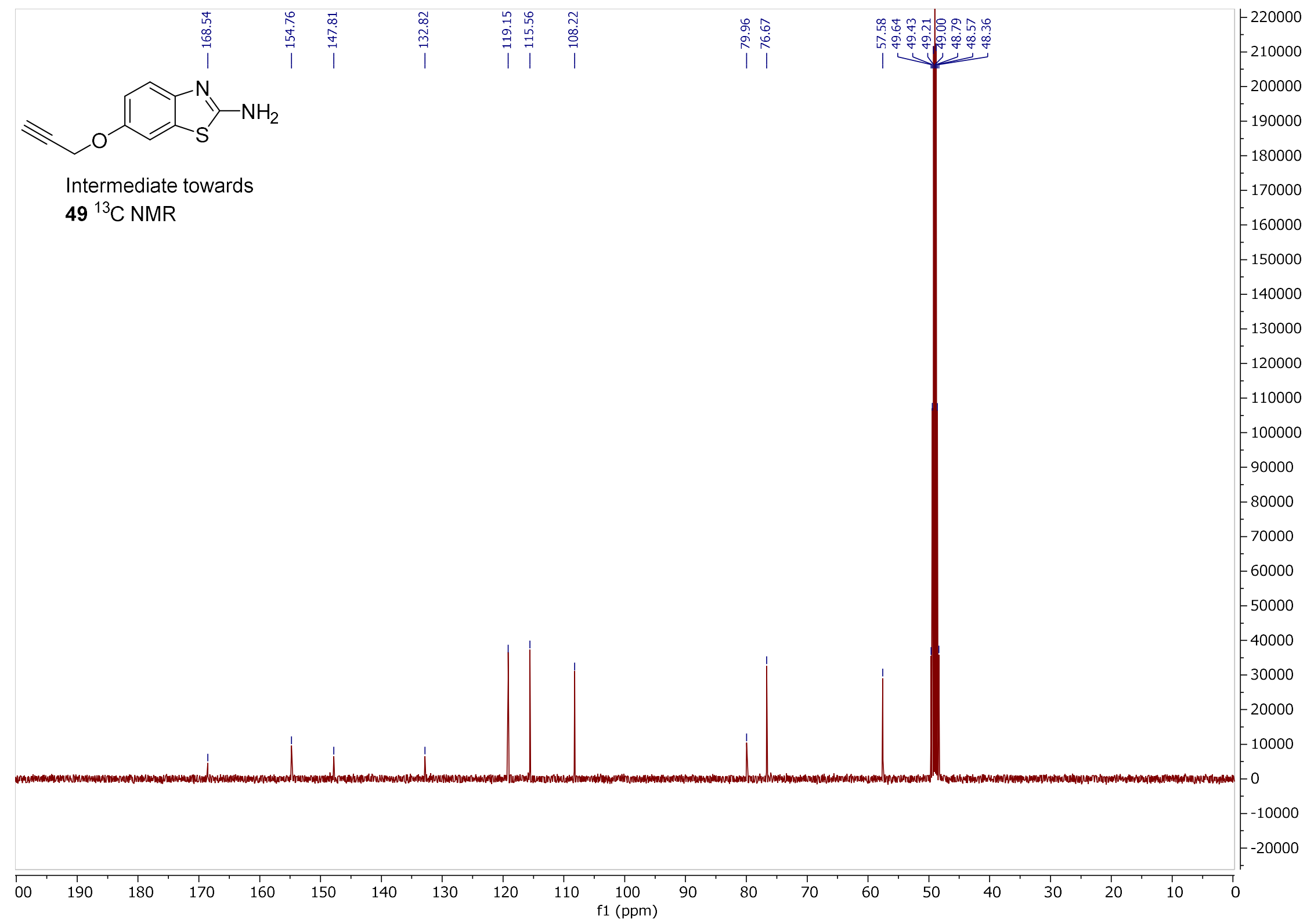




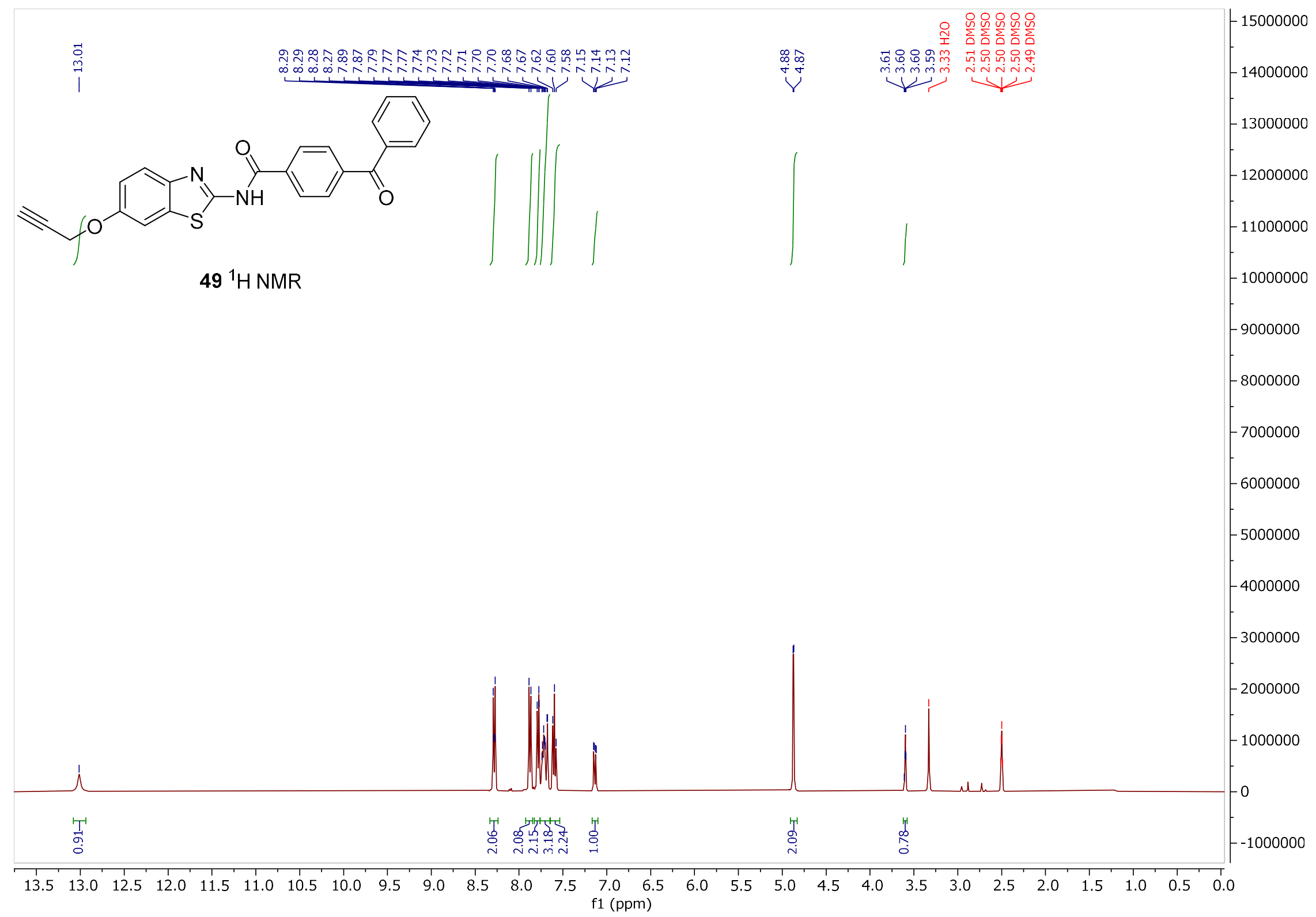




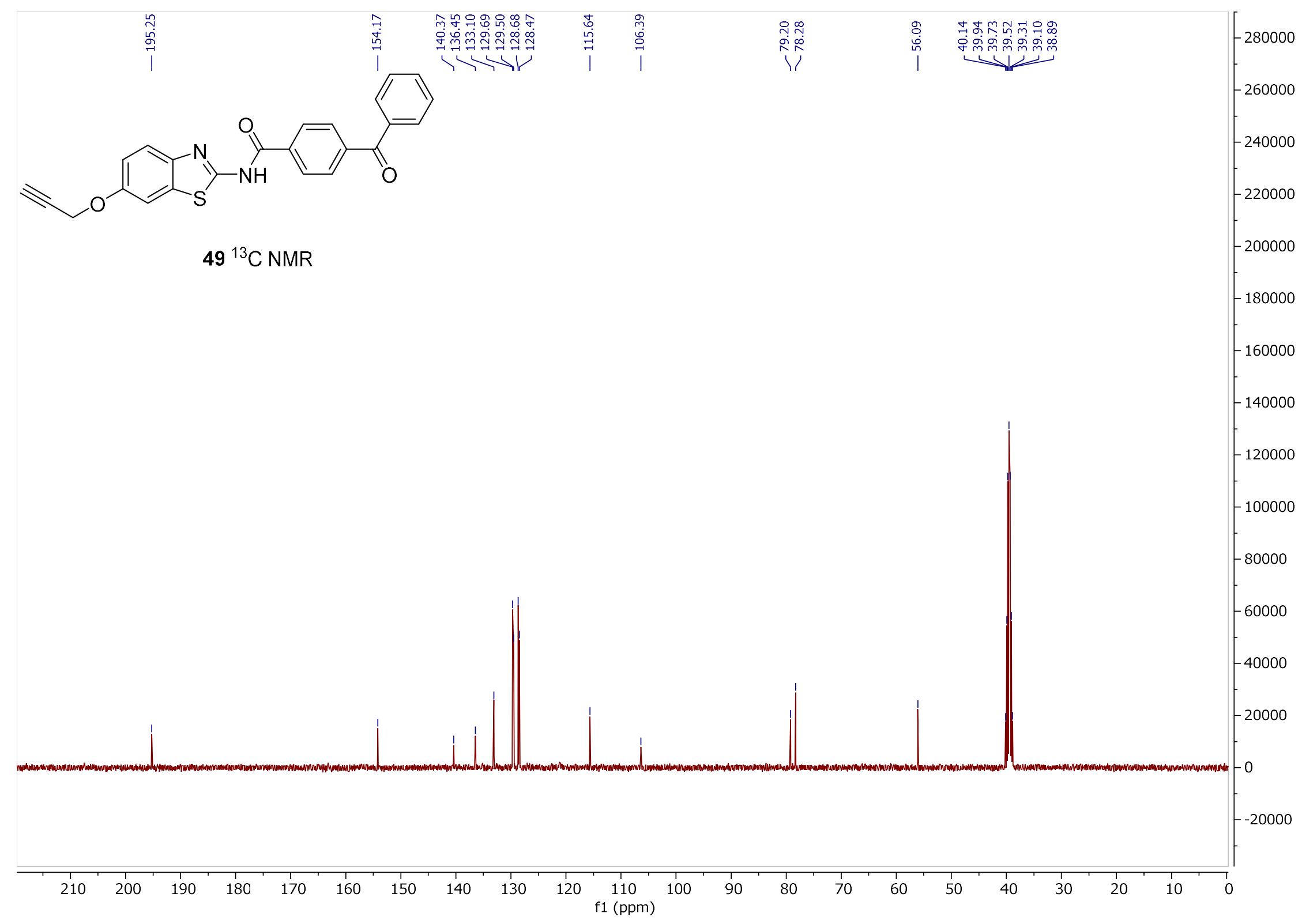




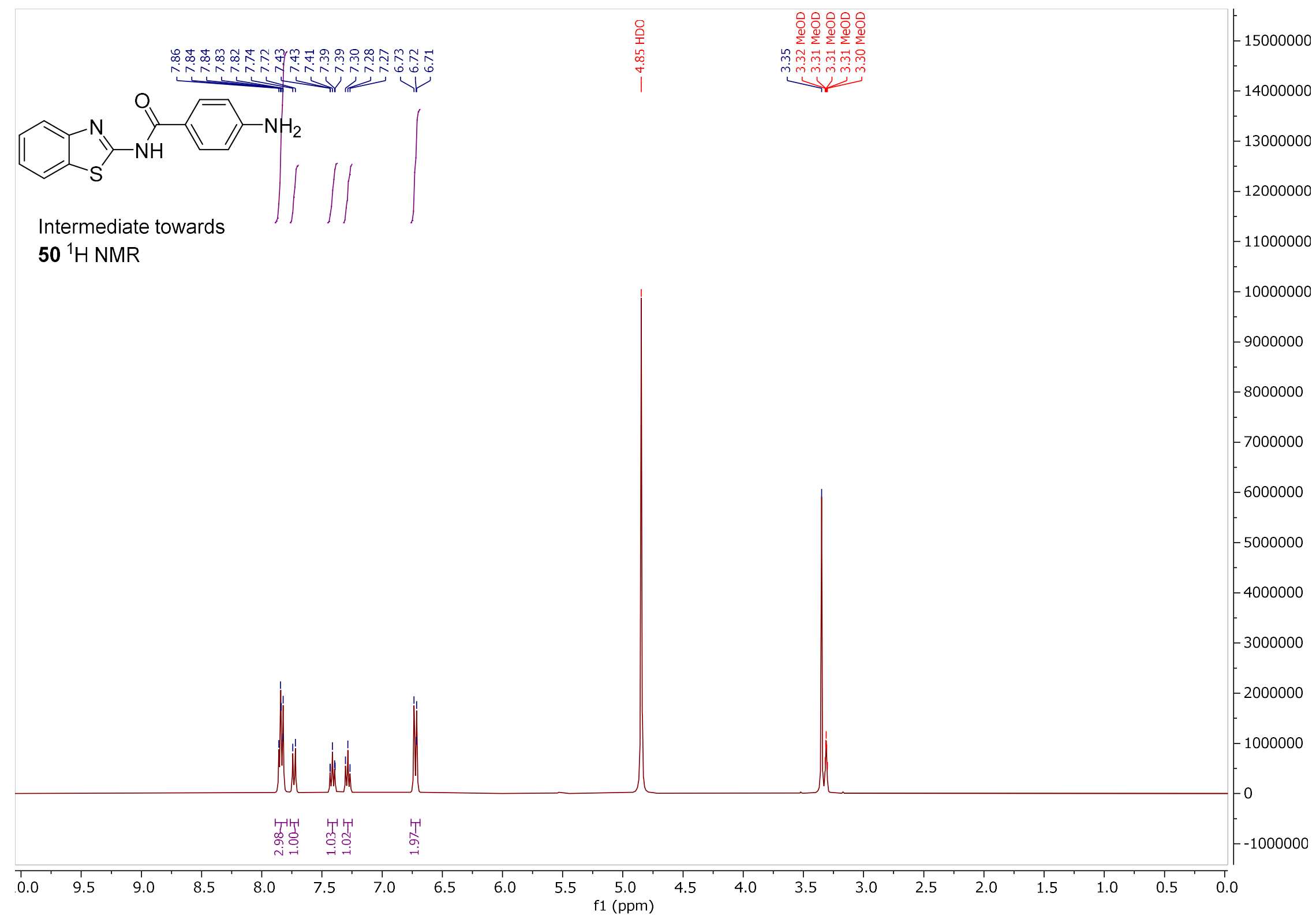




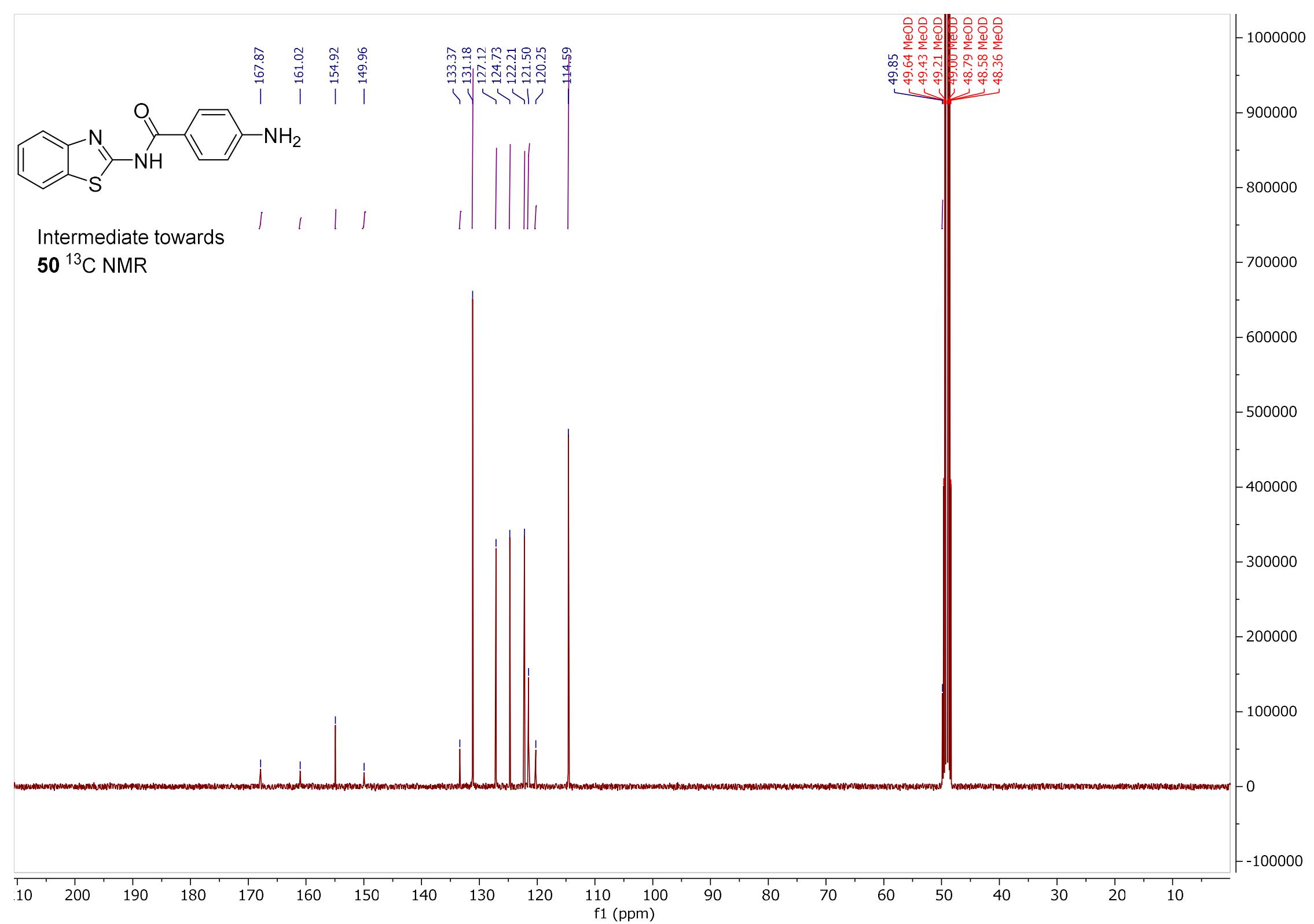




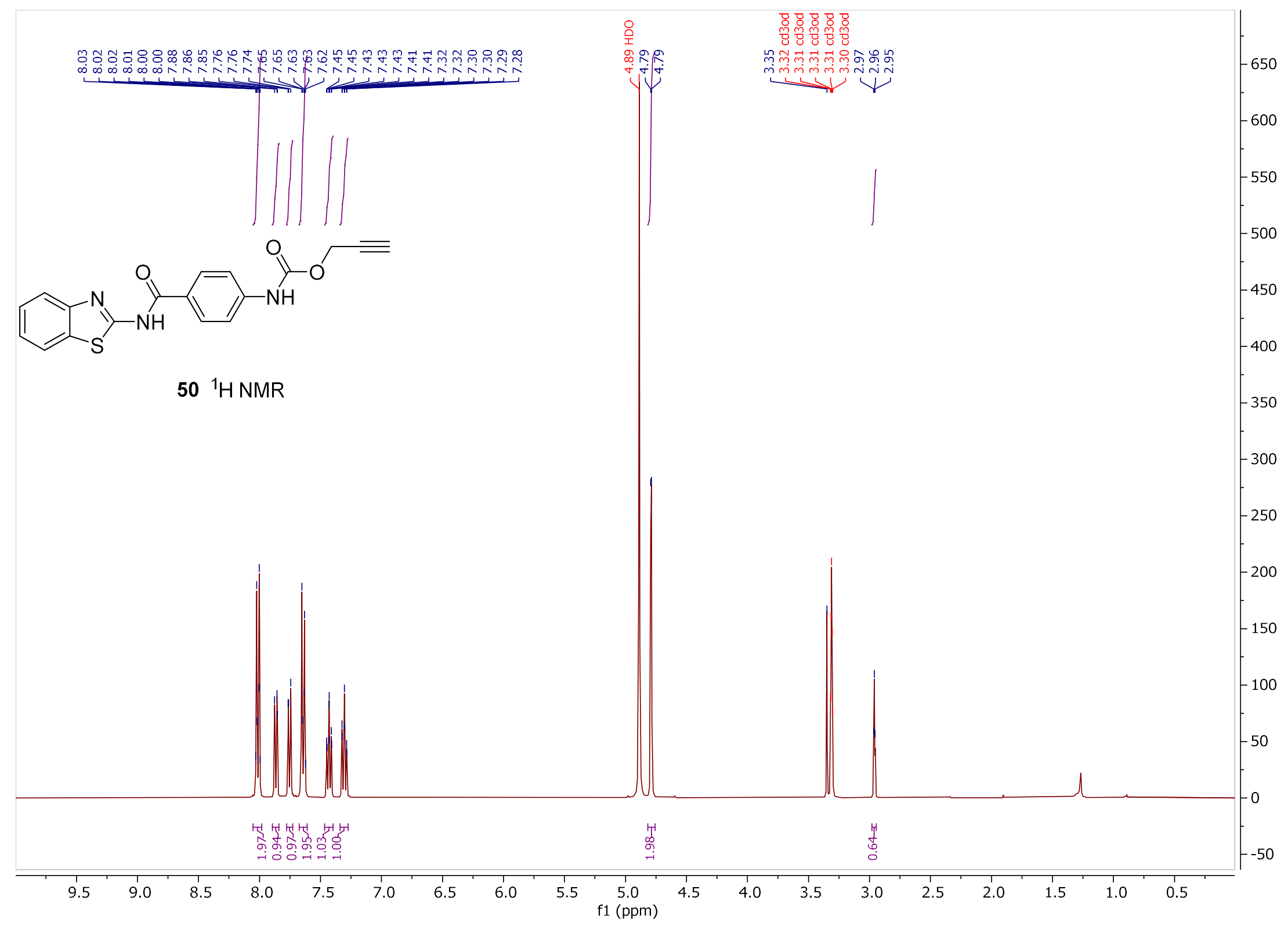




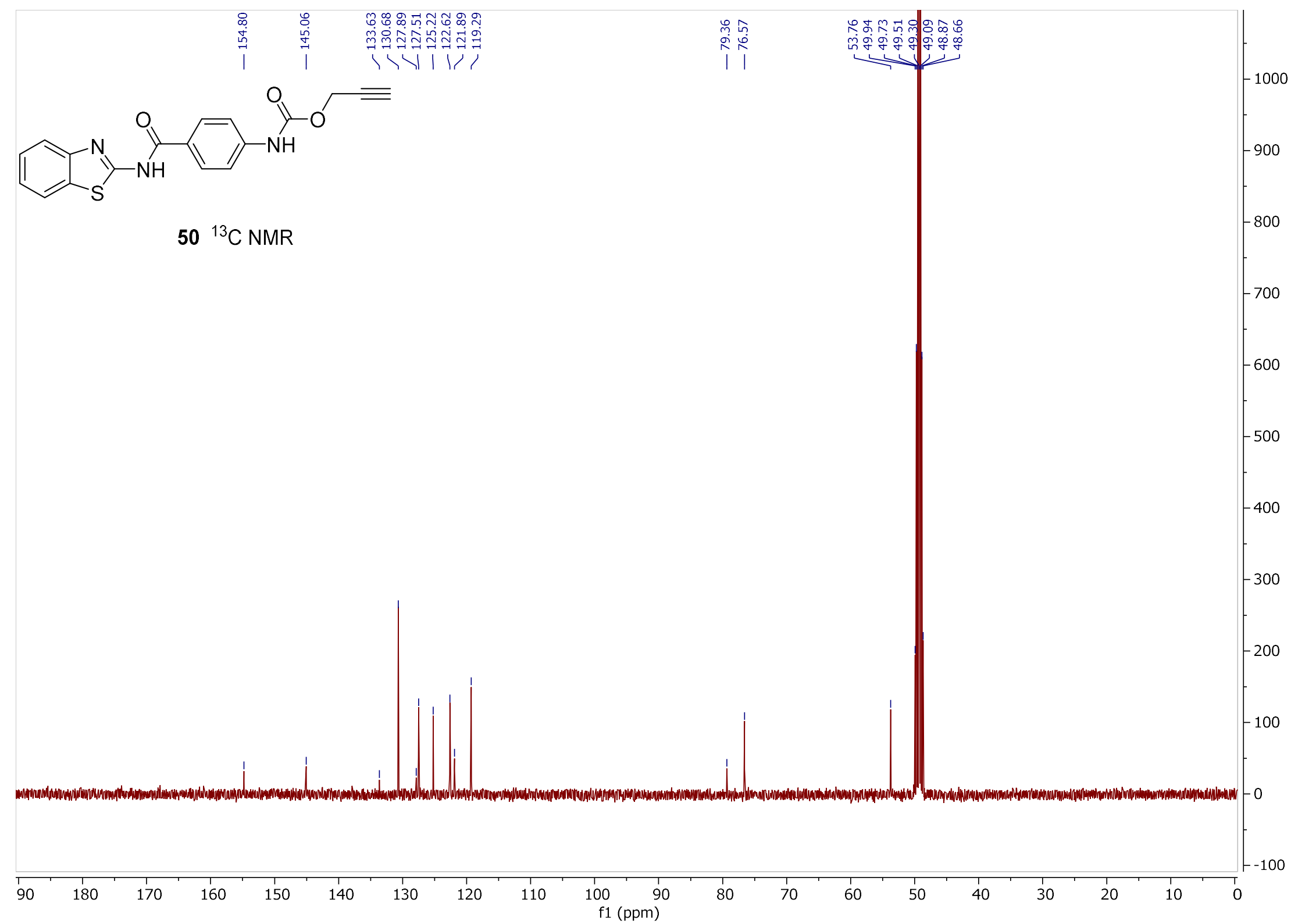




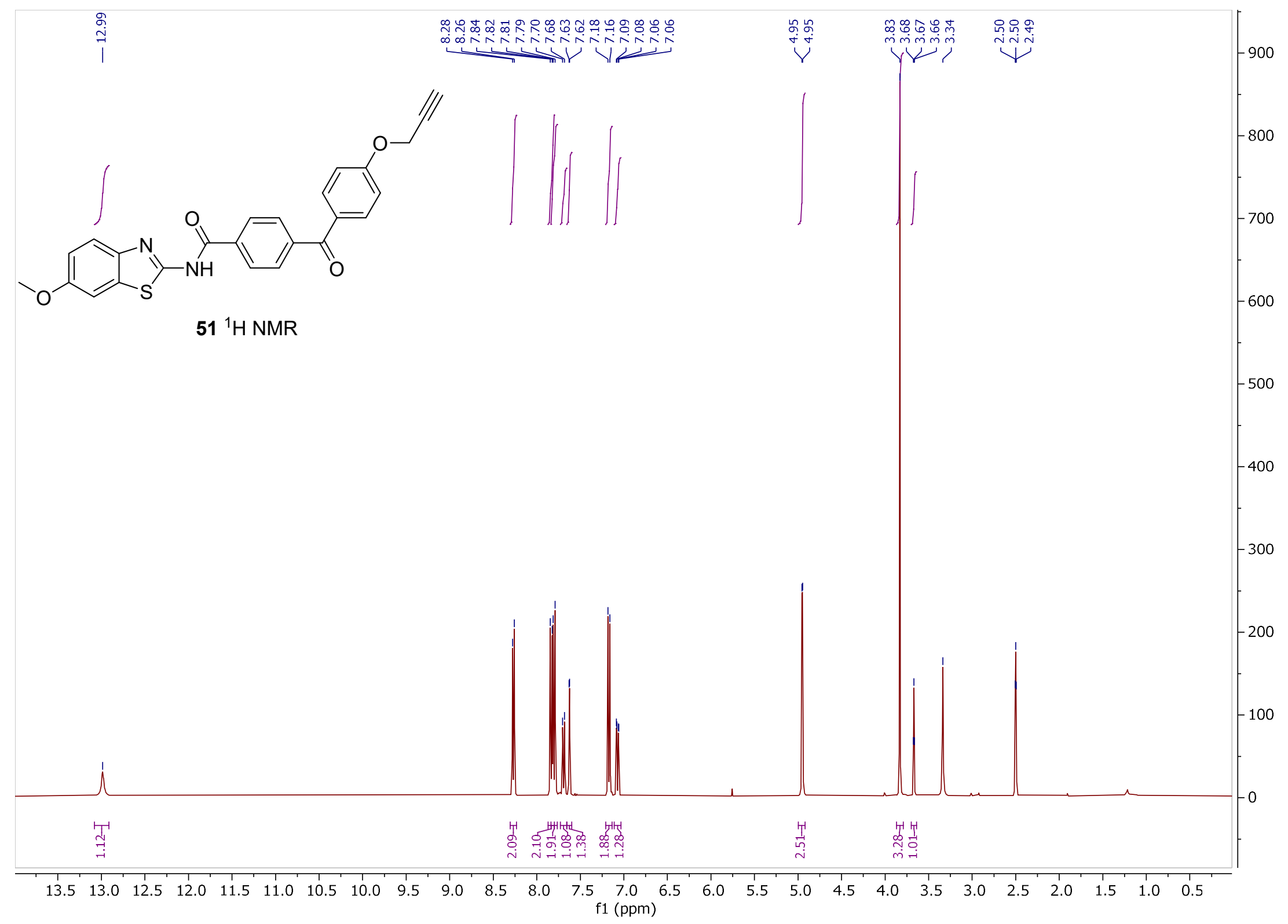




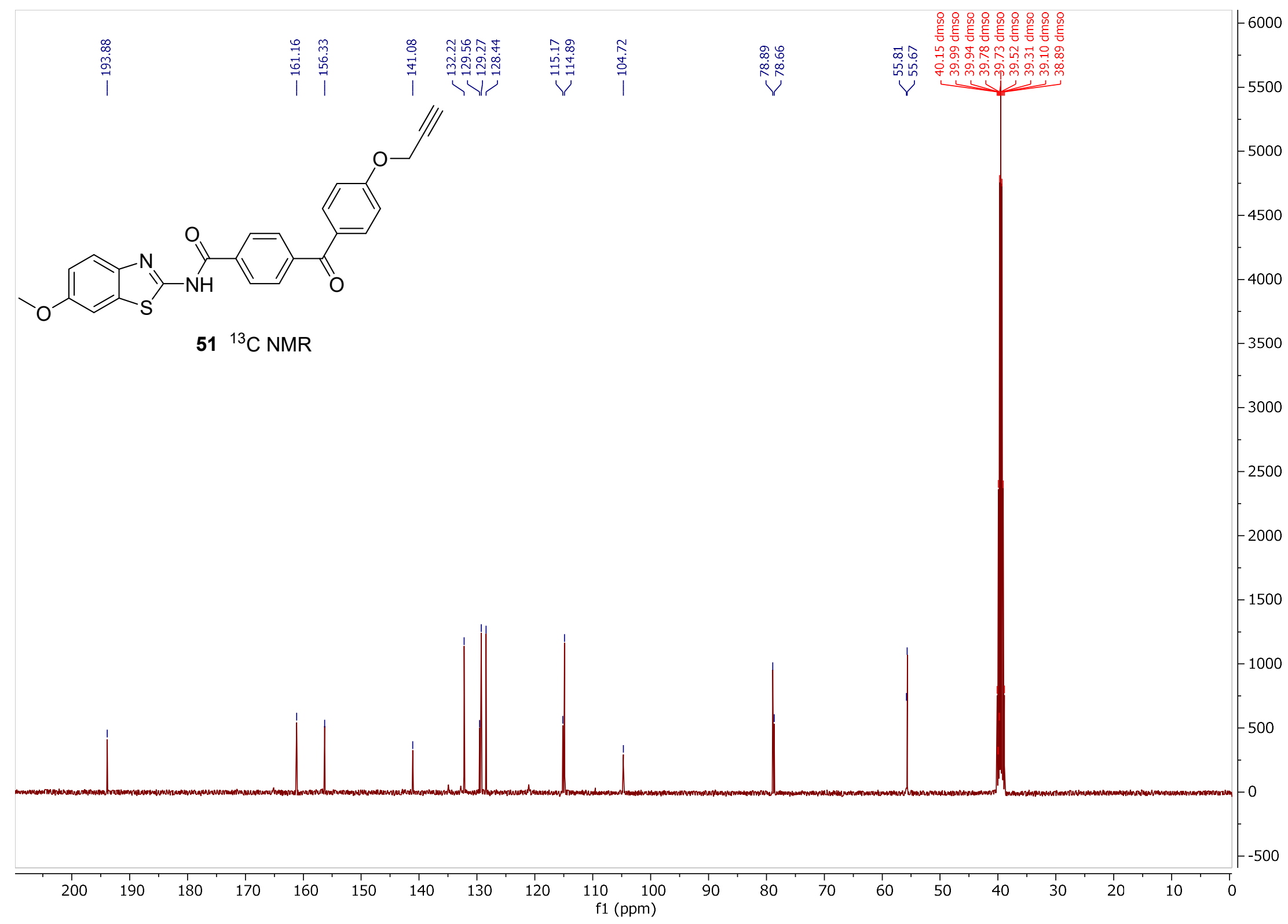




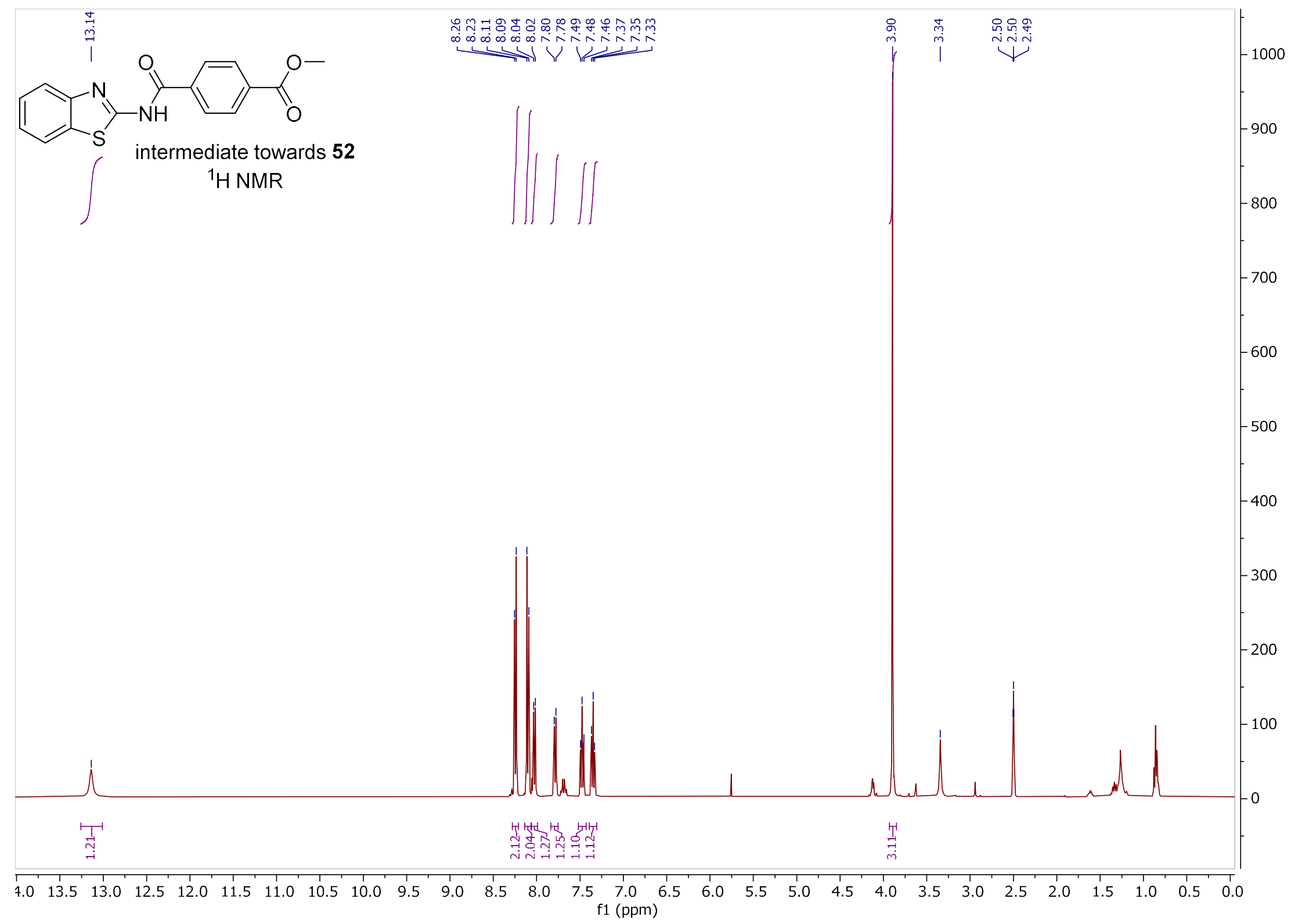




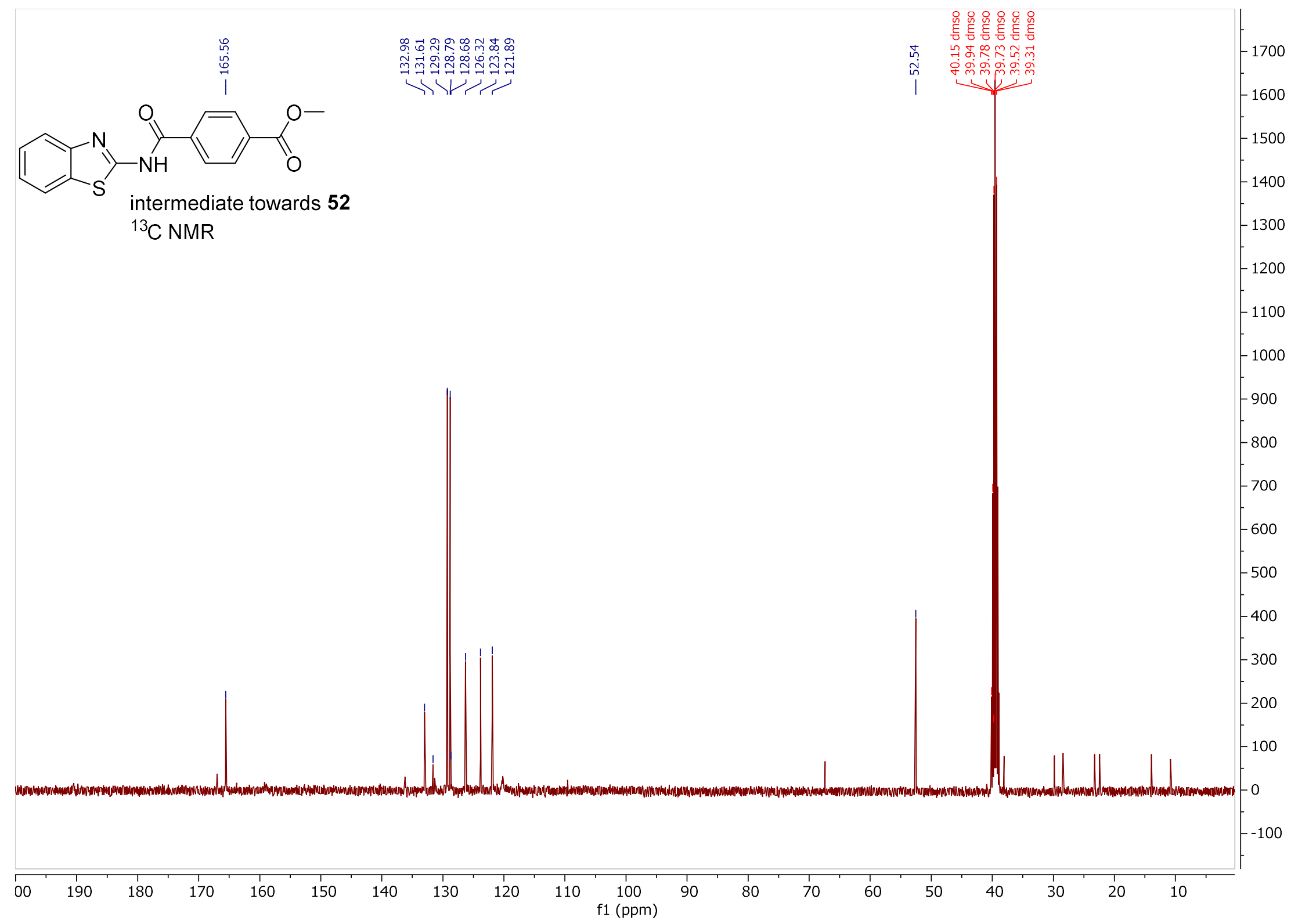




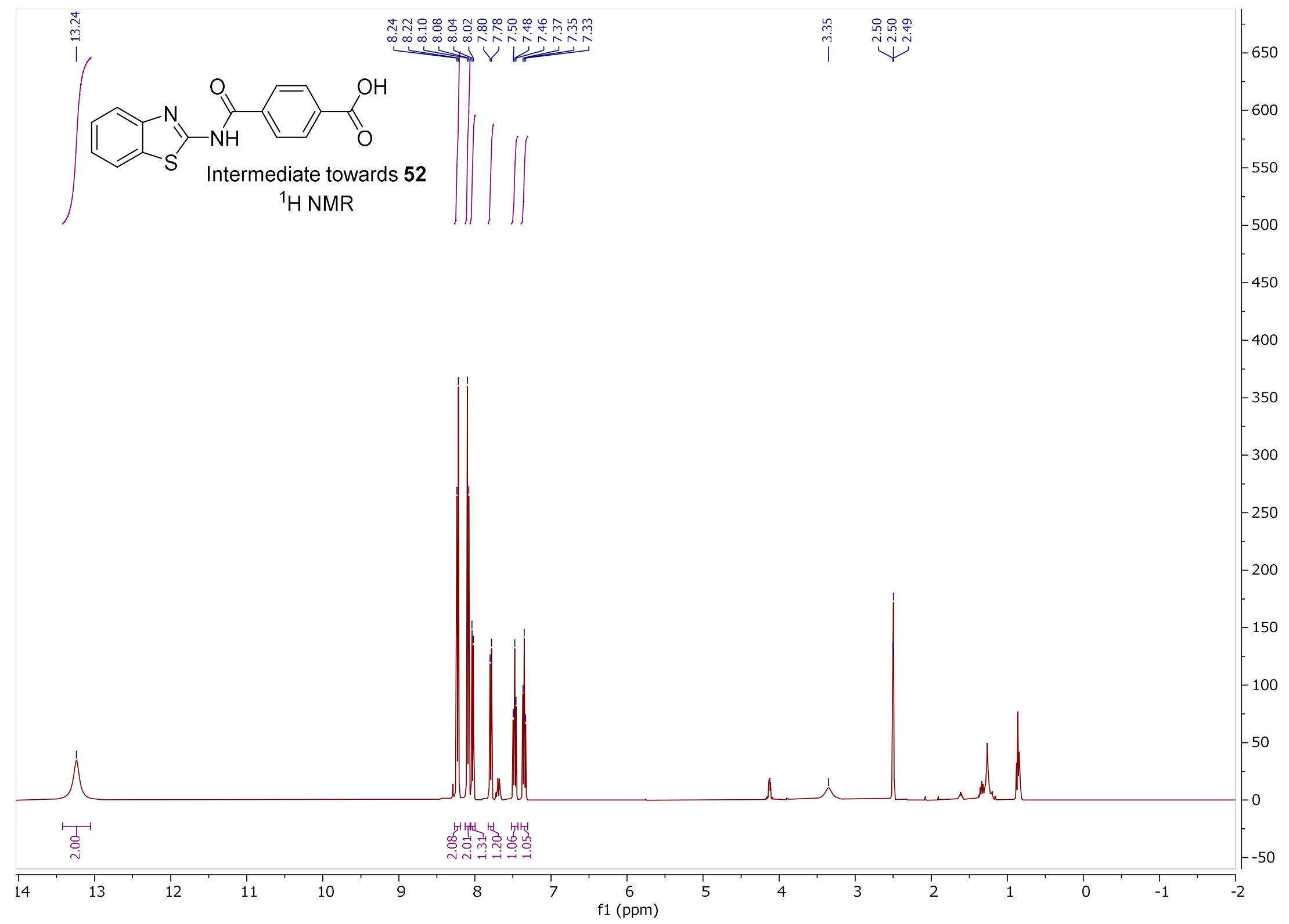




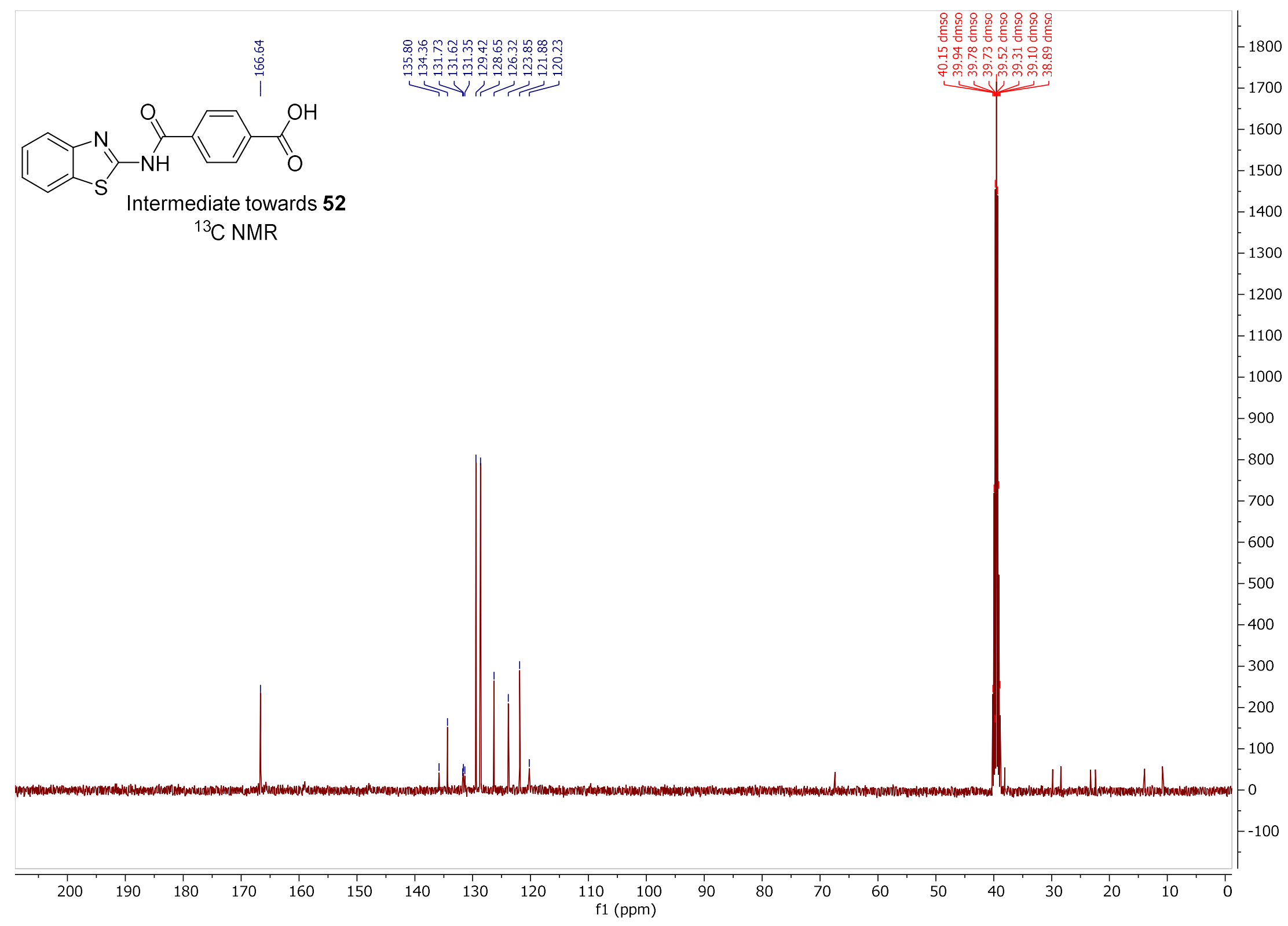




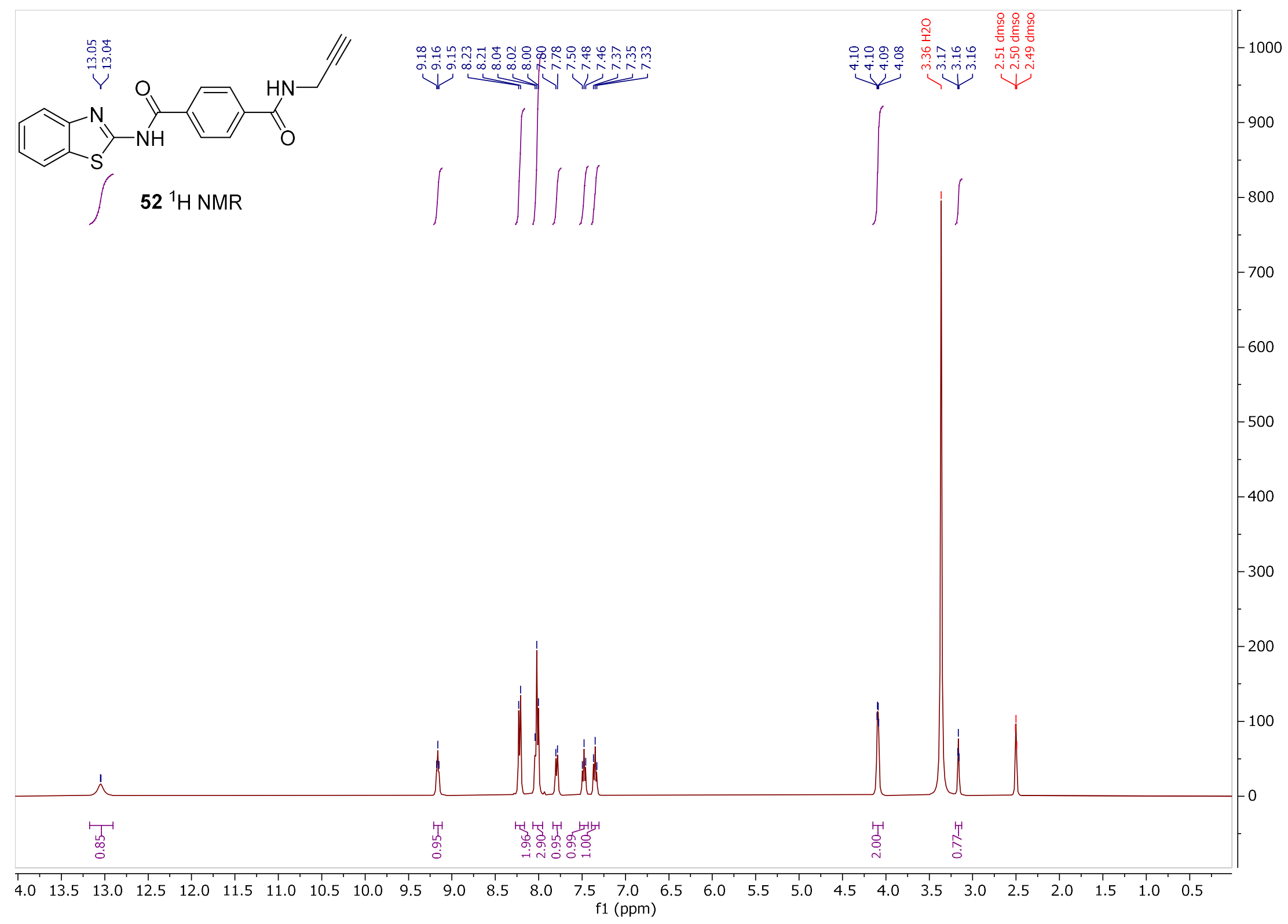




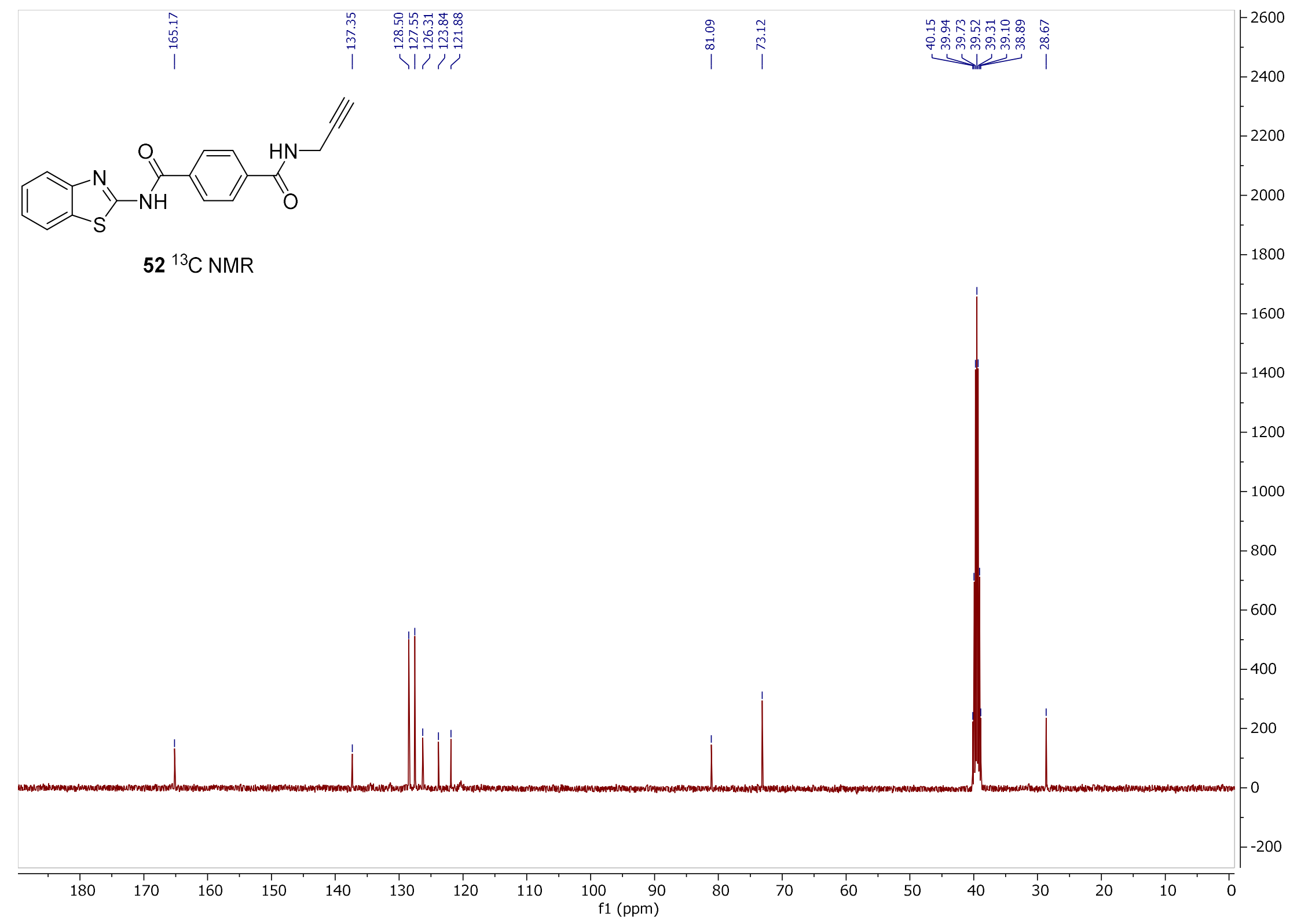




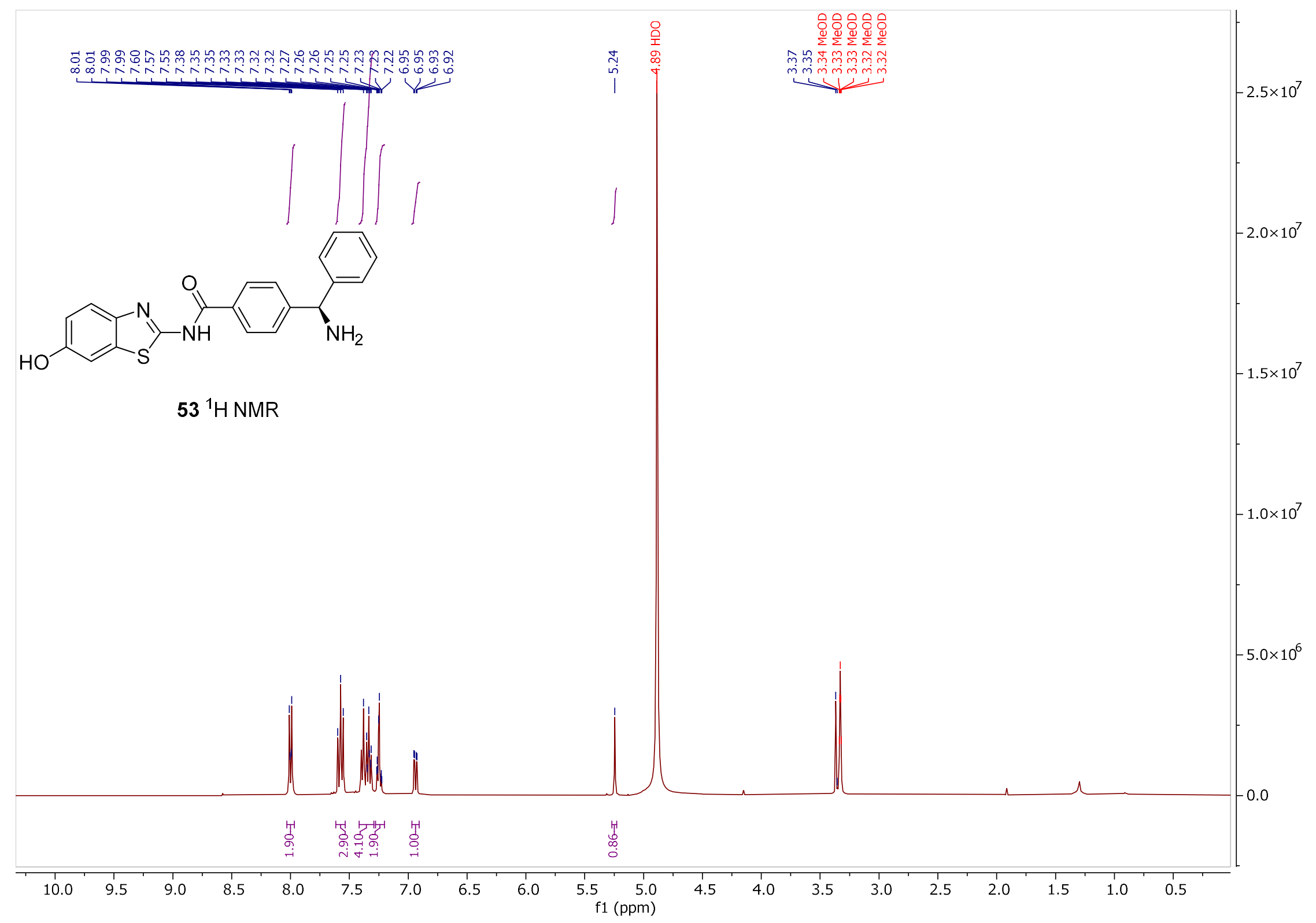




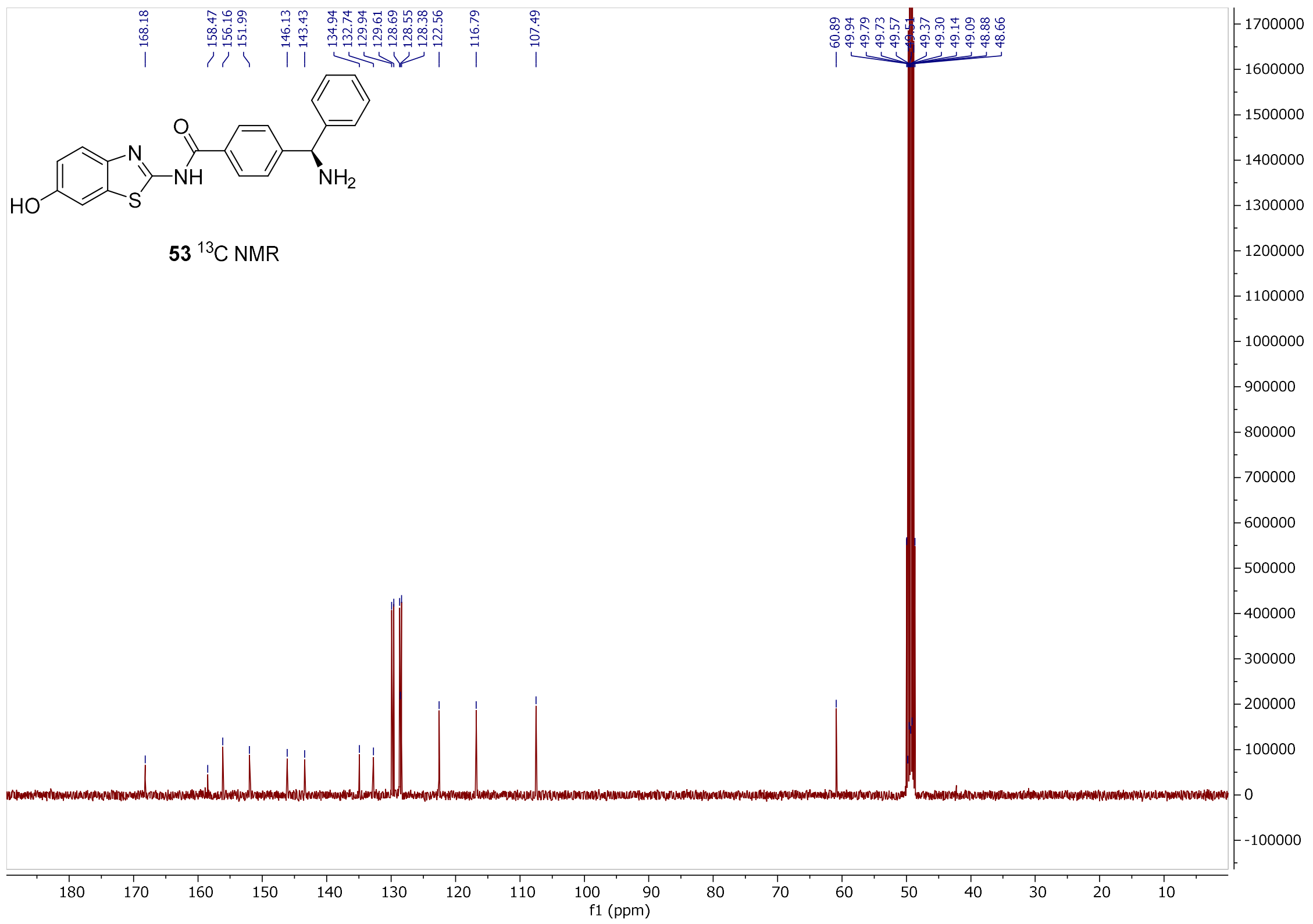




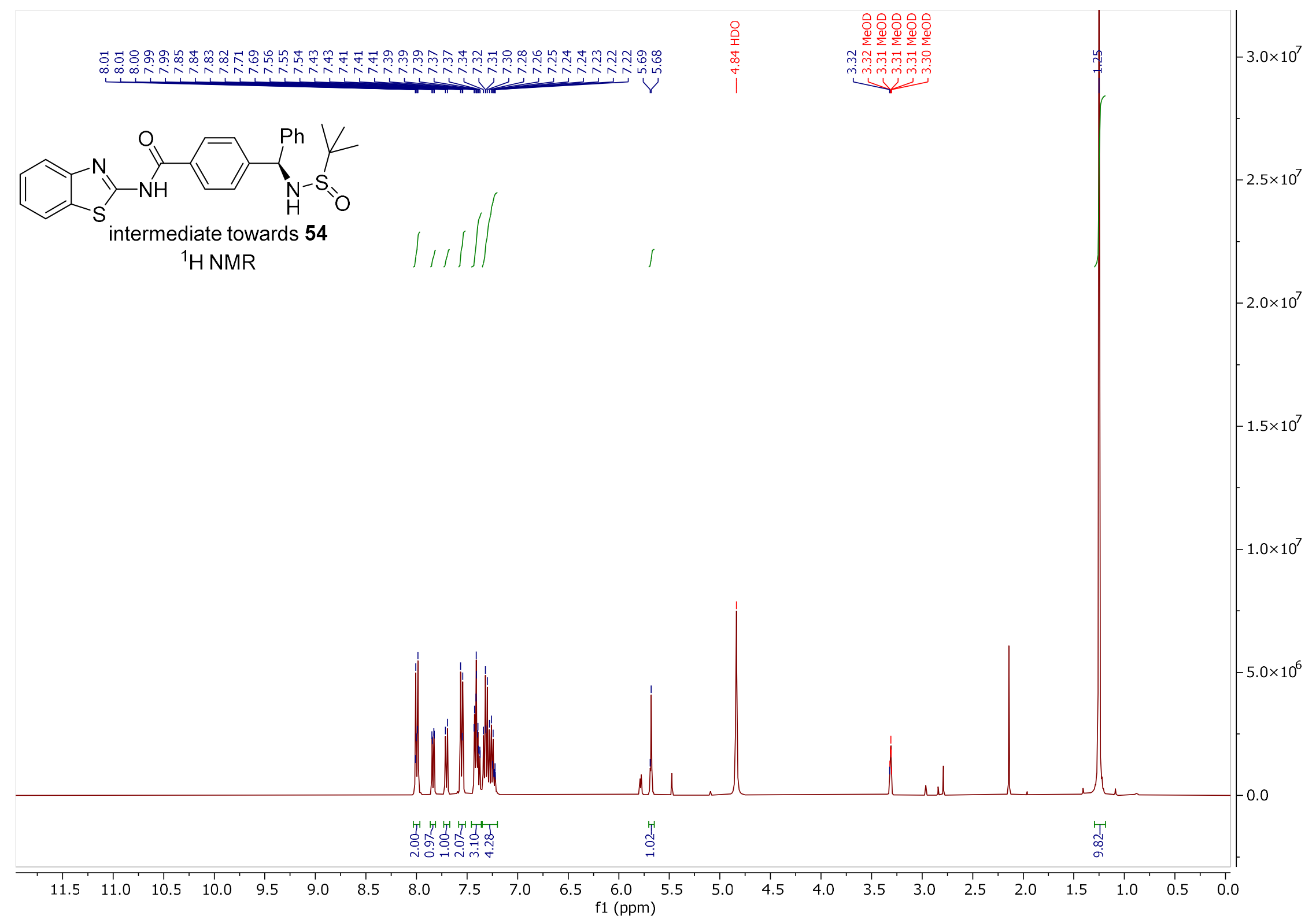




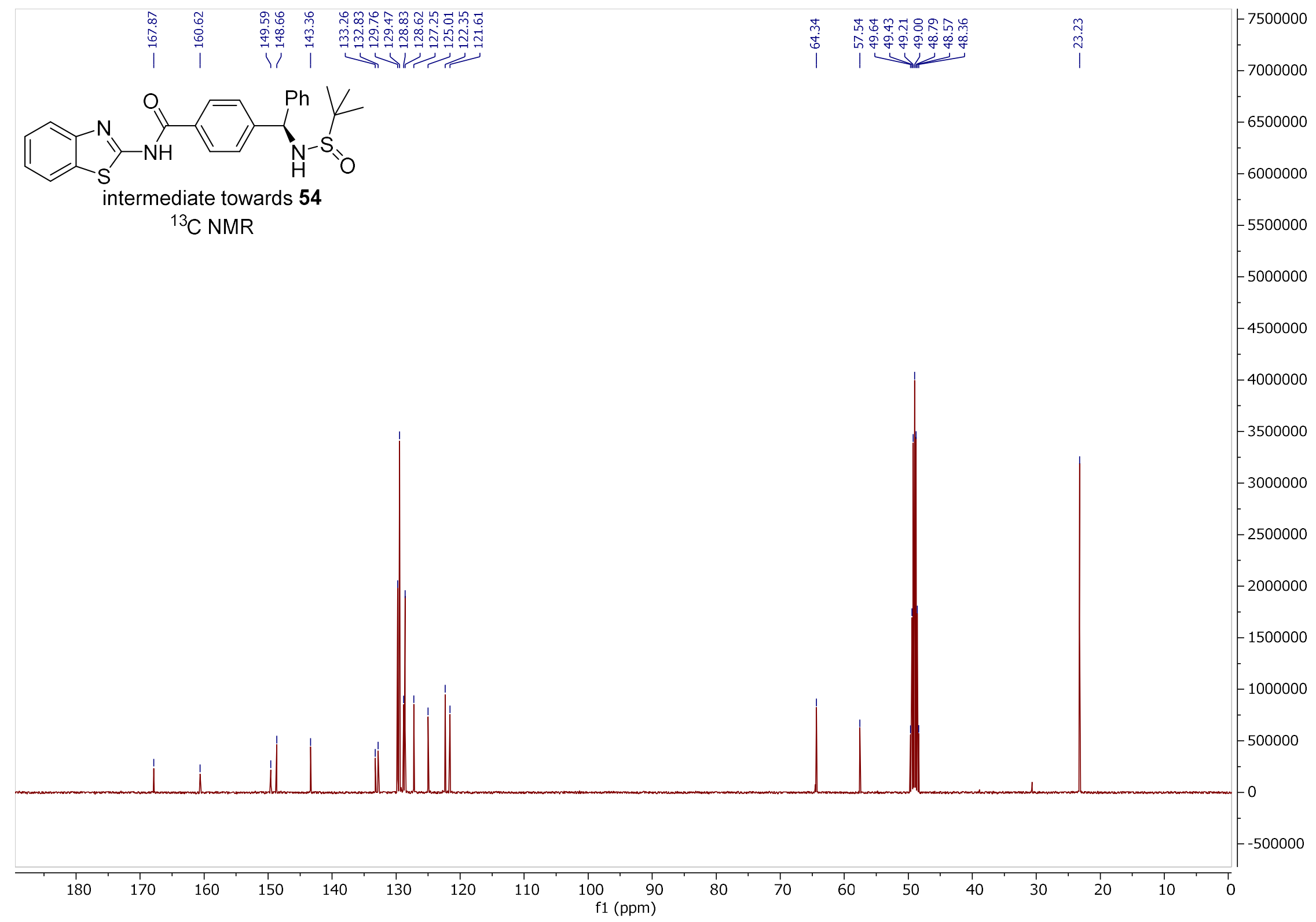




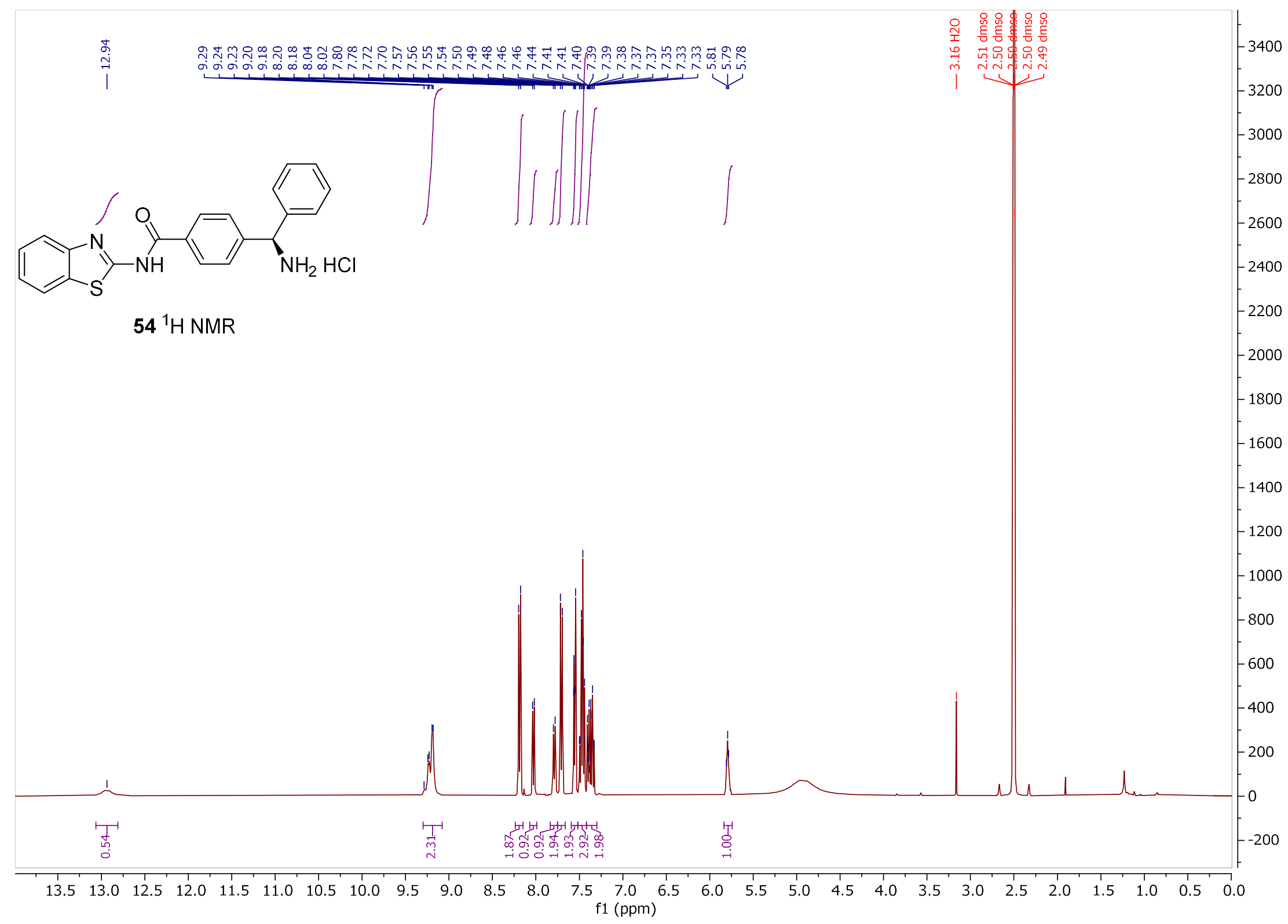




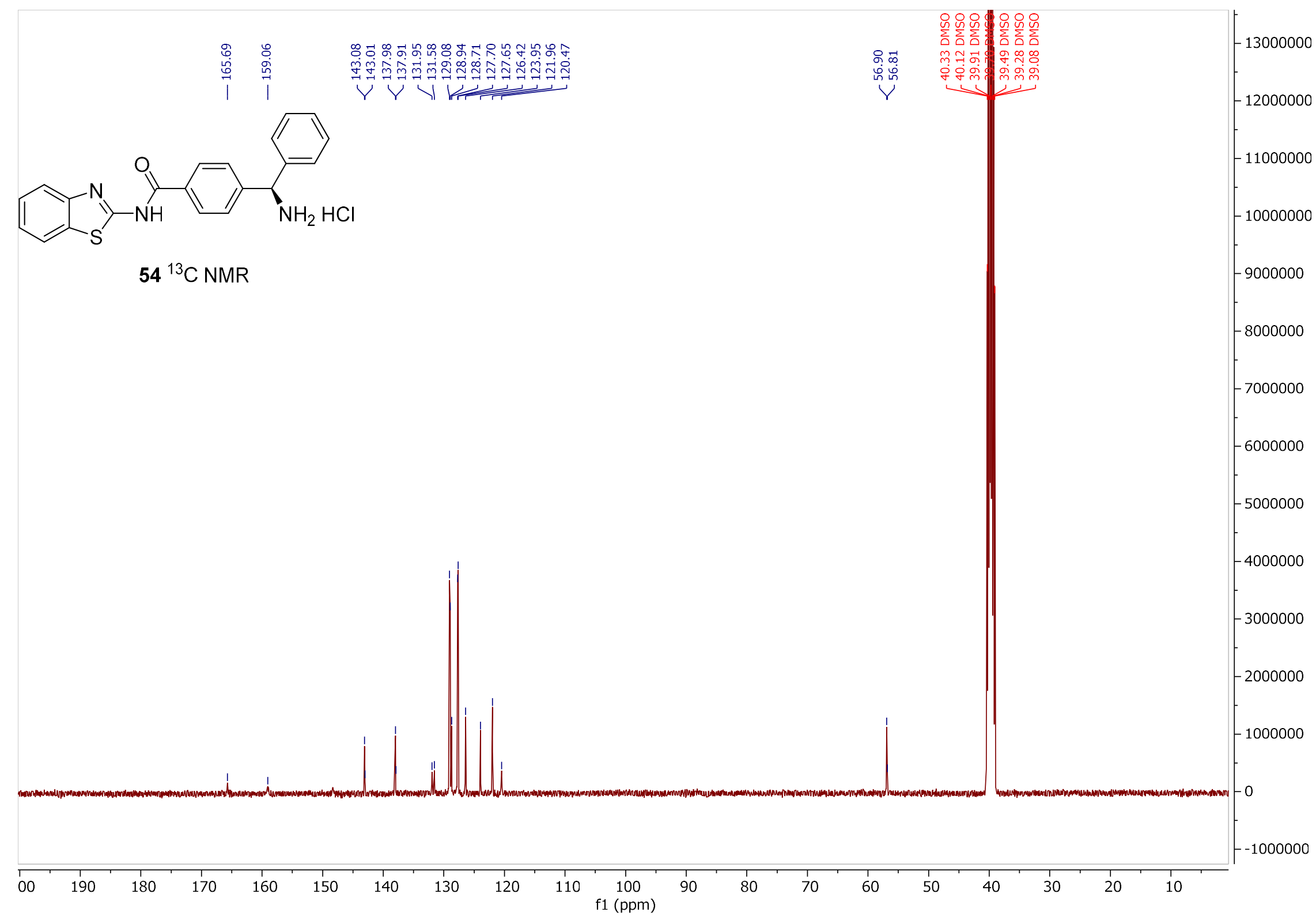


